Portland State University

PDXScholar

1995

\title{
Spiritual Health: Association for the Advancement of Health Education Instructors' Attitudes, Practices and Training
}

Susanne Meyer Christopher

Portland State University

Follow this and additional works at: https://pdxscholar.library.pdx.edu/open_access_etds

Part of the Health and Physical Education Commons

Let us know how access to this document benefits you.

\section{Recommended Citation}

Christopher, Susanne Meyer, "Spiritual Health: Association for the Advancement of Health Education Instructors' Attitudes, Practices and Training" (1995). Dissertations and Theses. Paper 1235.

https://doi.org/10.15760/etd.1234

This Dissertation is brought to you for free and open access. It has been accepted for inclusion in Dissertations and Theses by an authorized administrator of PDXScholar. Please contact us if we can make this document more accessible: pdxscholar@pdx.edu. 


\section{SPIRITUAL HEALTH: ASSOCIATION FOR THE ADVANCEMENT \\ OF HEALTH EDUCATION INSTRUCTORS' ATTITUDES, PRACTICES AND TRAINING}

\section{by}

SUSANNE MEYER CHRISTOPHER

A dissertation submitted in partial fulfillment of the requirements for the degree of

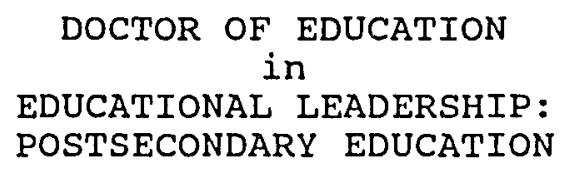


UMI Number : 9529752

Copyright 1995 by Christopher, Susanne Meyer

All rights reserved.

UMI Microform 9529752

Copyright 1995, by CMI Company. All rights reserved.

This microform edition is protected against unauthorized copying under Title 17, United States Code.

\section{UMI}

300 North Zeeb Road

Ann Arbor, MI 48103 
The abstract and dissertation of Susanne Meyer Christopher for the Doctor of Education in Educational Leadership: Postsecondary Education were presented February 1, 1995, and accepted by the dissertation committee and the doctoral program.

COMMITTEE APPROVALS:
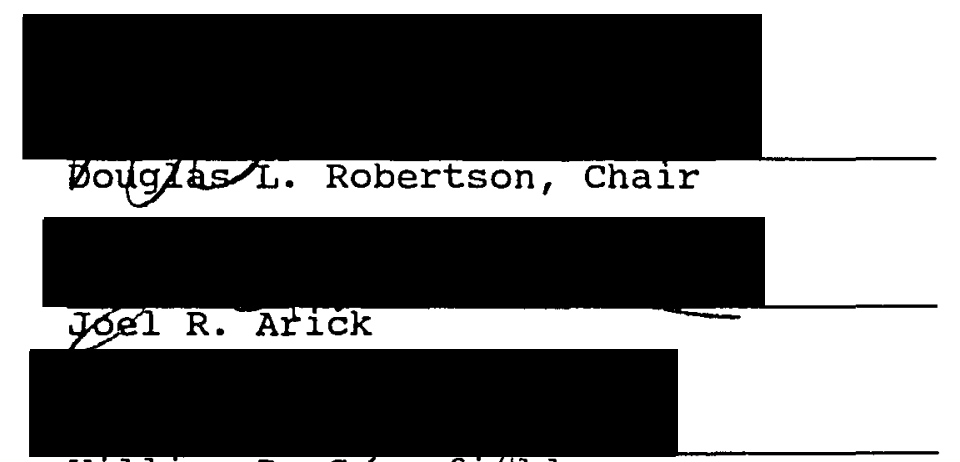

William D. Gyeenfipeld

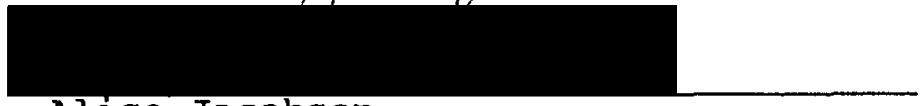

Alice Jacobson

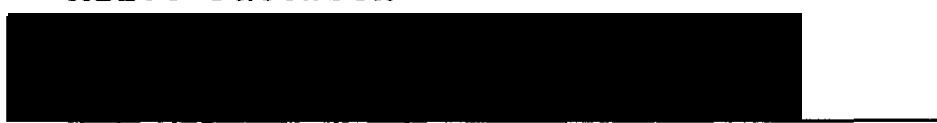

Leslie G. MćBride

Representative of the Office of Graduate Studies

DOCTORAL PROGRAM APPROVAL:

Robert B. Everhart, Dean

School of Education

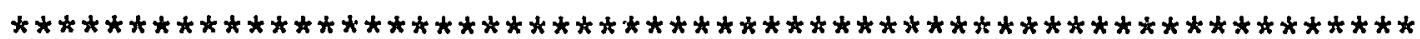

ACCEPTED FOR PORTLAND STATE UNIVERSITY BY THE LIBRARY

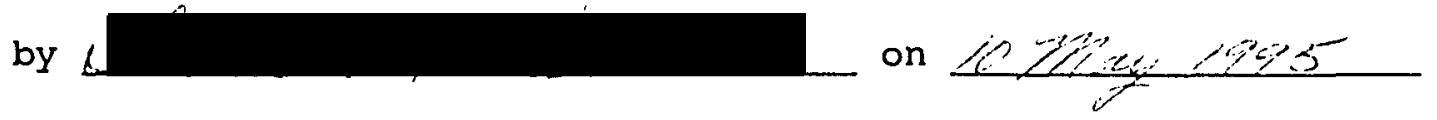




\begin{abstract}
An abstract of the dissertation of Susanne Meyer Christopher for the Doctor of Education in Educational Leadership: Postsecondary Education presented February 1, 1995.

Title: Spiritual Health: Association for the Advancement of Health Education Instructors' Attitudes, Practices and Training

Health education uses a holistic, multi-dimensional perspective (Hoyman, 1961; Donatelle, 1991; Hales, 1992). In recent years an emergent issue in health education is concern for disproportionate representation among the human dimensions--emotional, social, physical, intellectual, spiritual. Discussion occurs over the apparent underrepresentation of spiritual health in health education materials (Chandler \& Kolander, 1990).

While the professional literature contains articles discussing the under-representation of spiritual health (Jose \& Taylor, 1986; Bensley, 1991), no empirical studies are available to assess the current status of spiritual health in health education materials or the spiritual health attitudes of health educators.
\end{abstract}


This study provides empirical data on the status of spiritual health in health education materials and health educators' attitudes towards spiritual health in the university and college setting. A descriptive research study was done on the university and college members of the Association for the Advancement of Health Education (AAHE). A spiritual health survey was developed to provide insights into AAHE university/college health educators and sent to 500 random AAHE members nationally. This study was pretested for surface validity. A response rate of $52 \% \quad(\underline{N}=256)$ was achieved. The survey covered: (a) spiritual health attitudes, (b) attitudes toward including spiritual health in college general health courses, (c) current practices about including spiritual health in curriculum, and (d) spiritual health training.

The major findings are:

1. respondents expressed attitudes that supported spiritual health's importance and influence on the wellbeing of an individual;

2. respondents expressed concerns about including spiritual health in college general health courses, but supported the concept;

3. of those respondents who currently teach a college general health course, $65.6 \frac{8}{8}(\mathrm{~N}=82)$ include spiritual health; 
4. spiritual health is currently included in college courses on a limited bases

5. a connection exists between spiritual health training experiences and respondents' attitudes toward spiritual health. 


\section{DEDICATION}

This dissertation is dedicated to my husband, David Reed Christopher and my daughters, Shannon Kriste Heselius and Megan Elizabeth Christopher. Their sense of humor, support, encouragement, and love were steadfast and greatly appreciated.

It is also dedicated to my parents, Kurt Werner Meyer and Rosemary Kretz Meyer, who, as immigrants to this country, believed in the American dream and in me. My thanks and love. 


\section{ACKNOWLEDGEMENTS}

I wish to express my sincere appreciation to Dr. Douglas Robertson for his counsel, encouragement, and assistance in the dissertation process. My appreciation is extended also to Dr. Joel Arick, Dr. Bill Greenfield, Dr. Alice Jacobson, and Dr. Leslie McBride for their interest, persistent encouragement, and constructive suggestions.

I am grateful to Ms. Nancy Crain of Portland state University for her administrative assistance and support in the doctoral program.

I would like to express my appreciation to Portland Community College for providing the sabbatical to make the doctoral study possible and to my colleagues for their continued encouragement. 
TABLE OF CONTENTS

PAGE

ACKNOWLEDGEMENTS. . . . . . . . . . . . . . . . . i i

LIST OF TABLES. . . . . . . . . . . . . . . . . vii

CHAPTER

I INTRODUCTION . . . . . . . . . . . 1

Introduction . . . . . . . . . . 1

Purpose statement. . . . . . . . 7

Research Questions . . . . . . . 8

Significance of the study. . . . . . 9

Limitations. . . . . . . . . . . 10

II IITERATURE REVIEW. . . . . . . . . . . . . 12

Introduction . . . . . . . . . . 12

Spiritual Influence on Health and

Well-being

Integration into secular

Professional Practices

Dominant Research Strategies

Literature suppositions. . . . . . 21

Spiritual Health Definition

Spiritual Health Measurement . . . . 26

Health Education's Professionalism

Church and state

Cultural Influence

Professional Training

Conclusion . . . . . . . . . . 33 
III METHODOLOGY. . . . . . . . . . . . . 35

Introduction . . . . . . . . . . 35

Population and Sampling. . . . . . . 35

Instrumentation. . . . . . . . 38

Data Collection. . . . . . . . . 39

Data Analysis. . . . . . . . . . 40

Analysis of Research Questions . . . . 40

Introduction . . . . . . . . . . . 44

Respondents' General Characteristics . . 45

Personal Characteristics

Respondents' Institution Characteristics

Respondents' Health Education Experiences

General Health course characteristics

Spiritual Health Attitudes . . . . 50

Including Spiritual Health Attitudes • . 54

Current Spiritual Health Inclusion . . . 57

Spiritual Health Inclusion . . . . . 58

Spiritual Health Attitudes and

Demographic Variables. . . . . . . 61

Highest Academic Degree

Personal Religious Preference

Taught a General Health Course

Primary Teaching Responsibility

Spiritual Health Training

Age

Respondents' Institution

Religious Affiliation

Signing a Faith statement

other Variables

Summary 
Including Spiritual Health Attitudes and Demographics. . . . . . . . . 84

Highest Academic Degree Taught a General Health Course Primary Teaching Responsibility Focus of Highest Academic Degree Spiritual Health Training Respondents' Institution Type Religious Affiliations Institutional Religious Affiliation Signed a Faith statement Geographic Region Research Question Summary

Spiritual Health Training. . . . . . 113

Discriminate Factors . . . . . . . 117 


\section{LIST OF TABLES}

TABLE

PAGE

1. Alliances Demographics . . . . . . . 37

2. Correlation Between Research Questions and Survey Questions........... . 38

3. Respondents' Personal Characteristics. . . . 46

4. Respondents' Institution Characteristics . . 47

5. Respondents' Health Education Experiences. - 48

6. General Health Course Characteristics. . . 51

7. Respondents' Spiritual Health Attitudes Mean Scores $(\underline{N}=256)$. . . . . . . . 53

8. Respondents' Attitudes Toward Including Spiritual Health in college General Health Courses $(\underline{N}=256)$. . . . . . . 55

9. Amount of Time spent on Spiritual Health content in college General Health courses on the Quarter System. . . . . . 59

10. Amount of Time spent on Spiritual Health Content in College General Health Courses on the Semester system . . . . 60

11. Respondents' Highest Academic Degree and Spiritual Health Attitudes . . . . . . 63

12. Respondents' Personal Religious Preference and Spiritual Health Att tudes . . . . 65

13. Respondents Who Teach a 'sllege Level General Health Course and spiritual Health Attitudes... . . . . . . . 67

14. Including Spiritual Health in college General Health Course and Spiritual Health Attitudes . . . . . . . . . 69 
15. Respondents' Primary Teaching Responsibility and Spiritual Health

Attitudes. . . . . . . . . . . . 71

16. Respondents Who Have Attended a Spiritual Health Seminar/Workshop and Spiritual

Health Attitudes........... . 73

17. Respondents Who Have Done Personal studies in Spiritual Health and Spiritual Health Attitudes... . . . 74

18. Respondents Who Took a Specific College course in Spiritual Health and Spiritual Health Attitudes... . . . . . . 75

19. Respondents Who Took a College course that Included Spiritual Health content and Spiritual Health Attitudes . . . . 76

20. Respondents' Age and Spiritual Health Attitudes. . . . . . . . . . . 79

21. Respondents' Institution Religious Affiliation and spiritual Health Attitudes. . . . . . . . . . . 81

22. Respondents signing an Institutional Faith statement and spiritual Health Attitudes............... . 83

23. Respondents' Highest Academic Degree and Attitudes Toward Including spiritual Health in College General Health Course. . . . . . . . . 86

24. Respondents Who Teach a General Health Course and Attitudes Toward Including spiritual Health in college General Health Courses. . . . . . . .

25. Respondents Who Include Spiritual Health in College Health Courses and Their Attitudes Toward Including Spiritual Health.......... . . 90

26. Respondents' Primary Teaching Responsibility and Attitudes Toward Including Spiritual Health in college General Health Course. . . . . . . . . 
27. Respondents' Highest Academic Degree Focus and Attitudes Toward Including Spiritual Health in College General Health Course. . . . . . . . . . . 96

28. Respondents Who Took a College course in Spiritual Health and Attitudes Toward Including Spiritual Health in College General Health Courses. . . . 98

29. Respondents Who Took a College course that Included Spiritual Health and Attitudes Toward Including Spiritual Health in College General Health Courses. • . . • . • . . . . • . . 99

30. Respondents Who Attended a Seminar/ workshop in Spiritual Health and Attitudes Toward Including Spiritual Health in College General Health courses. . . . . . . . . . . 100

31. Respondents Who Have Done Personal Studies in Spiritual Health and Attitudes Toward Including Spiritual Health in College General Health courses. . . . . . . . . . . . . 101

32. Respondents' Institution Type and Attitudes Toward Including spiritual Health in college General Health Course . . . . . . . . . . . . 103

33. Respondents Having a Personal Religious Preference and Attitudes Toward Including spiritual Health in College General Health Courses . . . . . . . 105

34. Respondents from an Institution with a Religious Affiliation and Attitudes Toward Including Spiritual Health in College General Health Courses. . . . 108

35. Respondents Who Sign an Institutional Faith statement and Attitudes Toward Including Spiritual Health in College General Health Courses... . . . . . 109

36. Respondents' Geographical Region and Attitudes Toward Including spiritual Health in College General Health course . . . . . . . . . . . . . . 
37. Spiritual Health Training. . . . . . . 114

38. A Comparison of the Respondents who Felt Adequately Trained and the Percentage who Attended Training Activities . . . . . . . . . . . . .

39. A Comparison of the Respondents who Felt Inadequately Trained and the Percentage who Attended Training Activities . . . . . . . . . . . 115

40. A Comparison of Respondents who Include Spiritual Health in a college Health Course and Perceived Adequacy of Spiritual Health Teaching.

41. Factor Analysis Results from Spiritual Health Attitudes and Attitudes Toward Including Spiritual Health...... . 118

42. Multiple Regression Analysis of Spiritual Health Factors and Appropriateness of Including spiritual Health in a college General Health Course. . . . . . . 


\section{CHAPTER I}

\section{INTRODUCTION}

\section{Introduction}

United states government agencies at the national, state and local levels, along with nonprofit health organizations, support a loosely woven national health agenda. They establish health programs and goals, the intention of which is to provide an atmosphere that promotes and maintains the health of its citizenry. Healthy People 2000 (U.S. Department of Health and Human Services [USDHHS], 1990) is an example of a national report issued by president Bush's administration that encourages all Americans to adopt a healthier lifestyle.

As it attempts to meet national and local health goals, an emergent issue in the health education profession is the realization, by some health educators, that the holistic framework representing all the human dimensions--emotional, social, physical, intellectual, spiritual--in health materials and curricula represents the human dimensions disproportionately. Spiritual health is under-represented in health education curricula and materials (Bensley, 1991a; Chandler \& Kolander, 1990). This realization has brought concurrent discussion on the appropriateness of including 
spiritual health in health education curricula and materials (Goodloe \& Arreola, 1992; Jose \& Taylor, 1986).

Health education is not the only profession struggling with the concept of spiritual health. Greater recognition and incorporation of the human spiritual dimension is an emergent issue in other health related professions, such as psychology (Lukoff, Turner, \& Lu, 1993) and nursing (Boutell \& Bozett, 1990). In these disciplines, discussions center around the concerns of spiritual health's definition (Bensley, 1991a) and appropriate inclusion and integration of spiritual health in present curricula and materials (Diaz, 1993; Kelly, 1992; Lannert, 1991; Stoll, 1979).

In the health education literature several suppositions are cited to explain spiritual health's underrepresentation: (a) our culture's emphasis on materialism (Fahlberg \& Fahlberg, 1991), (b) the difficulty in defining spiritual (Bensley, 1991a; Seaward, 1991), (c) concern about separation of church and state (Chapman, 1986; Fahlberg \& Fahlberg, 1991; Seaward, 1991), (d) difficulties in measuring the concept (Fahlberg \& Fahlberg, 1991; Seaward, 1991) and (e) a threat to health education being acknowledged as a profession by other medical and sciencebased professions (Sechrist, 1979).

Insinuated in the spiritual health discussions held by health educators are three significant questions, the answers to which may present a quandary for the health 
education profession: (a) If spiritual health is underrepresented in health education materials and curricula, then is the health education profession achieving one of its goals to teach health and well-being from a holistic perspective, or is the profession guilty of omission or misrepresentation?; (b) Can health education achieve its intended goal to promote healthful lifestyles without addressing spiritual health?; and (c) Where spiritual health is being included in curricula and health education materials, is it being taught by health educators who are trained in this subject area? A review of the health education literature reveals little empirical evidence is currently available to discuss and answer these questions. The current status of spiritual health in health education needs to be examined for pertinent and worthwhile discussion of these questions and their subsequent resolution to occur. Empirical information is needed in three areas: (a) health educators' attitudes toward spiritual health, (b) health educators' attitudes toward including spiritual health in health education curricula and materials, and (c) health educators' current practices of including spiritual health materials and curricula in their work. In addition, this further information will permit examination of suppositions made in the literature about the current degree of spiritual health inclusion in health education materials, the attitudes of health educators 
toward spiritual health, and the attitudes of health educators to including spiritual health.

A descriptive study was done to gather empirical data that gives insights into the current status of spiritual health in health education. Health educators practice in varied societal organizations, such as hospitals, worksite health promotion, public health, private healch agencies, and schools. However, for the manageability of this study the population of health educators studied was limited to those teaching health education in a college or university setting.

Colleges and universities were chosen because they support government and societal health goals through their offerings of college health services, health programs, and health education courses (DeArmond, 1990). College students are required or recommended to take lower division, general health courses with the belief that health knowledge and educational opportunities encourage the student to establish and maintain a healthful lifestyle. In addition, college and university health education programs provide an opportune arena to compile more information about the current status of spiritual health since these programs are offered nationwide, affect a large number of the college student populations, and train potential health educators. The population studied was further limited to only those health educators who were active members of 
Association for the Advancement of Health Education (AAHE). AAHE is one of several affiliate organization that forms the professional organization American Association of Physical and Health Education, Recreation, and Dance (AAHPERD). AAHPERD is the national professional organization for health educators, physical educators, dance and recreation educators. AAHPERD is divided into professional sub-groups. AAHE, a sub-group of AAHPERD, asks members to designate their primary health education area. College and university programs are one of the designated areas. It has a membership of approximately 1,700. AAHE was chosen for the following reasons: (a) it is acknowledged in the field as a university and college health educators' professional organization; (b) it conducts national and regional conferences that provide professional updating and training; (c) it publishes a professional journal, Health Education, containing the latest health education research; (d) it has a nationwide membership; and (e) it provides ease of access to a sample population.

In the descriptive study, AAHE university and college health educators were asked the following: (a) their spiritual health attitudes; (b) their attitudes toward including spiritual health in general health courses-personal health, health and fitness, wellness; (c) their practice of including spiritual health in general health 
courses; (d) their spiritual health training; and (e)

personal and institutional demographics.

Lower division general health courses were chosen as a focus for assessing the inclusion of spiritual health in health education material for two reasons: (a) in these health courses, human health and well-being is generally taught from a holistic framework that presents the many dimensions of the human being (physical, mental, social, emotional, spiritual) as complex and interrelated (Donatelle \& Davis, 1994), thereby giving an opportunity to explore the inclusion of spiritual health in a course that purportedly emphasizes the holistic framework; and (b) general health courses are often required or strongly recommended, thus influencing a large number of college students. Therefore, the findings from this survey have the potential to impact a large number of college and university students.

A review of the current professional literature revealed no empirical evidence on the current status of spiritual health in college general health courses, collegiate health educators' spiritual health attitudes, collegiate health educators' attitudes toward including spiritual health or collegiate health educators' spiritual health training. The information gathered from this study provides empirical evidence on spiritual health that increases professional understanding about the current status of including spiritual health in health education 
materials and adds insight into identifying the issues involved with the including of spiritual health in health education materials and curricula.

Purpose statement

Spiritual health inclusion in health education materials and curricula is an emergent issue for some health educators. The professional literature discusses the importance of human spirituality in the holistic health approach most commonly used in health education materials and curricula. Individual opinions are put forth in the literature as to the concerns and barriers for including spiritual health in health education materials and curricula. Relatively few data are available on the attitudes of college health educators about spiritual health and including spiritual health in their course materials. No empirical evidence is available regarding the current practices of including spiritual health in college general health courses.

The purpose of this study is to do a descriptive survey of AAHE members that extends the current information on the practices and attitudes of college health educators in the area of spiritual health by: (a) ascertaining the current level of inclusion of spiritual health as a part of college general health courses, (b) determining the collegiate health educators' spiritual health attitudes, (c) 
determining the attitudes of collegiate health educators toward including spiritual health in their general health course, and (d) assessing health educators' training in spiritual health.

\section{Research Questions}

The study was designed to answer the following research questions:

1. What are AAHE collegiate health educators' spiritual health attitudes?

2. What are AAHE collegiate health educators' attitudes about including spiritual health in general health courses?

3. What proportion of collegiate general health courses taught by AAHE members addresses spiritual health?

4. Within collegiate general health courses which address spiritual health, what amount of time is spent on spiritual health subject area and how is the spiritual health material covered?

5. Do significant differences exist in each demographic variable (gender, age, ethnicity, geographical region, institution type, institution's religious affiliation, personal religious affiliation, faith statement, highest academic degree, highest academic degree focus, teach a general health course, primary teaching responsibility, and attending spiritual health training 
opportunities) and the respondents' spiritual health attitudes?

6. Do significant differences exist in each demographic variable (gender, age, ethnicity, geographical region, institution type, institution's religious affiliation, personal religious affiliation, faith statement, highest academic degree, highest academic degree focus, teach a general health course, primary teaching responsibility, and attending spiritual health training opportunities) and the respondents' attitudes toward including spiritual health in college general health courses?

7. Do AAHE college health educators perceive themselves to be adequately trained to teach spiritual health?

8. From the demographic data, spiritual health attitude data, including spiritual health data, and spiritual health training data collected on the survey, comprise a set of predictor factors present that can discriminate who would include and who would not include spiritual health in their general health courses?

\section{Significance of the study}

Professional debate and discussion are occurring as to the importance of spiritual health in an individual's total well-being. Along with other health-related professions, 
health education is discussing the meaning of spiritual health and the appropriateness of greater representation of spiritual health in health education curricula. Implied in these discussions is the question of whether or not the health education profession can achieve its professional goal to promote and maintain healthful lifestyles without adequate representation of the spiritual dimension in its materials and curricula.

This study increases the understanding of current practices, attitudes and training of AAHE college health educators and gives a better understanding of the variables that influence the inclusion of spiritual health in college general health courses. The study provides empirical evidence to substantiate or refute suppositions made in the literature regarding spiritual health and its inclusion in health education programs.

\section{Limitations}

The sample in the survey only included members of AAHE as of April 1994. Other active university/college health educators are not represented in the survey results.

The generalizability of the study was limited to AAHE health educators who were practicing in a university or college setting.

In addition, the study contains the following limitations: 
1. Self selection. Only respondents willing to complete and return the survey were included.

2. Inaccurate completion of the returned survey limited data availability.

3. Descriptive surveys provide superficial observations.

This study is designed to provide empirical evidence that gives a broad overview of current practices and attitudes, which is currently missing in the literature. Further research is needed to give a fuller, richer picture of the descriptive study results. 
CHAPTER II

\section{LITERATURE REVIEW}

\section{Introduction}

Promotion of personal health and well-being is a goal woven throughout national (Healthy people 2000 [USDHHS, 1990]) and state (Certificate of Initial Mastery/Certificate of Advanced Mastery [Oregon House Bill 3565, 1991]) educational goals and objectives. Healthy People 2000 , a national report published by the Bush administration, asks all U.S. citizens to adopt healthier living practices. When releasing this report, Dr. Louis $W$. Sullivan (cited in Witmer \& Sweeney, 1992), then Secretary of Health and Human Services, noted that $75 \%$ of the U.S. health care dollars are spent caring for individuals with chronic diseases (heart disease, cancer, strokes) while at the same time less than one half of $1 \%$ is spent on preventing these same diseases. Colleges and universities support societal health goals through the college health services, allied health programs, and health education courses. College health services are involved in providing health services and education that support the college student's health. In calling for new approaches to student college health services, DeArmond 
(1990) noted that the major health challenges of college students are complex and multi-faceted.

Recognizing the impact of lifestyle choices as a factor in an individual's health, many colleges require or recommend a general health course in the student's first two years of study. While the name of this course may vary (Personal Health, Health and Fitness, Personal Wellness), the intent of the course is similar: to offer health knowledge and educational opportunities that will encourage the student to establish and maintair a lifestyle that promotes personal health and well-being.

An educational perspective that emphasizes a multidimensional approach to attain optimal personal health and well-being is usually recommended in course materials by health education professionals. Optimum personal health is presented in concepts that endorse the integration of the physical, mental, emotional, social and spiritual dimensions of an individual (Chapman, 1987; Donatelle \& Hales, 1991; Hoyman, 1966). Support for "integration" and "wholeness" as concepts integral to human health is observed in psychological theory. Jung (1958) concluded that the human psyche seeks integration and has an instinctive drive toward wholeness and health. Later Maslow (1970), in his study on healthy individuals, supported Jung's observations with the conclusion that growth, self-actualization, and the pursuit 
of health appear to be widespread and, perhaps, universal human proclivities.

All the human dimensions (physical, social, mental, emotional, spiritual) are presented as valuable in order to attain personal health and well-being in a holistic model. However, a review of health education materials, curricula, and research reveals that there is a serious underrepresentation in spiritual health (Banks, 1980; Bensley, 1991a; Chandler \& Kolander, 1990).

Dialogue supporting and promoting the human spiritual dimension in health education is not new (Hoyman, 1966; Oberteuffer \& Beyrer, 1966; Osman \& Russell, 1979). Recent position papers have appeared in professional journals suggesting that spiritual health and its fuller integration into health education are emerging as important interests in the health education field (Bensley, 1991a; Chandler, Holden, \& Kolander, 1992; Goodloe \& Arreola, 1992). Three research and dialogue trends appear to be promoting further discussion in health education regarding the role of spiritual health: (a) professional literature regarding the influence of spirituality on personal health and well-being, (b) dialogue on the extent of integration of the spiritual into secular counseling practices, and (c) a general movement within health-related disciplines in academia to question the long-held norms of positivism as the only legitimate research strategy for attaining 
knowledge. These trends are briefly discussed in order to fully understand each of their influences.

Spiritual Influence on

Health and Well-being

support for the influential effects of the spiritual

dimension on general health and well-being is gaining ground in the psychological and mental health literature. Grof's (cited in Chandler et al., 1992) psychospiritual model provides one source of support. Grof developed a psychospiritual model from his work with lysergic acid diethylamide (LSD) users. Grof observed that repeated LSD users would have an existential crisis generated by:

the shattering encounter with . . critical aspects of human existence--i.e., birth, physical pain and agony, aging, disease and decrepitude, dying and death--and the deep realization of the frailty and impermanence of man as a biological creature. (p. 168)

He observed that this existential crisis elicited the following:

everyone who has reached these levels develops convincing insights into the utmost relevance of the spiritual and religious dimensions in the universal scheme of things. Even hard-core materialists, positivistically oriented scientists, skeptics and cynics, and uncompromising atheists and antireligious crusaders such as the Marxist philosophers suddenly become interested in a spiritual search after they (have) confronted these levels in themselves. (p. 169)

Recent articles in counseling and psychotherapy suggest a renewed interest in the function of spirituality and religion in counseling (Bergin, 1980; Coughlin, 1992). In 
part, this renewed interest is stimulated by an increased professional acknowledgment that an individual's spiritual and religious concerns may be therapeutically pertinent in secular and pastoral counseling settings (Kelly, 1992). Additional support for the spiritual influence on wellbeing occurs in the psychology literature that reports the importance of the spiritual dimension when an individual recovers from traumatic situations, e.g., rape, near death experiences, physical injury, and captivity (Grof \& Grof, 1989). Similarly, in their literature review on the psychospiritual dimensions of healing, Lukoff, Turner, and Lu (1993) noticed significant developments in psychology's diagnostic nomenclature, medical and psychiatric establishments and mass media (e.g., Public Broadcasting Station's Bill Moyer's Healing of the Mind) that support spirituality as an important aspect of a person's wellbeing.

The nursing profession is another discipline whose literature contains articles supporting the spiritual influence on well-being (Stoll, 1979). In a study with a random sample of practicing nurses in oklahoma, Boutell and Bozett (1990) reported that the majority of nurses felt the spiritual needs of their patients were important and that they assessed their patients' spiritual needs to be moderate to considerable. 
Integration into secular

Professional Practices

The re-emergence of professional interest in

spirituality and its influence on personal health and wellbeing is occurring simultaneously with a dialogue that addresses spiritual health's "appropriate" integration into professional practices. In the health education literature recent articles advocate a greater exploration and inclusion of spiritual health in health education materials and courses (Bensley, 1991a; Chapman, 1986; Goodloe \& Arreola, 1992). Outside the health education profession, the professional literature in psychology, counseling, and nursing contains articles grappling with the issue of "appropriate" integration of the human spiritual dimension in their work.

In a 1990-1991 national study of Association of Psychology Internship Centers, Lannert (1991) raised serious ethical issues for the psychology profession regarding the inclusion of spiritual issues in its specialty. None of the respondents to her survey indicated that they had received education or training in spiritual/religious concerns during their formal internships. Yet a significant number (72\%) dealt with these concerns in their clinical practice. Lannert pointed out that this could be evidence for a potential violation of the American Personnel and Guidance Association and American Psychological Association guidelines for ethical behavior. According to those 
guidelines therapists are prohibited from operating outside the boundaries of professional competence. Lannert raised the intriguing consideration that psychologists often recognize the patient's spiritual concerns during their practice and discuss them with clients, yet the psychologists are not trained to address these concerns.

A second ethical issue raised by Lannert (1991) was in the area of respecting individual dignity, uniqueness, and freedom of choice. Lannert argued that imposing therapists' values on a client, in this case overt and covert religious/spiritual attitudes, violates this ethic. While this concern is not new, it is commonly interpreted to mean that therapists will not impose their particular religious views on their clients. Lannert suggested that this ethic also includes the understanding that a therapist cannot exclude a client's religious and/or spiritual beliefs in treatment without diminishing the individual's dignity, uniqueness, and freedom of choice.

An absence of professional training in spiritual issues found substantiation in another national survey. In a study of professional counseling schools, Kelly (1992) investigated how counselor education programs prepare students to deal with religious and spiritual issues in counseling. Using a descriptive study, Kelly surveyed 525 counselor education program department chairs. With a $65 \%$ response rate, Kelly found $22 \%$ of counselor education 
programs addressed spiritual and religious issues in their curriculum. Not surprisingly, those institutions with religious affiliations reported a higher rate than stateaffiliated schools. Lannert (1991) and Kelly provided evidence that the counseling psychology profession may be remiss in not providing adequate training in spiritual/religious issues.

The manner in which professionals view their own spirituality could influence the integration of spirituality into professional practices. seeking a greater understanding of how psychologists view their own spirituality and religion, Shafranske and Malony (1990) surveyed 1,000 psychologists randomly from the APA Division of Clinical Psychology. With a $40 \%$ response rate, $65 \%$ of the respondents reported spirituality to be a personally relevant issue. Additional support for this finding is found in a study by Bergin and Jensen (1990). In a survey of psychiatrists, psychologists, social workers, and marriage and family counselors, Bergin and Jensen found that 68\% supported the item indicating that they "seek a spiritual understanding of the universe and one's place in it." In completing their studies, the authors concluded that the psychology profession needed to revisit its attitudes toward religion and spirituality (Bergin \& Jensen, 1990; Shafranske \& Malony, 1990). 


\section{Dominant Research strategies}

Health educators are not alone in recognizing an underrepresentation of spiritual health in their profession. Spirituality's influence on an individual's well-being and spirituality's integration into professional practices appears to be emergent issues in several human and health services professions. These emergent issues coincide, and are influenced by, the movement in health education and health-related disciplines within academia to question the exclusive use of the positivist approach to gain knowledge about and understand humans.

Diaz (1993) stated that theories of health education and health promotion are frequently chosen from world views and theories based on empirical, natural sciences. This point of view presupposes that all phenomena can be explained on the basis of natural laws and causes (Nichols \& Gobble, 1991). A new willingness to examine the limitations of a positivistic research perspective and explore other forms of acquiring knowledge is being discussed and supported in the health education literature (Diaz, 1993; Fahlberg \& Fahlberg, 1991; Nichols \& Gobble, 1991) and the literature of related fields. Lather (1986) offered this observation on the philosophical shift in academia:

currently we are in a period of dramatic shift in our understanding of scientific inquiry . . . No longer does following the correct method guarantee true results. . . It is increasingly recognized that the fact-value dichotomy simply drives values underground. Facts... are as much social 
constructions as are theories and values. (p. 259)

When discussing the implications of the philosophical shift, Lather noted:

Postpositivism has cleared methodology of prescribed rules and boundaries. The result is a constructive turmoil that allows a search for different possibilities of making sense of human life, for other ways of knowing which do justice to the complexity, tenuity, and interminacy of most of human experience. (p. 259)

This time of "constructive turmoil" may provide a rich opportunity for health education to re-examine and explore spiritual health's inclusion in the curriculum.

\section{Iiterature Suppositions}

In order to discuss and achieve a greater understanding of the emergent issue, "spiritual health," this section of the chapter explores and discusses the dominant suppositions cited in the literature to interpret spiritual health's under-representation: (a) how spiritual health is defined, (b) difficulties of measurement, (c) separation of church and state, (d) a cultural emphasis on the material and tangible, and (e) spiritual health's threat to health education's status as a profession.

\section{Spiritual Health Definition}

Health education is not alone in attempting to understand, define, and integrate spirituality into its profession. Other professions which work closely with the 
many dimensions of the human being are also grappling with defining spirituality and spiritual well-being.

Several authors speculate that the personal and intangible nature of spiritual health makes it difficult to get a consensual definition (Bensley, 1991a; Chandler, Holden, \& Kolander, 1992; Jose \& Taylor, 1986). Addressing this elusiveness in his definition, Edwards (1980) stated:

- at its fullest (spirituality) refers to that
most subtle, integral dimension of our awareness,
where we sense and trust ourselves belonging
through and beyond our ego image to a larger,
invaluable horizon that impinges on all we are and
do. - This is an obscure knowing, not a
rationaily clear one. (p. 9)

In researching and developing the spiritual Well-Being scale, Ellison (1982) also discussed the difficulty in defining spiritual well-being for research:

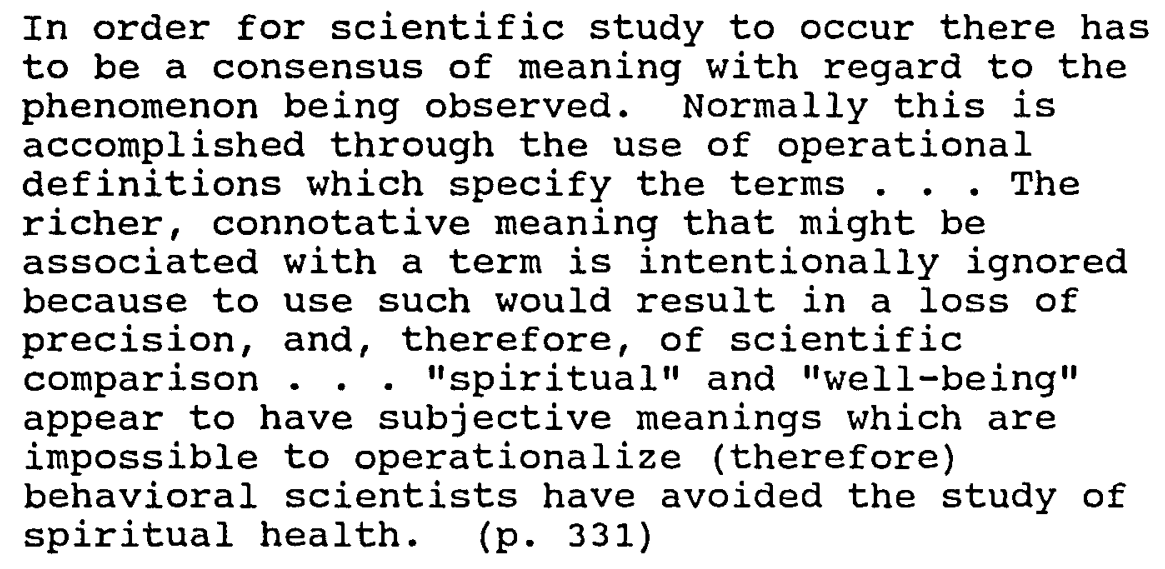

The inclusion and advocacy of spiritual health in the health education profession are not new ideas. In 1961, as the health education profession was emerging, Hoyman (cited in Goodloe \& Arreola, 1992) purposed three dimensions to health: (a) physical fitness, (b) mental health, and (c) 
spiritual faith. Hoyman defined spiritual faith as "the centered movement of the whole person toward something that has ultimate meaning and significance for him" (p. 221). Since Hoyman's (cited in Goodloe \& Arreola, 1992) initial attempt to define spiritual health, additional definitions have been put forth in the literature. An early definition was put forth by Ellison (1982). Ellison proposed a definition of spiritual well-being that, enables and motivates us to search for meaning and purpose in life, to seek the supernatural or some meaning which transcends us, to wonder about our origins and our identities, to require morality and equity. (p. 332)

Ellison's definition finds support in Banks' (cited in Banks, Poehler, \& Russell, 1984) research. Banks investigated the spiritual health perspectives of retired health professionals, active health professionals, and graduate teaching assistants. Banks observed and reported that her interviewees identified what gave their life meaning and purpose as the spiritual dimension.

Acknowledging the difficulties in developing a spiritual health definition, Chapman (1986) proposed the following criteria for guidance: (a) do not attempt to recreate or duplicate theology, (b) the definition must be practical, (c) must recognize the other health education dimensions, (d) needs to relate to health, (e) develop an appropriate scientific base, and (f) be flexible enough to include new ideas and concepts. The definition chapman 
(cited in Donatelle, Davis, \& Hoover, 1991) derived from his criteria is a spiritual health definition frequently found in college health texts:

Optimal spiritual health may be described as the ability to develop our spiritual nature to its fullest potential. This would include our ability to discover and articulate our own basic purpose in life, to learn how to experience love, joy, peace, and fulfillment, and to help others achieve their full potential. (p. 5)

Bensley (1991b) presented an additional definition. In investigating the prevalence and perceived need for spiritual health as a component of a worksite health promotion program, Bensley defined spiritual health as:

developing and/or reinforcing attitudes and beliefs toward one's purpose and meaning in life; learning how to experience fulfillment; and assisting one's self and others to strive toward their full potential. (p. 352)

In another article, Bensley (1991a) noted that personal values are implicitly and explicitly included and emphasized in spiritual health definitions. While health education curricula include current issues that have value components (HIV disease, alcohol and drug usage, death and dying, health care), research and discussion on value instruction and development of the college student are more often expressed in the student development literature (Blimling, 1990; Friend, 1991; Ignelzi, 1990; Mentkowski, 1988) than in the health education literature. In the student development literature, Sprinthall and McVay (1987) asserted that the college years represent an important opportunity for value development because "the research has shown that it is 
during this time that the question of principled values can come to the surface" (p. 128). Greater inclusion of spiritual health into the college health course curriculum could provide an opportunity for college students to identify, clarify, and process their personal values.

In psychology, models exist that include spirituality in the concept of "personhood." Maslow (1971) asserted that the spiritual life is a defining characteristic of human nature. In particular, the transpersonal psychology literature contains articles that focus on the psychospiritual dimensions of health. Chandler, Holden, and Kolander (1992) offered the following definition of spirituality in an attempt to synthesize spiritual definitions purposed by various psychological models, "Pertaining to the innate capacity to, and tendency to seek to, transcend one's current locus of centricity, which transcendence involves increased knowledge and love" ( $p$. 169).

Though there are difficulties in reaching a precise definition for spiritual health, common themes exist in definitions previously offered that can be incorporated into an operable definition. The identified themes are: (a) beliefs and attitudes toward one's purpose and meaning in life, (b) fulfillment, and (c) altruistic values (service to others, love, selflessness). 


\section{Spiritual Health Measurement}

Measurement of spirituality and its influence on an individual's well being enjoys a long and rich tradition in the religious literature. Allport is viewed as the modern father in the measuring of spirituality and christian religion (Sappington \& Wilson, 1990). Allport developed the Religious orientation Inventory (ROI). Since its inception, this measurement tool has been used in several research studies. The ROI identifies four types of religious orientation/motivation: (a) intrinsic, (b) extrinsic, (c) indiscriminately pro-religious, and (d) indiscriminately anti-religious. The ROI is limited to studying religious behaviors, beliefs, and attitudes.

Ellison (1982) developed the spiritual Well-Being (SWB) measurement tool. Ellison's underlying assumption, which correlates with his spiritual well-being definition given earlier in this paper, is that the human spirit enables and motivates one to search for meaning and purpose in life, and to seek transcendence. The SWB consists of a 20-item scale that measures two dimensions: (a) religious well-being, and (b) existential well-being. The SWB's use in many studies has shown it to be a reliable instrument (Sappington \& Wilson, 1990).

The Spiritual orientation Profile (SOP) was initially created for Catholic priests at the center for Human Development, University of Notre Dame. This 72-question 
instrument "inquires about faith in God, the perceived relationship of physical and emotional aspects to the spiritual life" (DeJong \& Donovan cited in Sappington \& wilson, 1990, p. 64). The underlying assumptions in the development of the sop were: (a) spirituality is a process, (b) it is a developmental process, (c) it is a uniquely personal process, and (d) spirituality possesses similar, common themes.

The ROI, SWB, and SOP define spirituality using a Christian faith framework. All these tools have been criticized in the secular professional literature for their reliance on a deity framework and/or adherence to a specific creed or dogma (Sappington \& Wilson, 1990). Ellison's spiritual well-being instrument has found greatest acceptance outside the christian religious literature. This greater acceptance may be related directly to Ellison's broader and more inclusive definition of spiritual wellbeing as not associated with a specific formal religious dogma (Sappington \& Wilson, 1990).

The inability to have a precise definition for spiritual health creates difficulty in the validation and measurement of spiritual health (Chandler, Holden, \& Kolander, 1992; Jose \& Taylor, 1986), particularly when predominately employing objective and quantifiable research techniques (Goodloe \& Arreola, 1992). 
Similar measurement issues were discussed by collins, Hurst, and Jacobson (1987) in their student development work. They concluded that there was a "blind spot" in academia toward students' spiritual health and development because the content area (spiritual health) did not lend itself to scientific inquiry.

A limitation of the studies of spiritual health and well-being mentioned in this section, is their exclusive use of positivistic research techniques to attain a measurement for spiritual health and well-being. As was noted by Chapman (1986) and Ellison (1982), reducing spiritual health to a precise, operational definition robs the concept of its connotative, richer meaning. A reductionistic research format that is focused on facts rather than construction of meaning is not well suited for research into spiritual health and well-being (Jose \& Taylor, 1986; Lather, 1986). Discussions on the definition of spiritual health would benefit from additional research that applies qualitative, ethnographic approaches.

\section{Health Education's}

Professionalism

Spiritual health does not lend itself easily to a reductionist, positivist mode of measurement. For this reason, some members within the health education profession feel that including spiritual health in health education is a movement in the wrong direction. Concern exists that this 
movement undermines how other professions and the scientific community view the "professionalism" of health education (Goodloe \& Arreola, 1992). Sechrist (1979) articulated this concern:

If we (health educators) depart radically from problem-oriented health education programs and commit a large percentage of our precious resources to programs with targets . . . nebulous and immeasurable . . . we may not generate the research base essential to building our credibility. (p. 27)

The dominant paradigm in health education supports the belief that health education should concern itself predominantly, perhaps exclusively, with health-promoting behaviors and decreasing morbidity and mortality rates-concerns that are more readily tested and measured in the positivist research tradition.

The health education profession has undergone change and growth as a profession since sechrist's observations in 1979. When the Health Education profession was in its infancy, many health educators considered the promotion of spiritual health to be a "death-blow" to the profession. As a young profession, Health Education aspired to earn the respect of other professions which used a natural science (positivist) model to legitimize their professionalism. An indication that Health Education has evolved into a more mature discipline is observed by the formation of The National Commission for Health Education Credentialing, Inc., which introduced the certified Health Education 
Specialist (CHES) certificate in 1989 (Girvan, Hamburg, \& Miner, 1993). The CHES is based on the belief that a strong profession must have consistent professional preparation, a process which tests for competencies, and members who remain current in their discipline throughout their professional career (Donatelle, Schima, Champeaus, \& Malkin-Washeim, 1993). The cHES certificate provides the first means, other than a college degree, by which the health education profession can establish role delineation, provide professional verification, and measure health education competencies (Nolte \& Hamburg, 1993).

Health education has matured into an established and more confident profession. Currently, a certain readiness to move into issues using other research paradigms may be present.

\section{Church and state}

Another supposition identified in the literature is a prevailing attitude of "taboo" in secular schools surrounding topics that are related--or could be related--to issues of religion and separation of state and religion (Bensley, 1991a; Chandler, Holden, \& Kolander, 1992; Goodloe \& Arreola, 1992; Jose \& Taylor, 1986). Jose and Taylor (1986) presented this concern well:

The historical separation of church and state and the close linkage of religion with spirituality in the popular mind, have led many away from a conscious recognition of the spiritual nature of humankind. Since the ratification of the First 
Amendment, education in the United states has made great efforts to separate itself philosophically from its origins in Christian, predominately Protestant, tradition . . Following the First Amendment mandate for separation of church and state, the supreme court upheld numerous rulings which banned tax-supported schools from offering courses which teach religious doctrine or from sanctioning the practice of religious exercises - . It is not surprising then, that many shy away from dealing with the spiritual dimension, because of the misconception that this is tantamount to teaching religion. (p. 17)

While discussing the issue of religion and spirit, Banks, Poehler, and Russell (1984) offered a solution to the spirit-religion concern that acknowledges and assists in clarifying the differences between spirit and religion:

The term and concept "spirit" (or "spiritual") is not synonymous with "religion" (or "religious"). Persons with a well-developed spiritual dimension may reject religion completely, may belong to no organized religion, or may be diffident to active members of any religious group or organization. (p. 19)

\section{Cultural Influence}

Scholars in anthropology and psychology have suggested that our culture's emphasis is predominantly material- and sensate-oriented, thereby ignoring topics that are not tangible in nature. Fahlberg and Fahlberg (1991) articulated this point of view well:

Evidence of an overriding emphasis on the sensate realm--the turf of the five senses--manifests itself in philosophy as materialism, in science as scientism, in social and behavioral science as behaviorism, and in the popular world as material triumvirate. (p. 273) 
Seaward (1991) observed our culture's lack of emphasis on spiritual matters from the linguistic frame of reference. When discussing the growing interest in spiritual well-being Seaward stated,". . the language to understand man's spiritual nature is in an embryonic state and thus impedes full understanding of dynamics of the human spirit" ( $p$. 166).

Bragdon (1990) suggested that our culture discourages open discussion on spiritual experiences:

People in our culture are afraid of speaking openly about their spiritual experiences, because psychic phenomena. . . have been considered symptomatic of psychosis. (p. 12)

\section{Professional Training}

From the literature, the main suppositions given for the under-representation of spiritual health in health education curricula and programs appear to be: (a) defining spiritual health, (b) measuring spiritual health, (c) separating church and state, (d) emphasizing the material and the tangible in our culture, and (e) perceiving a threat to healich education's professionalism. Based on this researcher's interviews and observations, an additional barrier to including spiritual health in health education is lack of professional preparation. From previous conversations held by the author with community college health educators, it was noticed that all instructors mentioned "no training" or "inadequate training" in 
spiritual health as a reason for why they would feel uncomfortable presenting more information in their courses. These observations coincide with the findings of Kelly (1992) and Lannert (1991) in psychology.

Lannert (1991) concluded from her study of psychology internship centers that therapists were at risk of ethical violation because they dealt with patients' spiritual concerns without professional training in the subject area. Kelly (1992) raised similar professional ethical questions when he found similar results in his national survey of professional counseling.

\section{Conclusion}

Strong recognition is emerging in health education and several health-related disciplines for the importance of the human spiritual dimension in obtaining and maintaining optimal health and well-being. Concurrently, strong support is growing for greater inclusion of spiritual health in these disciplines. Spiritual health was included in early health education definitions of health and well-being (Hoyman, 1966). Including spiritual health has recently found expanding support in the health education literature (Bensley, 1991a).

Numerous conjectures are presented in the literature to explain spiritual health's under-representation in health education. Further research is needed to validate or refute 
suppositions made in the literature regarding spiritual health and incorporating spiritual health in health education materials and curricula. The data gained from this research assists in answering the questions posed in the introduction of this paper: (a) If spiritual health is under-represented in health education materials and curricula, then is health education attaining its stated goal to teach health and well-being from a holistic perspective or is the profession guilty of omission or misrepresentation?; (b) can health education achieve its intended goal to promote healthful lifestyles without addressing spiritual health?; and (c) where spiritual health is being included in curricula and health education materials, is it being taught by health educators who are trained in this subject area?

The review of the professional literature found that no research is available on the current state of spiritual health inclusion in collegiate general health courses. A descriptive study of college health educators was completed to assess the following: (a) spiritual health attitudes, (b) attitudes toward including spiritual health in college general health courses, (c) current practices of college health educators toward including spiritual health materials and curricula in their general health courses, and (d) spiritual health training. 
CHAPTER III

\section{METHODOLOGY}

Introduction

The purpose of this descriptive research was to survey AAHE (Association for the Advancement of Health Education) university and college health educators regarding spiritual health attitudes and practices. The data collected were from current (April 1994) AAHE college and university members. This chapter presents the research methodology and includes discussion of population and sampling, instrumentation, data collection, and data analysis.

\section{Population and sampling}

The population studied was university and college health educators who were members of AAHE, an affiliate of AAHPERD (American Alliance for Health, Physical Education, Recreation, and Dance).

AAHPERD had a membership of 29,000, as of November 1993. The alliance's stated goals are:

1. Encourage, guide, and support professional growth and development in health, leisure, and movement-related programs based on individual needs, interests, and capabilities. 
2. Communicate the importance of health, leisure, and movement-related activities as they contribute to human well-being.

3. Encourage and facilitate research which will enrich health, leisure, and movement-related activities and to disseminate the findings to professionals and the public.

4. Develop and evaluate standards and guidelines for personnel and programs in health, leisure, and movement-related activities.

5. Coordinate and administer a planned program of professional, public, and government relations that will improve education in areas of health, leisure, and movement-related activities.

6. Conduct other activities for the public benefit. (Staff, 1994a, p. 3)

In addition, the AAHE affiliation has identified

association values and goals. The five recognized values-health for all, education for health promotion and disease prevention, leadership in the profession, excellence and integrity in health education and professional practice, and cultural pluralism--serve as a foundation for AAHE's goals, objectives, and activities. The associated stated goals are:

1. Advocate for legislation and promote policies that positively impact individual and community health.

2. Define and promote professional preparation and continuing education for health education specialists and other health professionals.

3. Participate actively in defining the research agenda in health education; promote research and evaluation skills; enhance the translation and application of research into practice.

4. Promote the use of ethical standards in professional conduct. 
5. Support continued development and

implementation of standards of professional practice.

6. Facilitate communication among individuals and organizations to enhance personal and community health.

7. Promote health education as a nationwide priority.

8. Maximize the capacity of the organization to enable AAHE to fulfill its mission and goals.

9. Ensure cultural pluralism as it applies to the mission and goals of AAHE. (Staff, 1994b, pp. 1, 6).

The AAPHERD alliance publishes a professional journal, Health Education, and organizes and promotes district and national conventions and conferences yearly. Table 1 provides demographic information on the AAHPERD alliance members. AAHPERD does not have demographic information available on individual affiliates, such as AAHE.

Table 1

Alliances Demographics

\begin{tabular}{lrlrlr}
\hline \multicolumn{2}{c}{ Income Level } & \multicolumn{2}{c}{ Ethnicity } & \multicolumn{2}{c}{ District } \\
\hline$<20,000$ & $13.9 \%$ & White & $89.2 \%$ & South & $25 \%$ \\
$20-29,000$ & $20.7 \%$ & African-Amer & $2.5 \%$ & Northwest $4 \%$ \\
$30-39,000$ & $22.2 \%$ & Asian Pacific & $.9 \%$ & Southwest $10 \%$ \\
$40-49,000$ & $18.1 \%$ & Spanish Surname $1.1 \%$ & Eastern & $31 \%$ \\
$50+$ & $19.0 \%$ & Native America & $1.0 \%$ & Central & $11 \%$ \\
No answer & $6.1 \%$ & Other & $.8 \%$ & Mid-west & $18 \%$ \\
& & no answer & $4.6 \%$ & & \\
\hline
\end{tabular}


AAHPERD allows purchasing of its mailing lists for approved projects. This project was submitted and approved by AAHPERD. A random sample of 500 members was selected from AAHE's university/college 1,763 member mailing list. The randomly selected members were sent the survey.

\section{Instrumentation}

The data collection instrument, a descriptive survey, was designed specifically for this research. Specific survey sections were developed to support the research questions: spiritual health attitudes; attitudes toward including spiritual health in college general health courses; training in spiritual health; current spiritual health inclusion practices; and, personal and institutional demographics. Table 2 presents a correlation between research questions and survey questions.

Table 2

Correlation Between Research Questions and Survey Questions

\begin{tabular}{|c|c|c|c|}
\hline Research & Question \#1 & Items & $\# 1-8$ \\
\hline Research & Question \#2 & Items & $\# 9-19$ \\
\hline Research & Question \#3 & Item & $\# 43$ \\
\hline Research & Question \#4 & Items & $\# 44,45$ \\
\hline Research & Question \#5 & Items & $\# 1-8,24-32$, \\
\hline Research & Question $\# 6$ & Items & $24-31,34-36$ \\
\hline Research & Question \#7 & Item & \#19 \\
\hline Resea & Question \#8 & Items & $\# 1-19 ;$ \\
\hline
\end{tabular}


The specific survey questions in each section of the instrument were composed in two stages. In stage one, survey questions were developed based on stated suspicions in the literature about potential barriers to including spiritual health in health education materials and curricula, information gathered from previous spiritual health discussions with community college health instructors, and input from dissertation committee members. Consultation was held with statistics experts to ensure appropriate survey format.

In stage two the survey was pretested for surface validity. A purposive sample of content area specialists-five local community college and university health instructors--were sent the survey. They were asked to evaluate the survey for clarity, organization, and content. Survey revisions were made in accordance with pretesting results. A final survey was composed incorporating the focus group's feedback (see Appendix A).

\section{Data Collection}

Data collection began following approval from Portland State University's Human Subjects Committee. Final survey distribution included a letter that explained the nature and use of the research and guaranteed the respondent's anonymity. This letter was composed with the assistance of a professional direct-mail consultant with the intention of 
increasing the survey's response rate. In addition, a preaddressed, stamped return envelope was provided to the respondent to increase the likelihood of response. Since the majority of universities and colleges contacted were on the semester system, the survey needed to be sent no later than mid-April. The survey was sent April 18,1994 .

\section{Data Analysis}

Returned surveys were analyzed using the SYSTAT statistical program (Wilkinson, 1990). A code book was designed to enter the information from the completed surveys. Once all the data were entered, data analysis began on the research questions. In these analyses the respondents' spiritual health attitudes and attitudes toward including spiritual health in a college general health course were treated as dependent variables. The respondents' personal and institutional demographics and spiritual training were treated as independent variables.

\section{Analysis of Research Questions}

Research questions for this study were analyzed using the following techniques: (a) descriptive statistical methods including frequencies, means as measures of central tendencies, percentages; (b) chi-square test of significance; (c) univariate, one-way analysis of variance 
design with a .05 level of significance, and where appropriate, Bonferroni post-hoc analysis; (d) factor analysis; and (e) multiple regression.

To answer the first research question, what are AAHE collegiate health educators' spiritual health attitudes, mean and standard deviation descriptive statistics were run on respondents' answers to survey questions \#1-8.

To answer the second research question, what are AAHE collegiate health educators' attitudes about including spiritual health in general health courses, mean and standard deviation descriptive statistics were run on respondents' answers to survey questions \#9-19.

To answer the third research question, what proportion of collegiate general health courses taught by AAHE members address spiritual health, frequency data were used. Survey question \#43 was used to gather this information.

To answer the fourth research question, what amount of course time is spent covering spiritual health in collegiate general health courses that address spiritual health and how is that material covered, the data were analyzed in three sections. To assess the amount of time spent on spiritual health, the data were separated into academic systems, quarter or semester. Analysis by cross-tabulation between amount of time and type of academic system was done. Survey question \#44 was used to collect information. To assess how 
the spiritual health material is covered in the course, frequency responses to survey question \#45 were calculated.

To answer the fifth research question, if significant differences exist in respondent and institution demographic variables and spiritual health attitudes, one-way analysis of variance was used. Where significant results were obtained, a Bonferroni post-hoc test was done to test the strength and location of the variance. Demographic survey questions \#24-32 and 34-36 were treated as independent variables. Spiritual health attitude survey questions \#1-8 were treated as dependent variables.

To answer the sixth research question, if significant differences exist in respondent and institution demographic variables and attitudes toward including spiritual health, one-way analysis of variance was used. Where significant results were obtained, a Bonferroni post-hoc test was done to test the strength and location of the variance. Demographic survey questions $\# 24-32$ and 34-36 were treated as independent variables. Attitudes toward spiritual health survey questions \#9-19 were treated as the dependent variables.

To answer the seventh research question, do AAHE college health educators perceive themselves to be adequately trained to teach spiritual health, the mean response to survey question \#19 was calculated. 
To answer the eighth research question, from the demographic data, spiritual health attitude data, including spiritual health attitude data, and spiritual health training data collected on the survey, are there a set of factors that can discriminate who would include and who would not include spiritual health in their general health courses, two statistical steps were done. A factor analysis was done on survey questions \#1-19. Two factors with an eigenvalue greater than one were identified and named. A multiple regression was done on significant findings from the factor analysis and ANOVAs from previous research questions. 
CHAPTER IV

FINDINGS

Introduction

In this chapter, the characteristics and analysis of the research questions as answered by the respondents are presented. These characteristics are followed by eight sections that answer the study's eight research questions. section one addresses the results of research question one which covers the respondents' spiritual health attitudes. Section two answers research question two which covers the AAHE members' attitudes toward including spiritual health in a college general health course. Section three discusses the findings of research question three which examines what proportion of college general health courses taught by AAHE members address spiritual health. Section four speaks to the fourth research question which discusses the amount of time spent on the subject of spiritual health within college general health courses that include spiritual health. Section five addresses research question five which covers the significant differences between demographic variables and spiritual health attitudes. Section six discusses the results of research question six which indicates significant differences between demographic variables and attitudes 
toward including spiritual health in general health courses. Section seven answers research question seven which presents AAHE members' perception of their adequacy of spiritual health training. Section eight discusses the results of research question eight which identifies factors that explain who are most likely to include spiritual health within their college general health course.

\section{Respondents' General Characteristics}

The Spiritual Health survey achieved a $54 \%$ return rate $(\underline{n}=256)$. The survey respondents' general characteristics are divided into four categories for clarification: (a) personal, (b) institution, (c) health education experience, (d) general health course. Each of these categories has a separate table and is discussed separately.

\section{Personal Characteristics}

AAHE members who responded to the survey were predominately white (96.4\%), middle aged (36-55 years) (65\%), and female (62.5\%). The sample population's highest degree was, most frequently, in health education (60.4\%). The majority reported having a doctorate degree (52.08). A large number, $\underline{n}=201(80.4 \%)$, characterized themselves as having a personal religious affiliation.

The respondents came from throughout the United states, with the largest representation coming from the Southern $(23.4 \%)$, Eastern (23\%), and Midwestern (22.2\%) regions. 
Table 3 presents a summary of the respondents' personal characteristics.

Table 3

Respondents' Personal Characteristics

\begin{tabular}{|c|c|c|}
\hline Characteristic & Number & Percentage \\
\hline $\begin{array}{l}\text { Gender } \\
\text { Male } \\
\text { Female }\end{array}$ & $\begin{array}{r}96 \\
160\end{array}$ & $\begin{array}{l}37.5 \% \\
62.5 \%\end{array}$ \\
\hline $\begin{array}{l}\text { Age } \\
\quad<25 \text { years } \\
26-35 \text { years } \\
36-45 \text { years } \\
46-55 \text { years } \\
+55 \text { years }\end{array}$ & $\begin{array}{r}8 \\
43 \\
94 \\
71 \\
38\end{array}$ & $\begin{array}{l}3.1 \% \\
16.9 \% \\
37.0 \% \\
28.0 \% \\
15.0 \%\end{array}$ \\
\hline $\begin{array}{l}\text { Ethnic Group } \\
\text { White } \\
\text { Spanish Surname } \\
\text { African American } \\
\text { Asian Pacific } \\
\text { Native American } \\
\text { Other }\end{array}$ & $\begin{array}{r}204 \\
3 \\
4 \\
1 \\
0 \\
0\end{array}$ & $\begin{array}{r}96.4 \% \\
1.4 \% \\
1.9 \% \\
.5 \% \\
0.0 \% \\
0.0 \%\end{array}$ \\
\hline $\begin{array}{l}\text { AAHERD Region } \\
\text { Northwest } \\
\text { Midwest } \\
\text { Southwest } \\
\text { Central } \\
\text { Eastern } \\
\text { South }\end{array}$ & $\begin{array}{l}28 \\
56 \\
30 \\
21 \\
58 \\
59\end{array}$ & $\begin{array}{r}11.1 \% \\
22.2 \% \\
11.9 \% \\
8.3 \% \\
23.0 \% \\
23.4 \%\end{array}$ \\
\hline $\begin{array}{l}\text { Highest Academic Degree } \\
\text { Bachelor } \\
\text { Master } \\
\text { Doctorate }\end{array}$ & $\begin{array}{r}21 \\
101 \\
132\end{array}$ & $\begin{array}{r}8.3 \% \\
39.8 \% \\
52.0 \%\end{array}$ \\
\hline $\begin{array}{l}\text { Highest Academic Degree } \\
\text { Health Education } \\
\text { Public Health } \\
\text { Exercise Physiology } \\
\text { Physical Education } \\
\text { Education } \\
\text { Other }\end{array}$ & $\begin{array}{r}154 \\
10 \\
13 \\
49 \\
13 \\
16\end{array}$ & $\begin{array}{r}60.4 \% \\
3.9 \% \\
5.1 \% \\
19.2 \% \\
5.1 \% \\
6.3 \%\end{array}$ \\
\hline
\end{tabular}


Respondents' Institution

Characteristics

The respondents worked predominately in higher

education organizations $(90.8 \%)$, and the minority identified

themselves as high school teachers, retired, or in private

industry. The most common higher education institution

represented was the public, doctorate granting university

$(38.6 \%)$, which was followed by the public, liberal arts with master's programs university (25.9\%).

Few respondents worked for an institution that required a signed faith statement (2.4\%) or had a religious affiliation (10\%). Institutional demographics are listed in Table 4 .

Table 4

Respondents' Institution Characteristics

\begin{tabular}{|c|c|c|}
\hline Characteristic & Number & Percentage \\
\hline $\begin{array}{l}\text { Primary classification } \\
\text { of University/College } \\
\text { Doctoral-granting, private } \\
\text { Doctoral-granting, public } \\
\text { Liberal arts, w/masters, public } \\
\text { Liberal arts, w/masters, private } \\
\text { Liberal arts, no masters, public } \\
\text { Liberal arts, no masters, private } \\
\text { Community College } \\
\text { Other }\end{array}$ & $\begin{array}{r}8 \\
97 \\
65 \\
13 \\
8 \\
10 \\
27 \\
23\end{array}$ & $\begin{array}{r}3.2 \% \\
38.6 \% \\
25.9 \% \\
5.2 \% \\
3.2 \% \\
4.0 \% \\
10.8 \% \\
9.2 \%\end{array}$ \\
\hline $\begin{array}{l}\text { Institution Religious Affiliation } \\
\text { Yes } \\
\text { No }\end{array}$ & $\begin{array}{r}25 \\
220\end{array}$ & $\begin{array}{l}10.0 \% \\
89.8 \%\end{array}$ \\
\hline $\begin{array}{l}\text { Sign a Faith statement } \\
\text { Yes } \\
\text { No }\end{array}$ & $\begin{array}{r}6 \\
241\end{array}$ & $\begin{array}{r}2.4 \% \\
97.6 \frac{8}{6}\end{array}$ \\
\hline
\end{tabular}


Respondents' Health Education

Experiences

The majority of respondents had, at one time in their career, taught general health courses (81.2\%). During the past two academic years, the majority of the respondents had taught at least one college general health course (51.8\%). At the time of the survey, the respondents' primary teaching responsibilities were predominately in general health (21.2\%) and wellness (17.4\%) courses (see Table 5).

Table 5

Respondents' Health Education Experiences

\begin{tabular}{lrr} 
Health Education Experience & Number & Percentage \\
\hline Primary Teaching Responsibility & & \\
Health Methods & 32 & $13.3 \%$ \\
Sexuality & 15 & $6.2 \%$ \\
Mental Health & 3 & $1.2 \%$ \\
First Aid & 6 & $2.5 \%$ \\
General Health & 51 & $21.2 \%$ \\
Wellness & 42 & $17.4 \%$ \\
Fitness & 20 & $8.3 \%$ \\
Nutrition Hommunity Health & 1 & $.4 \%$ \\
Environmental Health & 14 & $5.8 \%$ \\
Disease Prevention & 0 & $0.0 \%$ \\
Health Program Planning & 5 & $2.1 \%$ \\
Health Program Evaluation & 9 & $3.7 \%$ \\
Other & 4 & $1.7 \%$ \\
Teach a General Health Course & 39 & $16.2 \%$ \\
(in past two years) & & \\
Yes & & \\
No & 131 & $51.9 \%$ \\
\end{tabular}


Table 5

Respondents' Health Education Experiences (continued)

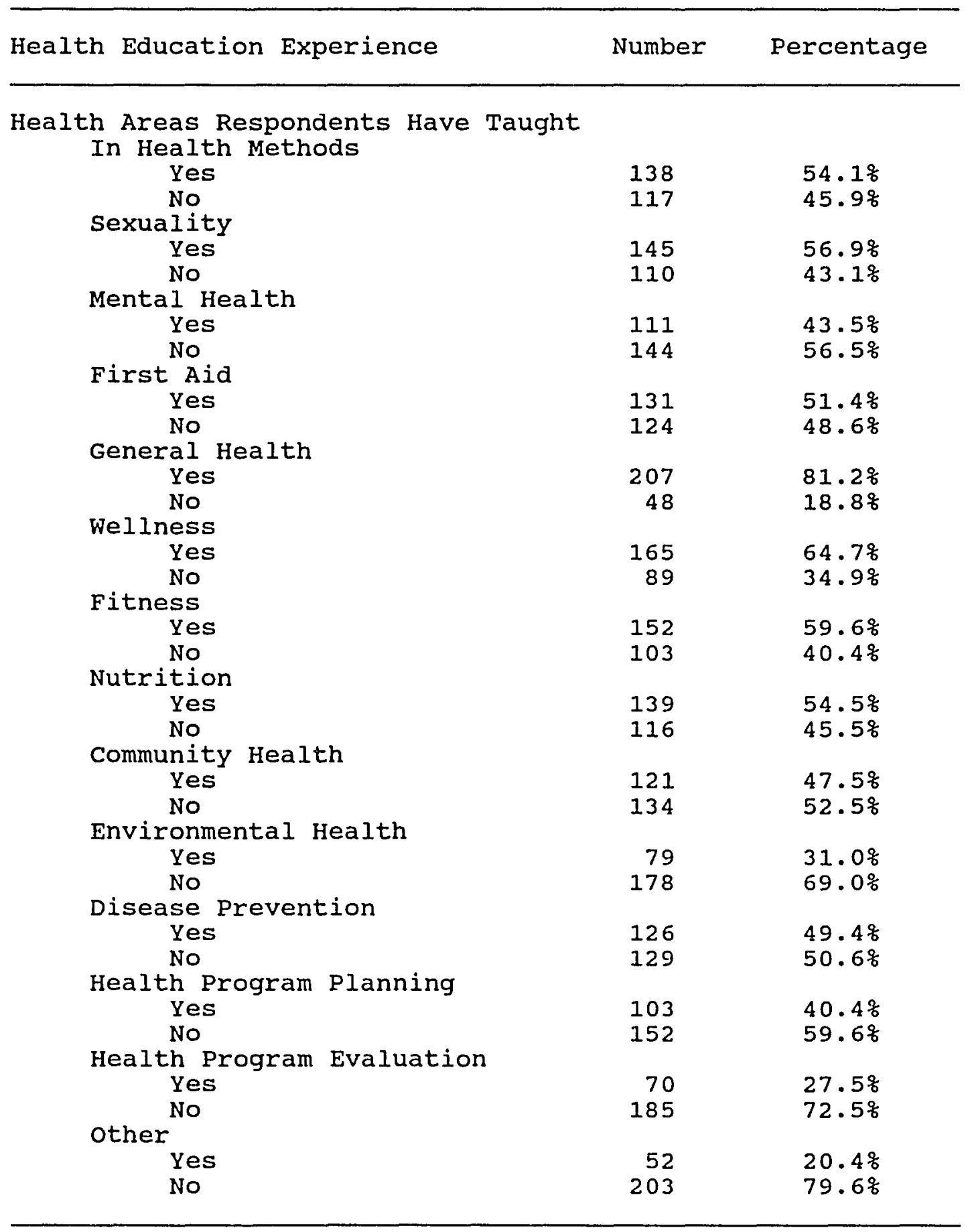


General Health course

Characteristics

The majority of respondents (51.8\%) were teaching a general health course on the semester system (84q). Less than 200 students in an academic year was the largest single cluster of student enrollment (43.1\%). Most AAHE members, who taught general health, taught six or fewer sections of personal health in a given academic year (89.3\%) and had taught it 10 years or less $(71.0 \%)$. A summary of AAHE members' general health course characteristics is given in Table 6 .

In summary, this study consists of an AAHE sample with doctorate-level education, an academic background in health education, experience in teaching college general health courses, a stated personal religious affiliation and were predominately white, middle-aged, and female.

\section{Spiritual Health Attitudes}

The first research question states, "What are AAHE collegiate health educators' spiritual health attitudes?" Means and standard deviation scores were calculated on the eight survey items to answer this question. A score of 2.5 or better is interpreted as a positive response.

Mean scores above 2.5 were reported by the respondents in seven spiritual health attitude statements. Four spiritual health attitude statements received "strong agreement" responses with mean scores above 3.5. The eighth 
spiritual health attitude statement reported a mean below 2.5. The data reveals agreement on spiritual health attitudes among respondents.

Table 6

General Health Course Characteristics

General Health Course Academic System

$\begin{array}{lll}\text { Quarter system } & =16 \% & (\underline{\mathrm{n}}=20) \\ \text { Semester system } & =84 \% & (\underline{\underline{n}}=107)\end{array}$

General Health Course as a Graduation Requirement

$$
\begin{array}{ll}
\text { Yes }=40.3 \% & (\underline{\underline{n}}=52) \\
\text { No }=59.7 \% & (\underline{\underline{n}}=77)
\end{array}
$$

Average Student Enrollment (all sections)/academic year

$\begin{array}{llrl}\text { less than 200 } & = & 43.1 \%(\underline{n}=56) \\ 200-400 & = & 22.3 \%(\underline{n}=29) \\ 400-600 & = & 13.8 \%(\underline{n}=18) \\ 600-800 & = & 6.9 \%(\underline{n}=9) \\ 800-1,000 & = & 3.1 \%(\underline{\underline{n}}=4) \\ \text { over } 1,000 & = & 10.8 \%(\underline{n}=14)\end{array}$

Number of sections AAHE member teach/academic year

$\begin{array}{llrl}1-3 & = & 65.6 \% & (\underline{n}=86) \\ 4-6 & = & 23.7 \%(\underline{n}=31) \\ 7-9 & = & 8.4 \%(\underline{n}=11) \\ 10-12 & = & 1.5 \%(\underline{n}=2) \\ \text { over 12 } & = & .8 \%(\underline{n}=1)\end{array}$

Years AAHE member has taught course

$\begin{array}{llll}0-5 \text { years } & = & 42.7 \% & (\underline{\underline{n}}=56) \\ 6-10 \text { years } & = & 28.2 \% & (\underline{\underline{n}}=37) \\ 11-15 \text { years } & = & 12.2 \% & (\underline{\underline{n}}=16) \\ 16-20 \text { years } & = & 4.6 \% & (\underline{\underline{n}}=6) \\ 21+\text { years } & = & 12.2 \%(\underline{\underline{n}}=16)\end{array}$


Survey results show a strong support for the importance and influence of spiritual health on a person's total wellbeing. These attitudes are in tandem with a strong agreement among respondents that their personal spiritual health was important to them. Also, spiritual health was seen by the respondents as including diverse cultural and religious traditions (see Table 7 ).

Considering the degree of debate in the literature over the definition of spiritual health and its importance for the classroom, the strong empirical evidence supporting the importance of spiritual health was unexpected. The data present the possibility that the sample population was biased toward those who found spiritual health important. Individuals who did not find spiritual health important may have disregarded the survey.

The data reveal that, while respondents felt spiritual health could include diverse cultural and religious traditions, they were less certain whether a clear conceptual difference between spiritual health and religion existed. An intriguing possible implication arises from these data. Respondents may be questioning if and how spiritual health occurs outside the frame of organized religion. 
Table 7

Respondents' Spiritual Health Attitudes

Mean Scores $(\underline{N}=256)$

\begin{tabular}{|c|c|c|}
\hline Attitude & Mean & $S D$ \\
\hline $\begin{array}{l}\text { Spiritual health is an important } \\
\text { dimension in a person's total } \\
\text { well-being. }\end{array}$ & 3.680 & 0.523 \\
\hline $\begin{array}{l}\text { My personal spiritual health is } \\
\text { important to me. }\end{array}$ & 3.656 & 0.552 \\
\hline $\begin{array}{l}\text { Spiritual health influences an } \\
\text { individual's physical, mental, } \\
\text { social, \& emotional well-being. }\end{array}$ & 3.612 & 0.542 \\
\hline $\begin{array}{l}\text { Spiritual health can include } \\
\text { diverse cultural and religious } \\
\text { traditions. }\end{array}$ & 3.557 & 0.550 \\
\hline $\begin{array}{l}\text { Spiritual health is a private, } \\
\text { personal journey. }\end{array}$ & 3.207 & 0.724 \\
\hline $\begin{array}{l}\text { I am satisfied with my spiritual } \\
\text { health. }\end{array}$ & 3.164 & 0.636 \\
\hline $\begin{array}{l}\text { I think there is a clear conceptual } \\
\text { difference between spiritual } \\
\text { health and religion. }\end{array}$ & 2.963 & 0.849 \\
\hline $\begin{array}{l}\text { Find spiritual health to be an } \\
\text { uncomfortable subject. }\end{array}$ & 1.830 & 0.769 \\
\hline
\end{tabular}

In summary, the data on respondents' spiritual health attitudes reveal individuals who placed importance on their personal spiritual health, were comfortable with spiritual health, viewed spiritual health as a private and personal journey, and strongly supported spiritual health as important and influential to a person's total well-being. 
Including Spiritual Health

Attitudes

The second research question states, "What are AAHE collegiate health educators' attitudes about including spiritual health in college general health courses?" Mean and standard deviation scores were calculated on the 11 survey items that addressed attitudes about including spiritual health in college general health courses. A mean score of 2.5 or higher was considered a positive response. Unlike the results in the previous research question, respondents were in less agreement as to their attitudes toward including spiritual health in college courses. In the 11 items surveyed, 4 reported mean scores above 2.5 . Respondents stated that spiritual health was both an important and an appropriate subject to present in a college general health course. This attitude existed even though the respondents' other responses demonstrated some concerns and uncertainties about including spiritual health content in a course. In addition, respondents agreed that more spiritual health materials are needed for teaching and they are adequately trained to teach spiritual health (see Table 8). Seven statements in this survey section report mean scores of less than 2.5. Respondents have expressed concerns and uncertainties about including spiritual health in a college general health course. These concerns appear 
to fall into two categories: (a) teaching logistics and (b) colleague support.

Table 8

Respondents' Attitudes Toward Including Spiritual Health in College General Health Courses

$(\underline{N}=256)$

Attitude

Mean

$S D$

Spiritual health is an important human dimension to present in a collegiate general health course.

Spiritual health is an appropriate content area to inciude in a college health course.

More spiritual health would be included if more resource materials were available.

I feel adequately trained to teach spiritual health.

Society's concern for separation of church and state makes teaching spiritual health difficult in a general health course.

Spiritual health's vague definition makes it a hard concept to include in a general health course.

I perceive lack of support from my administrators to include more spiritual health.

I perceive lack of support from my teaching peers to include more spiritual health.

I am uncomfortable including spiritual health materials because I have inadequate professional training in the subject area.

Including spiritual health would cause me concern about respecting the student's individual belief system.

Because a student's spiritual health is hard to evaluate and grade, it is best not to include spiritual health in a general health course.

$(1=$ strongly disagree; $4=$ strongly agree $)$ 
The response to three attitude statements in the survey relates to respondents' attitudes toward teaching concerns when including spiritual health in college general health courses. These concerns were: (a) spiritual health's vague definition makes it a hard concept to include, (b) students' spiritual health is hard to grade, and (c) students' individual belief systems must be respected. The uncertainty expressed by these three attitudes, coupled with previous reports of strong support for including spiritual health in the courses suggest that respondents may be caught between wanting to include spiritual health and being unsure as to how one proceeds with including these subjects. If this dilemma exists, a partial explanation may be found in a respondent's teaching paradigm and a lack of training in spiritual health. If the respondent's teaching paradigm focuses on objective, measurable content, spiritual health may be more difficult to teach and measure. Through exploring other teaching paradigms, the respondent may alleviate these teaching concerns. The concerns may also be eased by adequate training in spiritual health. Teachers who know their content area well may feel more assured in their presentation and ability to evaluate the subject matter.

The results further indicate that respondents had concerns about colleague support for including spiritual health in college health courses. This concern was 
expressed in three of the attitude items surveyed. These were: (a) concern for separation of church and state, (b) lack of support from teaching peers, and (c) lack of support from administration.

In conclusion, while respondents expressed attitudes that support the importance and appropriateness of including spiritual health in college health courses, they also expressed attitudes that identified areas of concern when including the subject.

\section{Current Spiritual Health Inclusion}

Research question three asks, "What proportion of college general health courses taught by AAHE members addresses spiritual health?" Frequency data were tabulated to answer this research question. The data show, in the sample population, that a majority of respondents, $52.8 \%$ $(\underline{N}=131)$, had taught a lower division general health course in the past two academic years. The most common course taught was Personal Health $(55.8 \%)$, followed by Wellness (13.2\%) and Fitness (10.9\%).

Statistical data reveal that spiritual health was included in $65.6 \%(\underline{N}=82)$ of the lower division general health courses taught by respondents. Statistical tabulation indicates that lecture (95\%) was the most frequent method chosen to present spiritual health material in the general health course, followed by text (58.5\%), 
classroom activities (45\%), class assignments (31\%), and media $(9.8 \%)$.

When the respondents were asked if they felt spiritual health was adequately covered in their course, 24 (28.6\%) stated yes, $41(48.8 \%)$ stated no, and 19 (22.6\%) were uncertain. When asked to describe what they felt was needed to adequately cover spiritual health, few written responses were given. When a written response was given, the response suggested a need for additional class time and spiritual health materials.

The high number of respondents who included spiritual health content in college general health courses was a surprise finding that appeared to contradict assumptions made in the professional literature about current practices of including spiritual health in the course work. The data suggest that, while some members of the health education profession are debating the merits of including spiritual health in health education, a significant portion of college health educators are including the topic area.

\section{Spiritual Health Inclusion}

Research question four asks, "Within collegiate general health courses that address spiritual health, what amount of time is spent on a spiritual health subject area?" Respondents' answers were analyzed in two groups in order to answer this research question: semester and 
quarter systems. The majority of the respondents, $82 \%$ ( $\underline{N}=$ 107), taught in the semester system. Cross-tabulations were done on each group to determine the amount of time allotted for spiritual health.

The quarter system's cross-tabulation findings indicate that the norm was less than one class hour spent on spiritual health (see Table 9).

Table 9

Amount of Time Spent on Spiritual Health Content in College General Health Courses on the Quarter system

\begin{tabular}{lccccc}
\hline $\begin{array}{l}\text { Number of } \\
\text { quarter hrs }\end{array}$ & $\begin{array}{c}\text { spending } \\
<1 \mathrm{hr}\end{array}$ & $\begin{array}{c}\text { \& spending } \\
1-2 \text { hrs }\end{array}$ & $\begin{array}{c}\text { \&pending } \\
3-4 \text { hrs }\end{array}$ & $\begin{array}{c}\text { spending } \\
>4 \text { hrs }\end{array}$ \\
\hline $2 \mathrm{crs}(\underline{\mathrm{n}}=2)$ & $100 \%$ & - & - & - \\
$3 \mathrm{crs}(\underline{\underline{n}}=7)$ & $71 \%$ & $29 \%$ & - & - \\
$4 \mathrm{crs}(\underline{\underline{n}}=2)$ & $50 \%$ & - & - & $50 \%$ \\
\hline
\end{tabular}

The semester system's cross-tabulation findings indicate that the majority of semester courses spent 2 hours or less on spiritual health (see Table 10). It appears that there is a relationship between the length of the course and the amount of time devoted to spiritual health materials. In both systems, the amount of time spent on spiritual health was minimal. 
Table 10

Amount of Time spent on Spiritual Health Content in College General Health Courses on the semester system

\begin{tabular}{lccccc}
\hline $\begin{array}{l}\text { Number of } \\
\text { semester hrs }\end{array}$ & $\begin{array}{c}\text { spending } \\
<1 \mathrm{hr}\end{array}$ & $\begin{array}{c}\text { spending } \\
1-2 \text { hrs }\end{array}$ & $\begin{array}{c}\text { spending } \\
3-4\end{array}$ & $\begin{array}{c}\text { hrs } \\
\text { spending } \\
>4\end{array}$ \\
\hline $1 \mathrm{cr}(\underline{\mathrm{n}}=8)$ & $25 \%$ & $63 \%$ & $13 \%$ & - \\
$1.5 \mathrm{crs}(\underline{\mathrm{n}}=1)$ & - & $100 \%$ & - & - \\
$2 \mathrm{crs}(\underline{\mathrm{n}}=17)$ & $24 \%$ & $59 \%$ & $12 \%$ & $6 \%$ \\
$3 \mathrm{crs}(\underline{\mathrm{n}}=40)$ & $40 \%$ & $45 \%$ & $13 \%$ & $3 \%$ \\
\hline
\end{tabular}

Several explanations could account for the minimal amount of time given to spiritual health material. Findings may suggest that, when competing with other health education subject areas, spiritual health was seen as less important and, therefore, allocated less time. Another explanation may be that including spiritual health in the course work is a recent phenomenon for general health courses, and the small amount of time indicates the early stages of a growing trend. The author has noticed that in an informal review of leading college general health texts, a marked increase in including spiritual health has occurred during the last two academic years.

The degree of spiritual health included by respondents in their health courses softens the results of the previous research question. While a surprisingly high percentage, $65.6 \%$, of the sample population included spiritual health, 
the depth and degree of including the subject appear to be limited.

\section{Spiritual Health Attitudes and Demographic Variables}

The fifth research question states, "Are there significant differences in each demographic variable and the respondents' spiritual health attitudes?" One-way analysis of variances (ANOVA) were completed on each spiritual health attitude and each independent, demographic variable. Where an independent variable contained more than two categories and significant ANOVA results at $\underline{p}<.05$ were obtained, a Bonferroni post-hoc test was done to determine the strength and location of the variance. If the Bonferroni test showed no significant difference at a $\underline{p}<.05$ level, the results were interpreted as not significant.

The results from the tested demographic variables show significant differences exist between specific demographic variables and select spiritual health attitudes. Interestingly, the significant differences are in the strength of the respondents' spiritual health attitudes, not the direction of the response. Respondents had strikingly similar attitudes when the demographic variables were analyzed. The data analyzed for each demographic variable are discussed in the following sections. 


\section{Highest Academic Degree}

The demographic variable "highest academic degree" provides significant variance in five of the eight spiritual health attitude statements. These five are: (a) satisfaction with personal spiritual health, (b) spiritual health is an uncomfortable subject area, (c) spiritual health is a private, personal journey, (d) conceptual difference between spiritual health and religion, and (e) spiritual health can include diverse cultural and religious traditions.

Bonferroni post-hoc analysis was done to find the location of the differences that were reported. Post-hoc results indicate that respondents with doctorate degrees had significantly different attitudes than those with bachelor's and master's degrees. Respondents with doctorates were more likely to see clear conceptual differences between spiritual health and religion. Further, these respondents viewed spiritual health as a concept that could include diverse cultural and religious traditions. Viewing spiritual health as conceptually different from religion may, partially, account for the greater comfort level that doctorate respondents had with the spiritual health subject area. While all respondents viewed spiritual health as a private and personal journey, respondents with doctorates expressed greater agreement with this attitude (see Table 11). 
Table 11

Respondents' Highest Academic Degree and Spiritual Health Attitudes

\begin{tabular}{|c|c|c|c|c|c|c|c|}
\hline Attitudes & F-Value & DF & Prob. & $\frac{\text { Bachelor }}{X}$ & $\frac{\text { Master }}{X}$ & $\begin{array}{c}\text { Doctorate } \\
\bar{X}\end{array}$ & $\begin{array}{l}\text { Post Hoc } \\
\text { BonFerroni }\end{array}$ \\
\hline Important to total well-being & 0.176 & 2,251 & N.S. & $\mathrm{X}$ & $X$ & $\mathrm{X}$ & \\
\hline Personally important to me & 0.487 & 2,251 & N.S. & $\mathrm{X}$ & $\mathrm{X}$ & $X$ & \\
\hline Satisfied w/personal SH & 4.701 & 2,251 & .010 & 2.810 & 3.139 & 3.250 & $1-3$ \\
\hline Uncomfortable subject & 5.687 & 2,251 & .004 & 1.762 & 2.025 & 1.689 & $2-3$ \\
\hline SH influences well-being & 1.886 & 2,250 & N.S. & & & & \\
\hline Diverse culture/religious traditions & 6.708 & 2,250 & .001 & 3.500 & 3.416 & 3.674 & $2-3$ \\
\hline Private, personal journey & 6.124 & 2,251 & .003 & 2.952 & 3.069 & 3.356 & $2-3$ \\
\hline Concept diff. betw. SH \& religion & 13.443 & 2,250 & .000 & 2.286 & 2.835 & 3.182 & $1-2,3 ; 2-3$ \\
\hline
\end{tabular}

${ }^{*} \mathrm{p} \leq$ (4 = strongly agree; $1=$ strongly disagree $)$ 
While all respondents were satisfied with their personal spiritual health and were comfortable with the subject area, those with doctorates were the most satisfied with their personal spiritual health and the most comfortable with the subject area. Findings indicate a possible relationship between personal satisfaction with spiritual health and comfort with the topic.

\section{Personal Religious preference}

Regarding the demographic variable, "personal religious preference," respondents showed significant variance in four spiritual health attitude statements. These were: (a) importance of spiritual health to total well-being, (b) spiritual health is personally important, (c) spiritual health is an uncomfortable subject, and (d) conceptual difference occurs between spiritual health and religion. Individuals who reported a personal religious preference had significantly stronger attitudes of agreement with these four areas than respondents who reported no personal religious preference. No significant differences were found in the other four spiritual health attitude statements (see Table 12).

The data show that respondents who did not state a personal religious preference (20\%), expressed similar attitudes with those who did. Spiritual health was seen by those who have no stated personal religion as personally important and important to the total well-being of the 
Table 12

Respondents' Personal Religious Preference and Spiritual Health Attitudes

\begin{tabular}{|l|l|l|l|l|l|}
\hline \multicolumn{1}{|c|}{ Attitudes } & F-Value & \multicolumn{1}{|c|}{ DF } & Prob. & Yes & No \\
\hline Important to total well-being & 6.897 & 1,248 & .009 & 3.726 & 3.510 \\
\hline Personally important to me & 11.114 & 1,248 & .001 & 3.716 & 3.429 \\
\hline Satisfied w/personal SH & 0.479 & 1,248 & N.S. & X & X \\
\hline Uncomfortable subject & 5.846 & 1,248 & .016 & 1.886 & 1.592 \\
\hline SH influences well-being & 2.452 & 1,247 & N.S. & $X$ & $X$ \\
\hline Diverse culture/religion traditions & 0.013 & 1,247 & N.S. & $X$ & $X$ \\
\hline Private, personal journey & 3.312 & 1,248 & N.S. & $X$ & $X$ \\
\hline Concept diff. betw. SH \& religion & 7.356 & 1,247 & .007 & 2.883 & 3.245 \\
\hline
\end{tabular}

$\star \underline{p} \leq .05$ ( $4=$ strongly agree; $1=$ strongly disagree) 
individual. Respondents without a religious preference appear to indicate that strong positive attitudes about the importance of spiritual health can occur outside religious framework. Respondents with a personal religious preference also reported attitudes that were both less certain about the conceptual difference between spiritual health and religion and more uncomfortable with the concept of spiritual health.

The data suggest a potential relationship between a respondent's conceptual views of spiritual health and religion and his or her level of comfort with the subject area.

\section{Taught a General Health}

\section{Course}

Respondents who taught a general health course in the last two years had significantly stronger attitudes on five of the eight spiritual health attitude statements. These were: (a) importance of spiritual health to well-being, (b) spiritual health is personally important, (c) satisfied with personal spiritual health, (d) spiritual health is not an uncomfortable topic, and (e) spiritual health is conceptually different from religion. No significance was reported in the other three spiritual health statements. The significant djfferences were in strength of response, not in direction of response (see Table 13). 
Table 13

Respondents who Teach a college Level General Health Course and Spiritual Health Attitudes

\begin{tabular}{|l|l|l|l|l|l|}
\hline \multicolumn{1}{|c|}{ Attitude } & F-Value & \multicolumn{1}{|c|}{ DF } & Prob.* & Yes & No \\
\hline Important to total well-being & 5.817 & 1,251 & .017 & 3.756 & 3.598 \\
\hline Personally important to me & 6.453 & 1,251 & .012 & 3.740 & 3.566 \\
\hline Satisfied w/personal SH & 19.855 & 1,251 & .000 & 3.328 & 2.984 \\
\hline Uncomfortable subject & 4.201 & 1,251 & .041 & 1.737 & 1.934 \\
\hline SH influences well-being & 3.442 & 1,250 & $\mathrm{~N} . \mathrm{S}$. & $\mathrm{X}$ & $\mathrm{X}$ \\
\hline Diverse cultural/religious trad. & 1.160 & 1,250 & $\mathrm{~N} . \mathrm{S}$. & $\mathrm{X}$ & $\mathrm{X}$ \\
\hline Private, personal journey & 1.294 & 1,251 & $\mathrm{~N} . \mathrm{S}$. & $\mathrm{X}$ & $\mathrm{X}$ \\
\hline Concept diff. betw. SH \& religion & 7.208 & 1,250 & .008 & 3.108 & 2.824 \\
\hline
\end{tabular}

${ }^{*} \mathrm{p} \leq .05$ ( $4=$ strongly agree; $1=$ strongly disagree $)$ 
Individuals who taught a general health course reported significantly more cercain spiritual health attitudes in four areas: (a) importance to the total well-being of a person, (b) spiritual health's importance to them personally, (c) their satisfaction with their spiritual health, and (d) their comfort level with the topic. Additionally, the data show that those who teach general health courses had more certainty that a clear conceptual difference exists between spiritual health and religion. With significant variance in five out of the eight spiritual health attitudes, teaching a general health course appears to have a strong connection with spiritual health attitudes. A possible explanation for this connection may be the influence of experience on attitudes.

Respondents who taught a general health course that had a holistic frame of reference may have had more experience counseling students on personal health issues than colleagues in other health education areas. It is possible that these experiences provided the opportunity to observe and reflect upon the influence of the spiritual dimensions on students' well-being. These experiential incidents may have been an influential factor in developing the teachers' strong attitudes about the importance of spiritual health. This previously mentioned demographic variable supports a finding in previous demographic analysis. A relationship appears to exist between a respondent viewing spiritual 
health as conceptually different from religion and the respondent's comfort level with spiritual health as a subject. This finding adds weight to the literature that advocates a need for discrimination between the two concepts before a possibility of including spiritual health materials occurs.

A second-level ANOVA analysis was completed to attain greater understanding in this variable. The analysis was made in order to ascertain if significant spiritual health attitude differences existed between those who included spiritual health in their general health course and those who did not (see Table 14).

\section{Table 14}

Including spiritual Health in college General Health course and spiritual Health Attitudes

\begin{tabular}{|c|c|c|c|c|c|}
\hline Item & F-Value & DF & Prob. & $\begin{array}{l}\text { Mean } \\
\text { Yes }\end{array}$ & $\begin{array}{l}\text { Mean } \\
\text { No }\end{array}$ \\
\hline Important to total well-being & 3.609 & 1,123 & N.S. & & \\
\hline Personally important to me & 4.744 & 1,123 & .031 & 3.829 & 3.628 \\
\hline Satisfied with personal SH & 1.998 & 1,123 & N.S. & & \\
\hline Uncomfortable subject & 2.601 & 1,123 & N.S. & & \\
\hline SH influences well-being & 1.719 & 1,123 & N.S. & & \\
\hline Diverse culture/religion traditions & 0.373 & 1,123 & N.S. & & \\
\hline Private, personal joumey & 0.270 & 1,123 & N.S. & & \\
\hline Concept diff, betw. SH \& religion & 0.229 & 1,122 & N.S. & & \\
\hline
\end{tabular}

$\mathrm{p}<.05$ ( $1=$ strongly disagree; $4=$ strongly agree $)$

Similar spiritual health attitudes emerged between those who chose to include spiritual health in their general 
health course and those who did not. Statistically, significant difference is reported in only one spiritual health attitude statement: "spiritual health is personally important to me."

Health educators who teach general health courses have strong, positive attitudes toward spiritual health, regardless of whether or not they include spiritual health material in their course. Results suggest that including spiritual health content in a course is a multi-faceted decision that extends beyond the respondents' positive spiritual health attitudes.

Primary Teaching Responsibility

Primary teaching responsibility provides no significant statistical difference in seven of the spiritual health attitude statements. The survey shows significant statistical difference in one spiritual health attitude: "spiritual health influences an individual's well-being." Bonferroni post-hoc analysis on the one significant variable shows that respondents whose primary teaching assignment was in health methods reported a significantly stronger positive response in spiritual health attitudes than did respondents whose primary teaching assignments were in community health, health program evaluation, and other. Also, Bonferroni post-hoc reports that respondents who primarily taught a wellness course were in significantly stronger agreement than those who primarily taught in health program evaluation (see Table 15). 
Table 15

Respondents' Primary Teaching Responsibility and Spiritual Health Attitudes

\begin{tabular}{|c|c|c|c|c|c|c|c|c|c|c|c|c|c|c|c|c|c|c|}
\hline Nisivitas & F.Value & $\mathrm{DF}$ & Prob & $\begin{array}{l}\text { InMth } \\
\text { Man } \\
\text { (I) }\end{array}$ & $\begin{array}{l}\text { Sex } \\
\text { Mear } \\
\text { (2) }\end{array}$ & $\begin{array}{l}\text { Merr } \\
\text { Mean } \\
\text { (3) }\end{array}$ & $\begin{array}{l}\text { FAid } \\
\text { Mean } \\
\text { (4) }\end{array}$ & $\begin{array}{c}\text { Cenht } \\
\text { Mans } \\
\text { (s) }\end{array}$ & $\begin{array}{l}\text { Well } \\
\text { Mean } \\
(\theta)\end{array}$ & $\begin{array}{c}\text { Fin } \\
\text { Man } \\
m\end{array}$ & $\begin{array}{l}\text { Nur } \\
\text { Moan } \\
\text { (B) }\end{array}$ & $\begin{array}{c}\text { Comh } \\
\text { Masn } \\
(9)\end{array}$ & $\begin{array}{l}\text { EmrH } \\
\text { Mean } \\
\text { (19) }\end{array}$ & $\begin{array}{l}\text { DPre } \\
\text { Mean } \\
\text { (11) }\end{array}$ & $\begin{array}{l}\text { HPP } \\
\text { Mass } \\
\text { (12) }\end{array}$ & $\begin{array}{l}\text { HPE } \\
\text { Mean } \\
\text { (13) }\end{array}$ & $\begin{array}{l}\text { Oar } \\
\text { Man } \\
\text { (14) }\end{array}$ & $\begin{array}{l}\text { Poon Hoc } \\
\text { Boor- } \\
\text { Forrori }\end{array}$ \\
\hline Importar to todel mentexing & 1.886 & 12.228 & .040 & 3.781 & 3.73 & 4.000 & 3.607 & 3.735 & 3.785 & 3.800 & 4.000 & 3.929 & - & 3.400 & 3.667 & 3.000 & 3.588 & N.S. \\
\hline Persomaly imperare to me & 1.891 & 12223 & .036 & 3.750 & 3.733 & 4.000 & 3.607 & 3.725 & 3.762 & 3.800 & 4.000 & 3.500 & . & 3.600 & 3.44 & 3.000 & 3.436 & N.S. \\
\hline Saciifixd w/proment SAI & 0.699 & 12.223 & N.S. & & & & & & & & & & & & & & & \\
\hline Unoomsarable utijece & 0.955 & 12.238 & N.S. & & & & & & & & & & & & & & & \\
\hline SH influenea well being & 2922 & 12227 & .001 & 3.875 & 3.607 & 4.000 & 3.500 & 3.588 & 3.000 & 3.650 & 4.000 & 3.286 & - & 3.000 & 3.750 & 2750 & 3.436 & 1.9. 13. \\
\hline 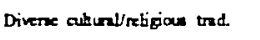 & 1.116 & 12.223 & N.S. & & & & & & & & & & & & & & & \\
\hline 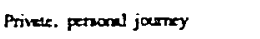 & 1.911 & 12,228 & .054 & 3.938 & 3.207 & 2687 & 3.167 & 3.224 & 3.107 & 2950 & 3.000 & 3.500 & - & 3.400 & 2.807 & 4.000 & 3.19 & N.S. \\
\hline Conape dit betw. $5 H$ \& rision & 1.274 & 12.277 & N.S. & & & & & & & & & & & & & & & \\
\hline
\end{tabular}

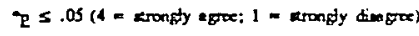


The reported variance in attitude may have an experiential explanation. Health educators whose professional emphasis was health of the individual may have had professional experiences that strengthened their attitude about spiritual health's influence on an individual's total well-being. Health educators whose professional field emphasis was program oriented (i.e., health program development, implementation, and evaluation) may not have the same set of professional experiences on which to base their spiritual health attitudes.

\section{Spiritual Health Training}

Respondents were asked to identify any spiritual health training experiences that they may have had in four categories: (a) attended a spiritual health seminar/ workshop, (b) personal studies, (c) college course in spiritual health, and (d) a college course that contained spiritual health content.

Spiritual health training is a variable that provides significant variance in the responses of the respondents (see Tables 16-19). All respondents expressed the attitude that spiritual health was important to an individual's total well-being, and those with spiritual health training expressed the same attitude but with greater strength and certainty in three of the four training categories. A similar pattern also emerged when the respondents stated their attitude that spiritual health was personally 
Table 16

Respondents Who Have Attended a Spiritual Health Seminar/ Workshop and Spiritual Health Attitudes

\begin{tabular}{|c|c|c|c|c|c|}
\hline \multirow{2}{*}{ Attitude } & \multirow{2}{*}{ F-value } & \multirow{2}{*}{$\mathrm{DF}$} & \multirow{2}{*}{ Prob. * } & \multicolumn{2}{|c|}{ Attended } \\
\hline & & & & $\frac{\text { Yes }}{x}$ & $\frac{\text { No }}{x}$ \\
\hline Important to total well-being & 8.572 & 1,253 & .004 & 3.804 & 3.607 \\
\hline Personally important to me & 4.314 & 1,253 & .039 & 3.750 & 3.601 \\
\hline Satisfied w/personal SH & 2.202 & 1,253 & N.S. & $\mathrm{x}$ & $\mathrm{x}$ \\
\hline Uncomfortable subject & 2.494 & 1,253 & N.S. & $\mathrm{x}$ & $\mathrm{x}$ \\
\hline SH influences well-being & 5.331 & 1,252 & .022 & 3.717 & 3.556 \\
\hline Diverse cultural/religious trad. & 5.237 & 1,252 & .023 & 3.663 & 3.500 \\
\hline Private, personal journey & 0.222 & 1,253 & N.S. & $\mathrm{x}$ & $\mathrm{x}$ \\
\hline Concept diff. betw. SH \& religion & 12.056 & 1,252 & .001 & 3.207 & 2.830 \\
\hline
\end{tabular}

$\star_{\underline{P}} \leq .05$ ( $4=$ strongly agree; $I=$ strongly disagree $) \underline{\mathrm{N}}=92$ 
Table 17

Respondents Who Have Done Personal studies in Spiritual Health and Spiritual Health Attitudes

\begin{tabular}{|c|c|c|c|c|c|}
\hline \multirow{2}{*}{ Attitude } & \multirow{2}{*}{ F-Value } & \multirow{2}{*}{$\mathrm{DF}$} & \multirow{2}{*}{ Prob.* } & \multicolumn{2}{|c|}{ Attended } \\
\hline & & & & Yes & $\frac{\text { No }}{x}$ \\
\hline Important to total well-being & 3.298 & 1,253 & N.S. & $\mathrm{x}$ & $\mathrm{x}$ \\
\hline Personally important to me & 5.713 & 1,253 & .018 & 3.740 & 3.576 \\
\hline Satisfied $\mathrm{w} /$ personal $\mathrm{SH}$ & 4.122 & 1,253 & .043 & 3.244 & 3.083 \\
\hline Uncomfortable subject & 6.507 & 1,253 & .011 & 1.703 & 1.947 \\
\hline SH influences well-being & 3.013 & 1,252 & N.S. & $\mathrm{x}$ & $\mathrm{x}$ \\
\hline Diverse cultural/religious trad. & 20.767 & 1,252 & .000 & 3.715 & 3.412 \\
\hline Private, personal journey & 0.112 & 1,253 & N.S. & $\mathrm{x}$ & $\mathrm{x}$ \\
\hline Concept diff. betw. SH \& religion & 8.213 & 1,252 & .005 & 3.123 & 2.822 \\
\hline
\end{tabular}

${ }^{*} \mathrm{p} \leq .05(4=$ strongly agree; $1=$ strongly disagree $) \underline{\mathrm{N}}=123$ 
Table 18

Respondents who Took a Specific College course in spiritual Health and Spiritual Health Attitudes

\begin{tabular}{|c|c|c|c|c|c|}
\hline \multirow{2}{*}{ Attitude } & \multirow{2}{*}{ F-Value } & \multirow{2}{*}{ DF } & \multirow{2}{*}{ Prob. * } & \multicolumn{2}{|c|}{ Attended } \\
\hline & & & & Yes & $\frac{\text { No }}{x}$ \\
\hline Important to total well-being & 4.233 & 1,253 & .041 & 3.938 & 3.661 \\
\hline Personally important to me & 4.522 & 1,253 & .034 & 3.938 & 3.636 \\
\hline Satisfied w/personal SH & 1.950 & 1,253 & N.S. & $x$ & $x$ \\
\hline Uncomfortable subject & 4.476 & 1,253 & .035 & 1.438 & 1.856 \\
\hline sH influences well-being & 2.302 & 1,252 & N.S. & $\mathrm{X}$ & $\mathrm{X}$ \\
\hline Diverse cultural/religious trad. & 0.930 & 1,252 & N.S. & $\mathrm{X}$ & $x$ \\
\hline Private, personal journey & 0.222 & 1,253 & N.S. & $\mathrm{X}$ & $\mathrm{X}$ \\
\hline concept diff. betw. SH \& religion & 5.646 & 1,252 & .018 & 3.467 & 2.935 \\
\hline
\end{tabular}

$\star^{p} \leq .05(4=$ strongly agree; $1=$ strongly disagree $) \underline{N}=16$ 
Table 19

Respondents Who Took a college course that

Included Spiritual Health content and

spiritual Health Attitudes

\begin{tabular}{|c|c|c|c|c|c|}
\hline \multirow{2}{*}{ Attitude } & \multirow{2}{*}{ F-Value } & \multirow{2}{*}{ DF } & \multirow{2}{*}{ Prob.* } & \multicolumn{2}{|c|}{ Attended } \\
\hline & & & & ${ }_{\frac{Y}{X}}$ & $\frac{\text { No }}{x}$ \\
\hline Important to total well-being & 12.576 & 1,253 & .000 & 3.820 & 3.587 \\
\hline Personally important to me & 3.943 & 1,253 & .048 & 3.740 & 3.600 \\
\hline Satisfied w/personal SH & 2.576 & 1,253 & N.S. & $\mathrm{x}$ & $\mathrm{x}$ \\
\hline Uncomfortable subject & 14.021 & 1,253 & .000 & 1.610 & 1.971 \\
\hline SH influences well-being & 5.985 & 1,252 & .015 & 3.717 & 3.548 \\
\hline Diverse cultural/religious trad. & 4.144 & 1,252 & .043 & 3.646 & 3.503 \\
\hline Private, personal journey & 0.163 & 1,253 & N.S. & $\mathrm{x}$ & $\mathrm{x}$ \\
\hline Concept diff. betw. SH \& religion & 0.334 & 1,252 & N.S. & $\mathrm{x}$ & $\mathrm{x}$ \\
\hline
\end{tabular}

${ }^{*} \mathrm{p} \leq .05(4=$ strongly agree; $1=$ strongly disagree $) \underline{\mathrm{N}}=100$ 
important to them. In this case, respondents in all four training categories reported a stronger positive spiritual health attitude than those respondents who did not have the training experience. Spiritual health training appears to provide greater clarity and certainty about the attitudes of one's spiritual health.

Interestingly, only respondents who stated that they had done personal studies in spiritual health recorded any variance in their personal level of satisfaction with spiritual health. An intriguing possibility arises. While formalized spiritual health training may assist an individual in understanding and clarifying one's spiritual health attitudes, it does not appear to significantly influence how an individual assesses his or her personal spiritual health. Studies of a personal nature appear to influence an individual's personal satisfaction with his/her spiritual health. Satisfaction with personal spiritual health may be a private, personal assessment that extends beyond cognitive knowledge.

Respondents reported greater comfort levels with spiritual health in three of the four spiritual health training categories. Increased cognitive knowledge appears to increase the respondents' comfort with the subject area. Respondents support the attitude that spiritual health influences well-being. Spiritual health training, in two of the four categories, significantly strengthens respondents' 
attitudes. Regardless of spiritual health training experiences, respondents viewed spiritual health as a private, personal journey.

Those respondents with spiritual health training reported spiritual health could accommodate diverse cultural and religious traditions and that it was conceptually different from religion.

The results associated with the spiritual health training demographic variables suggest that respondents gain better cognitive understanding of spiritual health and increases their personal comfort level with the subject area through spiritual health training experiences.

Age

Age did not prove to be a significant variable in seven spiritual health attitude statements. A significant variance was reported with the personal satisfaction attitude. The results indicate that as the age of respondents increased, so did their satisfaction with their personal spiritual health. Bonferroni post-hoc analysis reveals that significant differences exist in satisfaction with personal spiritual health between respondents under 45 years of age and those who are over 55 years of age (see Table 20). 
Table 20

Respondents' Age and Spiritual

Health Attitudes

\begin{tabular}{|c|c|c|c|c|c|c|c|c|c|}
\hline Attitudes & F-Value & DF & Prob.* & $\begin{array}{l}\text { Age } \\
<\frac{25}{X}\end{array}$ & $\begin{array}{l}\text { Age } \\
\frac{26-35}{X}\end{array}$ & $\begin{array}{l}\text { Age } \\
\frac{36-45}{\bar{X}}\end{array}$ & $\begin{array}{l}\text { Age } \\
\frac{46-55}{X}\end{array}$ & $\begin{array}{l}\text { Age } \\
55+ \\
\frac{X}{X}\end{array}$ & $\begin{array}{l}\text { Post Hoc } \\
\text { BonFerroni }\end{array}$ \\
\hline Important to totsl well-being & 0.653 & 4,249 & N.S. & $\mathrm{x}$ & $\mathrm{x}$ & $\mathrm{x}$ & $\mathrm{x}$ & $x$ & $x$ \\
\hline Personally imponant to me & 0.643 & 4,249 & N.S. & $\mathrm{x}$ & $\mathrm{x}$ & $\mathrm{x}$ & $\mathrm{x}$ & $\mathrm{x}$ & $\mathrm{x}$ \\
\hline Satisfied w/personal SH & 4.164 & 4,249 & .003 & 2.750 & 3.000 & 3.100 & 3.240 & 3.45 & $1,2,3-5$ \\
\hline Uncomfortable subject & 0.322 & 4,249 & N.S. & $\mathbf{x}$ & $x$ & $\mathrm{x}$ & $\mathrm{x}$ & $\mathrm{x}$ & $\mathrm{x}$ \\
\hline SH influences well-being & 0.836 & 4,249 & N.S. & $x$ & $\mathrm{x}$ & $x$ & $\mathrm{x}$ & $\mathrm{x}$ & $\mathbf{x}$ \\
\hline Diverse culture/religious traditions & 1.811 & 4,248 & N.S. & $\mathrm{x}$ & $\mathrm{x}$ & $x$ & $x$ & $\mathrm{x}$ & $x$ \\
\hline Private, personal joumey & 1.163 & 4,249 & N.S. & $x$ & $x$ & $\mathrm{x}$ & $\mathrm{x}$ & $\mathbf{x}$ & $\mathrm{x}$ \\
\hline Concept diff. betw. SH \& religion & 1.859 & 4,248 & N.S. & $\mathrm{x}$ & $x$ & $\mathrm{x}$ & $\mathrm{x}$ & $x$ & $\mathrm{x}$ \\
\hline
\end{tabular}

" $\mathrm{p} \leq .05$ (4 = strongly agree; 1 = strongly disagree) 
This result could indicate that, with age, spiritual concerns are resolved and/or that more time is given to reflect upon one's spirituality, thereby giving greater personal satisfaction. This latter interpretation would find support in Jung's (1958) view of personal growth (i.e., that the mid-years, 40-60, are a time of spiritual growth and resolution).

Respondents' Institution Religious Affiliation

Few respondents $(\underline{n}=25)$ worked at institutions that had a religious affiliation. The data show that those respondents who worked at an institution with a religious affiliation voiced significantly stronger agreement than those who did not work for such an organization on two spiritual health attitude statements: (a) importance of spiritual health and (b) personal satisfaction with their spiritual health (see Table 21). No significant differences occurred in the other six spiritual health attitude statements.

This finding could suggest that respondents who worked in environments that supported their spirituality had greater satisfaction with their spiritual health. The findings also suggest that those individuals who believed spiritual health to be very important may have selected institutions that had a religious affiliation. 
Table 21

Respondents' Institution Religious Affiliation and Spiritual Health Attitudes

\begin{tabular}{|l|l|l|l|l|c|}
\hline \multicolumn{1}{|c|}{ Attitude } & F-Value & \multicolumn{1}{|c|}{ DF } & Prob.* & Yes & No \\
\hline Important to total well-being & 5.869 & 1,243 & .016 & 3.920 & 3.659 \\
\hline Personally important to me & 3.046 & 1,243 & N.S. & $X$ & $X$ \\
\hline Satisfied w/personal SH & 6.563 & 1,243 & .011 & 3.480 & 3.136 \\
\hline Uncomfortable subject & 0.608 & 1,243 & N.S. & $X$ & $X$ \\
\hline SH influences well-being & 0.400 & 1,242 & N.S. & $X$ & $X$ \\
\hline Diverse cultural/religious trad. & 0.669 & 1,242 & N.S. & $X$ & $X$ \\
\hline Private, personal journey & 0.776 & 1,243 & N.S. & $X$ & $X$ \\
\hline Concept diff. betw. SH \& religion & 0.614 & 1,242 & N.S. & $X$ & $X$ \\
\hline
\end{tabular}

${ }^{*} \underline{\mathrm{p}} \leq .05$ ( $4=$ strongly agree; $1=$ strongly disagree $) \underline{\mathrm{N}}=25$ 
Signing a Faith statement

Very few respondents $(\underline{n}=6)$ worked at institutions that required them to sign a faith statement. The statistical analysis reports only one statistically significant finding regarding the attitude concerning a clear conceptual difference between spiritual health and religion. Respondents who signed a faith statement expressed an attitude that no clear conceptual difference existed between religion and spiritual health. No significant differences occurred in the other seven spiritual health attitude statements (see Table 22).

\section{other Variables}

No variance in spiritual health attitudes was found with the independent variables of institution type, gender, ethnicity, geographical region, and respondent's highest academic degree focus (see Appendix B).

\section{Summary}

In summary, specific demographic variables accounted for significant variance in certain spiritual health attitude statements. The demographic variables that offer the most explanation of respondents' spiritual health attitudes are: (a) highest academic degree, (b) teaching a general health course, (c) personal religious affiliation, and (d) spiritual health training experiences. 
Table 22

Respondents Signing an Institutional Faith statement and Spiritual Health Attitudes

\begin{tabular}{|c|c|c|c|c|c|}
\hline \multirow{2}{*}{ Attitude } & \multirow{2}{*}{ F-Value } & \multirow{2}{*}{ DF } & \multirow{2}{*}{ Prob.* } & \multicolumn{2}{|c|}{ Faith statement } \\
\hline & & & & $\frac{\text { Yes }}{X}$ & $\frac{\text { No }}{x}$ \\
\hline Important to total well-being & 2.343 & 1,245 & N.S. & $\mathrm{x}$ & $\mathrm{x}$ \\
\hline Personally important to me & 2.378 & 1,245 & N.S. & $\mathrm{x}$ & $\mathrm{x}$ \\
\hline Satisfied $\mathrm{w} /$ personal $\mathrm{SH}$ & 3.643 & 1,245 & N.S. & $x$ & $\mathrm{x}$ \\
\hline Uncomfortable subject & 1.081 & 1,243 & N.S. & $\mathrm{x}$ & $\mathrm{x}$ \\
\hline SH influences well-being & 1.074 & 1,244 & N.S. & $\mathrm{x}$ & $\mathrm{x}$ \\
\hline Diverse cultural/religious trad. & 0.056 & 1,244 & N.S. & $\mathrm{x}$ & $\mathrm{x}$ \\
\hline Private, personal journey & 1.703 & 1,245 & N.S. & $\mathrm{x}$ & $\mathrm{x}$ \\
\hline Concept diff. betw. SH \& religion & 8.543 & 1,244 & .004 & 2.0 & 3.01 \\
\hline
\end{tabular}

${ }^{*} \mathrm{p} \leq .05(4=$ strongly agree; $1=$ strongly disagree $) \underline{\mathrm{N}}=6$ 


\section{Including Spiritual Health Attitudes and Demographics}

The discussion now turns to the sixth research question, "Are there significant differences between each demographic variable and the respondents' attitudes toward including spiritual health in a college general health course?" ANOVAs were completed on each attitude and each independent demographic variable in order to answer this question. Where an independent variable contained more than two categories and significant ANOVA results were obtained, a Bonferroni post-hoc test was done to determine the strength and location of the variance. If Bonferroni's post-hoc showed no significant difference at a $\mathrm{p}<.05$ level, the results were interpreted as not significant. The data show no significant differences in attitudes exist for including spiritual health variables with the demographic variables of gender, ethnicity, and age (see Appendix B). Significant differences exist between remaining demographic variables and with specific attitudes with regards to including spiritual health in college general health course statements. The attitude variances are discussed according to each demographic variable in the following sections.

\section{Highest Academic Degree}

The demographic variable, "highest academic degree," was associated with significant differences in four specific 
attitudes toward including spiritual health in a college health course statements. No significant differences were reported in seven attitude statements.

Findings indicate that those respondents with a doctorate degree reported: (a) less concern about separation of church and state when including spiritual health materials, (b) less concern about teaching peer support, and (c) they felt more trained to teach spiritual health than those respondents with lesser degrees (see Table 23).

The data do not provide enough evidence to draw firm conclusions. However, a possible explanation for the reported differences in attitude with regard to concern for separation of church and state is found in the previous chapter section on spiritual health attitudes. In this previous section, it was reported that respondents with doctorates were more likely to see a clear conceptual difference between spiritual health and religion. The doctoral respondents who viewed spiritual health as conceptually distinct from religion, may have minimized the concern for separation of church and state when including spiritual health material. 
Table 23

Respondents' Highest Academic Degree and Attitudes Toward Including Spiritual Health in college General Health course

\begin{tabular}{|c|c|c|c|c|c|c|c|}
\hline Attitudes & F-Value & $\mathrm{DF}$ & Prob.* & Bachelor & $\frac{\text { Master }}{X}$ & Doctorate & $\begin{array}{l}\text { Post-Hoc } \\
\text { BonFerroni }\end{array}$ \\
\hline Vague definition & 2.106 & 2,251 & N.S. & & & & \\
\hline Important human dimen. & 0.807 & 2,250 & N.S. & & & & \\
\hline Separation church/state & 7.733 & 2,250 & .001 & 2.952 & 2.660 & 2.288 & $1,2-3$ \\
\hline Evaluate/grade students & 1.976 & 2,251 & N.S. & & & & \\
\hline Inadequate prof. train. & 6.976 & 2,249 & .001 & 2.476 & 2.370 & 2.023 & $1,2-3$ \\
\hline Respect indiv. beliefs & 1.820 & 2,251 & N.S. & & & & \\
\hline More resource material & 0.872 & 2,249 & N.S. & & & & \\
\hline Lack of support/peers & 5.023 & 2,241 & .007 & 2.700 & 2.372 & 2.173 & $1-3$ \\
\hline Lack of support/admin. & 3.680 & 2,241 & .027 & 2.600 & 2.419 & 2.179 & N.S. \\
\hline Appropriate content & 1.625 & 2,249 & N.S. & & & & \\
\hline Feel adequately train. & 5.818 & 2,247 & .003 & 2.381 & 2.475 & 2.777 & $2-3$ \\
\hline
\end{tabular}

$*_{\mathrm{p}} \leq .05$ (4= strongly agree; $1=$ strongly disagree $)$ 
Another significant difference that the data reveal is with the variable addressing respondents' self-perceptions about having adequate spiritual health training. Doctoral respondents perceived themselves to be more adequately trained to teach spiritual health than did other respondents. Several explanations may exist for this variance. The length of an individual's academic training may be one explanation. Doctoral respondents had long academic preparation experiences. The greater length of academic training may have provided opportunities for exposure to spiritual health materials that increased respondents' comfort with their spiritual health training. Additionally, doctoral training may have emphasized conceptual thinking. Respondents with doctorates may have felt more adequately prepared than those without doctorate level experience to teach concepts, regardless of the specific concept topic.

Finally, respondents with doctorates did not perceive a lack of support from their teaching peers for including more spiritual health materials. This significant difference may be explained by the location of the participant. Respondents with doctorates taught in four-year colleges or universities more often than did those respondents with bachelor's degrees. Colleges and universities have a rich tradition of academic freedom that could minimize a respondent's concern for faculty support when introducing 
classroom material. Doctoral respondents may work more independently than their master's and bachelor's level counterparts; therefore, peer support is not as highly valued.

A high academic degree appears to be a moderately significant variable when explaining differences in respondents' attitudes toward including spiritual health in college general health courses.

\section{Taught a General Health}

Course

Those who taught a general health course within the past two academic years reported significant differences in three attitudes toward including spiritual health statements. No significant differences occurred in the other eight attitudes toward including spiritual health statements (see Table 24).

Respondents who taught a general health course reported significantly stronger agreement than did other respondents with the attitude that spiritual health was an important dimension in a college health course. Respondents who taught general health courses also felt more certain of their spiritual health training. 
Table 24

Respondents who Teach a General Health Course and Attitudes Toward Including Spiritual Health in college General Health courses

\begin{tabular}{|c|c|c|c|c|c|}
\hline \multirow{2}{*}{ Attitudes } & \multirow{2}{*}{ F-Value } & \multirow{2}{*}{ DF } & \multirow{2}{*}{ Prob. * } & \multicolumn{2}{|c|}{ Teach a Course } \\
\hline & & & & $\frac{\text { Yes }}{X}$ & $\frac{\text { No }}{X}$ \\
\hline Vague definition & 0.113 & 1,250 & N.S. & & 3.104 \\
\hline Important human dimension & 5.671 & 1,249 & 0.018 & 3.324 & \\
\hline Separation church/state & 1.083 & 1,249 & N.S. & & \\
\hline Evaluate and grade students & 1.675 & 1,250 & N.S. & & \\
\hline Inadequate professional training & 6.356 & 1,248 & 0.012 & 2.078 & 2.331 \\
\hline Respect individual belief system & 2.181 & 1,250 & N.S. & & \\
\hline More resource material & 0.501 & 1,248 & N.S. & & \\
\hline Lack of support/peers & 0.984 & 1,241 & N.S. & & \\
\hline Lack of support/admin. & 0.919 & 1,241 & N.S. & & \\
\hline Appropriate content area & 2.402 & 1,248 & N.S. & & \\
\hline Feel adequately trained & 6.631 & 1,246 & 0.011 & 2.740 & 2.492 \\
\hline
\end{tabular}

${ }^{*} \mathrm{p} \leq .05$ ( $4=$ strongly agree; $1=$ strongly disagree) 
A second-level ANOVA analysis was done to acquire additional insight into attitudes about including spiritual health. The analysis was on respondents who included spiritual health in their college health course and those who did not. A significant variance occurred in 10 of the 11 attitudes toward including spiritual health variables (see Table 25).

Table 25

Respondents Who Include Spiritual Health in College Health Courses and Their Attitudes Toward Including Spiritual Health

\begin{tabular}{|c|c|c|c|c|c|}
\hline Attitudes & F-Ratio DF & Prob. & Mean & $\begin{array}{l}\text { Mean } \\
\text { Yes }\end{array}$ & No \\
\hline Vague Definition & 18.032 & 1,123 & .000 & 2.829 & 2.163 \\
\hline Important Human Dimension & 10.399 & 1,123 & .002 & 3.500 & 3.081 \\
\hline Separation church/state & 20.996 & 1,123 & .000 & 2.841 & 2.093 \\
\hline Evaluate \& grade students & 9.077 & 1,123 & .003 & 3.305 & 2.884 \\
\hline Inadequate prof. training & 43.646 & 1,121 & .000 & 3.247 & 2.357 \\
\hline Respect individ. belief sys. & 14.538 & 1,123 & .000 & 3.159 & 2.605 \\
\hline More resource material & 3.202 & 1,121 & N.S. & & \\
\hline Lack of support from teaching peers & 18.900 & 1,121 & .000 & 2.951 & 2.310 \\
\hline Lack of support from administration & 14.934 & 1,120 & .000 & 2.938 & 2.341 \\
\hline Appropriate content area & 7.508 & 1,122 & .007 & 3.439 & 3.071 \\
\hline Feel adequately trained & 19.157 & 1,121 & .000 & 2.970 & 2.390 \\
\hline
\end{tabular}

$\mathrm{p}<.05(1=$ strongly disagree; $4=$ strongly agree $)$

Those instructors who included spiritual health in their general health courses had the strongest positive attitudes about the importance of spiritual health, its appropriateness in the course, and their spiritual health training. The findings suggest that these attitudes may 
influence an individual decision to include spiritual health.

Those respondents who included spiritual health acknowledged and agreed with the concerns about including spiritual health material that were addressed in other demographic variables. These concerns primarily focused on spiritual health's vague definition, a concern for separation of church and state, and issues of student evaluation. Practitioners who included spiritual health appear, from experience, to be confirming that including spiritual health raises difficult student evaluation issues. In addition, those who included spiritual health reported a lack of support from their teaching peers and administration, yet they included spiritual health. A conclusion that may be drawn is that a strong attitude about spiritual health's importance coupled with training in spiritual health overrides specific concerns about including spiritual health.

Primary Teaching Responsibility

The primary teaching responsibility variable shows significant differences in 4 of the 11 attitudes in respondent statements for including spiritual health. Bonferroni post-hoc analysis reports that a significant difference exists between respondents whose primary teaching responsibility was health program evaluation and those 
respondents who primarily taught in other areas. No significant difference was reported in the other seven attitudes toward statements for including spiritual health (see Table 26).

The significance of this finding is weakened by the small numbers of responses in each category of this specific demographic variable (see Table 2). Nonetheless, the data show respondents who primarily taught health program evaluation did not view spiritual health as important or appropriate for a college general health course. These respondents also expressed significantly greater concern over how to evaluate the students' on spiritual health in a college general health course.

A possible explanation for the significant differences may be that those who taught health program evaluation defined the concept of evaluation exclusively through a positivistic, natural science perspective and, therefore, questioned the appropriateness of including and evaluating spiritual health. With this perspective, the evaluation of spiritual health could be viewed as a dubious, problematical process. 
Table 26

Respondents' Primary Teaching Responsibility and Attitudes Toward Including Spiritual Health in College General Health Course

\begin{tabular}{|c|c|c|c|c|c|c|c|c|c|c|c|c|c|c|c|c|c|c|}
\hline Atcitudat & F.Value & $\mathrm{DF}$ & Prob & $\begin{array}{c}\text { HMLh } \\
\text { Mean } \\
\text { (1) }\end{array}$ & $\begin{array}{l}\text { Sex } \\
\text { Mean } \\
\text { (2) }\end{array}$ & $\begin{array}{l}\text { Mens } \\
\text { Mean } \\
\text { (3) }\end{array}$ & $\begin{array}{l}\text { FAid } \\
\text { Meen } \\
\text { (4) }\end{array}$ & $\begin{array}{c}\text { Genll } \\
\text { Man } \\
\text { (s) }\end{array}$ & $\begin{array}{l}\text { Well } \\
\text { Mean } \\
\text { (6) }\end{array}$ & $\begin{array}{c}\text { Fitn } \\
\text { Mean } \\
(7)\end{array}$ & $\begin{array}{l}\text { Nurr } \\
\text { Mean } \\
\text { (8) }\end{array}$ & $\begin{array}{c}\mathrm{CanHH} \\
\text { Mean } \\
\text { (9) }\end{array}$ & $\begin{array}{l}\text { Exwil } \\
\text { Meser }\end{array}$ & $\begin{array}{l}\text { DPre } \\
\text { Man } \\
\text { (10) }\end{array}$ & $\begin{array}{l}\text { HPP } \\
\text { Men } \\
\text { (11) }\end{array}$ & $\begin{array}{l}\text { IPPE } \\
\text { Mana } \\
\text { (12) }\end{array}$ & $\begin{array}{l}\text { Othes } \\
\text { Mean } \\
\text { (13) }\end{array}$ & $\begin{array}{l}\text { Poat Hoc } \\
\text { Bonfertromi }\end{array}$ \\
\hline Vaque definition & 1.125 & 12,227 & N.S. & & & & & & & & & & & & & & & \\
\hline Imporaxy thamen dimen. & 2.749 & 12.226 & .002 & 3.219 & 3.267 & 4.000 & 3.417 & 3.320 & 3.452 & 3.100 & 3.000 & 3.071 & & 3.100 & 3.625 & 2.000 & 2.949 & 1, 3, 5, \\
\hline Seperation cturetistate & 1.553 & 12,226 & N.S. & & & & & & & & & & & & & & & \\
\hline Eveluate/gnde atudents & 2.996 & 12,227 &.$\infty 1$ & 1.656 & 1.933 & 1.667 & 2.167 & 1.920 & 1.833 & 2.000 & 2.000 & 1.857 & & 2.400 & 1.556 & 3.500 & 2.205 & $1,2,5,6$ \\
\hline tradequate prof. trisis. & 1.339 & 12,225 & N.S. & & & & & & & & & & & & & & & \\
\hline Respect indiv, beliefs & 0.494 & 12,227 & N.S. & & & & & & & & & & & & & & & \\
\hline More reacures materisl & 1.881 & 12,225 & .038 & 2.875 & 2.667 & 3.333 & 2.600 & 2.700 & 3.000 & 2.579 & 3.000 & 2.857 & & 2.600 & 3.111 & 1.750 & 2.692 & $0-12$ \\
\hline Leck of suppon'poers & 0.718 & 12,218 & N.S. & & & & & & & & & & & & & & & \\
\hline Lack of uspordedrition. & 0.584 & 12,218 & N.s. & & & & & & & & & & & & & & & \\
\hline Appropriate cordent & 1.885 & 12,225 & .037 & 3.344 & 3.200 & 4.000 & 3.333 & 3.265 & 3.262 & 3.250 & 3.000 & 3.143 & & 2.200 & 3.444 & 2.000 & 3.026 & $1,3-12$ \\
\hline Focl adequately trin. & 1.600 & 12,223 & N.S. & & & & & & & & & & & & & & & \\
\hline
\end{tabular}


As previously reported in the spiritual health attitude section, health program evaluation respondents rated their attitudes significantly lower than did other respondents that spiritual health influenced well-being. These findings suggest a possible connection exists between attitudes regarding spiritual health's influence and importance and spiritual health being included in a college general health course.

Focus of Highest Academic Degree

Respondents in the demographic variable "highest academic degree focus" yield significant results in one attitude toward the statement of including spiritual health. Bonferroni post-hoc analysis reports that a significant variance occurs between physical education and health education. No significant variance was reported in the 10 other attitude statements on including spiritual health (see Table 27).

Respondents whose highest degree was in physical education felt the most uncomfortable with including spiritual health material because they felt an inadequate professional training.

A possible explanation for this variance may be found when examining traditional college programs with majors in 
physical education and health education. It may be that, in the traditional college physical education program, a minimal amount of health education materials is included on human dimensions other than the physical.

\section{Spiritual Health Training}

In the four spiritual health training categories surveyed for this study, all four show similar attitude response patterns. Spiritual health training provides significant differences in 8 of the 11 statements on spiritual health attitude. The data show that respondents who had spiritual health training had significantly stronger positive attitudes regarding the importance and appropriateness of including spiritual health in college health courses than did other respondents. Those respondents with spiritual health training experience perceived themselves to be better trained in spiritual health. They were significantly less inclined to view spiritual health's vague definition or society's concern for church and state as obstacles when including spiritual health material. 
Table 27

Respondents' Highest Academic Degree Focus and Attitudes Toward Including Spiritual Health in College General Health Course

\begin{tabular}{|l|l|l|l|l|l|l|l|l|l|l|}
\hline \multicolumn{1}{|c|}{ Attitudes } & F-Value & DF & Prob.* & $\frac{\text { Hed }}{X}$ & $\frac{\text { PuH }}{X}$ & $\frac{\text { ExPh }}{X}$ & $\frac{\text { PEd }}{X}$ & $\frac{\text { Educ }}{X}$ & $\begin{array}{c}\text { Other } \\
\text { Post Hoc } \\
\text { Bonferroni }\end{array}$ \\
\hline Vague definition & 0.438 & 5,248 & N.S. & & & & & & & \\
\hline Important humen dimen. & 0.941 & 5,247 & N.S. & & & & & & & \\
\hline Separation church/stale & 1.696 & 5,247 & N.S. & & & & & & & \\
\hline Evaluate/grade students & 0.717 & 5,248 & N.S. & & & & & & & \\
\hline Inadequate prof. train. & 2.338 & 5,246 & .042 & 2.079 & 2.400 & 2.231 & 2.490 & 2.154 & 2.400 & $1-4$ \\
\hline Respect indiv. beliefs & 0.837 & 5,248 & N.S. & & & & & & & \\
\hline More resource material & 0.912 & 5,246 & N.S. & & & & & & & \\
\hline Lack of suppor/peers & 1.376 & 5,238 & N.S. & & & & & & & \\
\hline Lack of suppor/admin. & 0.850 & 5,238 & N.S. & & & & & & & \\
\hline Appropriate content & 0.646 & 5,246 & N.S. & & & & & & & \\
\hline Feel adequately train. & 0.973 & 5,244 & N.S. & & & & & & & \\
\hline
\end{tabular}

. $\mathrm{p} \leq .05$ (4 = strongly agrec; 1 = strongly disagree) 
Spiritual health training provides a consistent, significant, attitude variance between respondents who had or had not had a spiritual health training experience (see Tables 28-31). Spiritual health training appears to be an important demographic variable in explaining respondents differences in attitudes toward including spiritual health materials in a college general health course. These results seem to confirm the important influence spiritual health training has on respondents' attitudes toward including spiritual health in the classroom.

\section{Respondents' Institution}

Type

While the demographic variable, "respondents" institution type," shows no significant variance in the previous chapter section covering spiritual health attitudes, it does present significant findings in this research question. Significant results were attained in two statements on including spiritual health attitude. No significant differences were reported in the other nine attitudes toward including spiritual health statements.

Bonferroni post-hoc testing identifies a significant difference in respondents' attitudes on spiritual health's vague definition between: (a) respondents who teach at public, doctorate universities, (b) public and private liberal arts with master's universities, and (c) respondents who teach at public, liberal arts colleges with no master's 
Table 28

Respondents who Took a college Course in Spiritual Health and Attitudes Toward Including Spiritual Health

in College General Health Courses

\begin{tabular}{|c|c|c|c|c|c|}
\hline \multirow{2}{*}{ Attitudes } & \multirow{2}{*}{ F-Value } & \multirow{2}{*}{ DF } & \multirow{2}{*}{ Prob.* } & \multicolumn{2}{|c|}{ Attended } \\
\hline & & & & $\frac{\text { Yes }}{X}$ & $\frac{\text { No }}{x}$ \\
\hline Vague definition & 8.421 & 1,252 & 0.004 & 1.875 & 2.500 \\
\hline Important human dimension & 5.237 & 1,251 & 0.022 & 3.625 & 3.190 \\
\hline Separation church/state & 11.050 & 1,251 & 0.001 & 1.750 & 2.532 \\
\hline Evaluate and grade students & 7.852 & 1,252 & 0.005 & 1.438 & 1.971 \\
\hline Inadeguate professional training & 7.160 & 1,250 & 0.008 & 1.688 & 2.237 \\
\hline Respect individual belief system & 10.670 & 1,252 & 0.001 & 1.500 & 2.139 \\
\hline More resource material & 0.104 & 1,250 & N.S. & & \\
\hline Lack of support/peers & 2.428 & 1,242 & N.S. & & \\
\hline Lack of support/admin. & 2.301 & 1,242 & N.S. & & \\
\hline Appropriate content area & 11.457 & 1,250 & 0.001 & 3.813 & 3.167 \\
\hline Feel adequately trained & 12.192 & 1,248 & 0.001 & 3.250 & 2.573 \\
\hline
\end{tabular}

${ }^{*} \mathrm{p} \leq .05(4=$ strongly agree; $1=$ strongly disagree $)$ 
Table 29

Respondents who Took a college course that Included Spiritual Health and Attitudes Toward Including Spiritual Health

in College General Health Courses

\begin{tabular}{|c|c|c|c|c|c|}
\hline \multirow{2}{*}{ Attitudes } & \multirow{2}{*}{ F-Value } & \multirow{2}{*}{ DF } & \multirow{2}{*}{ Prob.* } & \multicolumn{2}{|c|}{ Attended } \\
\hline & & & & $\frac{\text { Yes }}{X}$ & $\frac{\text { No }}{\bar{x}}$ \\
\hline Vague definition & 15.291 & 1,252 & 0.000 & 2.210 & 2.623 \\
\hline Important human dimension & 14.908 & 1,251 & 0.000 & 3.434 & 3.078 \\
\hline Separation church/state & 21.545 & 1,251 & 0.000 & 2.160 & 2.693 \\
\hline Evaluate and grade students & 19.369 & 1,252 & 0.000 & 1.690 & 2.097 \\
\hline Inadequate professional training & 22.113 & 1,250 & 0.000 & 1.920 & 2.388 \\
\hline Respect individual belief system & 13.899 & 1,252 & 0.000 & 1.880 & 2.240 \\
\hline More resource material & 1.773 & 1,250 & N.S. & & \\
\hline Lack of support/peers & 3.504 & 1,242 & N.S. & & \\
\hline Lack of support/admin. & 8.960 & 1,242 & 0.003 & 2.106 & 2.430 \\
\hline Appropriate content area & 12.752 & 1,250 & 0.000 & 3.414 & 3.075 \\
\hline Feel adequately trained & 17.462 & 1,248 & 0.000 & 2.859 & 2.457 \\
\hline
\end{tabular}

$* \mathrm{p} \leq .05$ ( 4 = strongly agree; 1 = strongly disagree $)$ 
Table 30

Respondents Who Attended a Seminar/Workshop in Spiritual Health and Attitudes Toward Including Spiritual Health

in College General Health Courses

\begin{tabular}{|c|c|c|c|c|c|}
\hline \multirow{2}{*}{ Attitudes } & \multirow{2}{*}{ F-Value } & \multirow{2}{*}{ DF } & \multirow{2}{*}{ Prob. * } & \multicolumn{2}{|c|}{ Attended } \\
\hline & & & & $\frac{\text { Yes }}{\bar{X}}$ & $\frac{\text { No }}{x}$ \\
\hline Vague definition & 16.258 & 1,252 & 0.000 & 2.185 & 2.617 \\
\hline Important human dimension & 16.176 & 1,251 & 0.000 & 3.457 & 3.081 \\
\hline Separation church/state & 14.515 & 1,251 & 0.000 & 2.196 & 2.646 \\
\hline Evaluate and grade students & 13.080 & 1,252 & 0.000 & 1.717 & 2.062 \\
\hline Inadequate professional training & 41.075 & 1,250 & 0.000 & 1.804 & 2.431 \\
\hline Respect individual belief system & 9.656 & 1,252 & 0.002 & 1.902 & 2.210 \\
\hline More resource material & 0.976 & 1,250 & N.S. & & \\
\hline Lack of support/peers & 0.744 & 1,242 & N.S. & & \\
\hline Lack of support/admin. & 0.966 & 1,242 & N.S. & & \\
\hline Appropriate content area & 9.374 & 1,250 & 0.002 & 3.400 & 3.102 \\
\hline Feel adequately trained & 39.486 & 1,248 & 0.000 & 2.994 & 2.403 \\
\hline
\end{tabular}

$\star \underline{p} \leq .05$ ( 4 = strongly agree; 1 = strongly disagree) 
Table 31

Respondents Who Have Done Personal studies in Spiritual Health and Attitudes Toward Including Spiritual Health in College General Health Courses

\begin{tabular}{|c|c|c|c|c|c|}
\hline \multirow{2}{*}{ Attitudes } & \multirow{2}{*}{ F-Value } & \multirow{2}{*}{$\mathrm{DF}$} & \multirow{2}{*}{ Prob.* } & \multicolumn{2}{|c|}{ studies } \\
\hline & & & & ${ }_{\frac{Y}{X}}$ & $\frac{\text { No }}{X}$ \\
\hline Vague definition & 5.495 & 1,252 & 0.020 & 2.333 & 2.580 \\
\hline Important human dimension & 6.962 & 1,251 & 0.009 & 3.341 & 3.100 \\
\hline Separation church/state & 4.089 & 1,251 & 0.044 & 2.361 & 2.595 \\
\hline Evaluate and grade students & 5.047 & 1,252 & 0.026 & 1.829 & 2.038 \\
\hline Inadeguate professional training & 27.190 & 1,250 & 0.000 & 1.943 & 2.446 \\
\hline Respect individual belief system & 10.016 & 1,252 & 0.002 & 1.943 & 2.244 \\
\hline More resource material & 0.102 & 1,250 & N.S. & & \\
\hline Lack of support/peers & 1.545 & 1,242 & N.S. & & \\
\hline Lack of support/admin. & 0.402 & 1,242 & N.S. & & \\
\hline Appropriate content area & 6.774 & 1,250 & 0.010 & 3.333 & 3.089 \\
\hline Feel adequately trained & 17.804 & 1,248 & 0.000 & 2.889 & 2.355 \\
\hline
\end{tabular}

${ }^{\star} \mathrm{p} \leq .05$ ( 4 = strongly agree; $1=$ strongly disagree $)$ 
program. Those who teach at a public, liberal arts college without master's programs reported significantly less concern about spiritual health's vague definition. A significant difference was observed regarding a perceived inadequacy in professional training in spiritual health. Respondents who teach at public, liberal arts universities with master's programs and those who teach at public, liberal arts colleges with no master's programs reported less agreement than did respondents who taught at community colleges that their professional training in spiritual health was inadequate (see Table 32 ). The finclings: suggest a possible relationship exists between self-perceived, inadequate professional training in spiritual health and a concern for the vague definition of spiritual health when including spiritual health in a college general health course. This finding supports data reported earlier that respondents with perceived adequacy in spiritual health training are less concerned about spiritual health's vague definition when including spiritual health materials. 
Table 32

Respondents' Institution Type and Attitudes Toward Including Spiritual Health in College General Health Course

\begin{tabular}{|c|c|c|c|c|c|c|c|c|c|c|c|c|}
\hline Altitudes & F-Value & DF & Prob.* & $\begin{array}{l}\text { Priv } \\
\text { Doct } \\
\bar{X}\end{array}$ & $\begin{array}{l}\text { Publ } \\
\text { Doct } \\
\bar{X}\end{array}$ & $\begin{array}{l}\text { Publ } \\
\frac{w / m}{X}\end{array}$ & $\begin{array}{l}\text { Priv } \\
w / m \\
\bar{X}\end{array}$ & $\begin{array}{l}\text { Pubi } \\
\text { w/om } \\
\bar{X}\end{array}$ & $\begin{array}{l}\text { Priv } \\
\text { w/om } \\
\bar{X}\end{array}$ & $\begin{array}{l}\text { CC } \\
\bar{x} \\
\end{array}$ & $\begin{array}{l}\text { Other } \\
\bar{X}\end{array}$ & $\begin{array}{l}\text { Post Hoc } \\
\text { BonFerroni }\end{array}$ \\
\hline Vague definition & 2.508 & 7,242 & .017 & 2.375 & 2.433 & 2.492 & 2.846 & 1.375 & 2.500 & 2.593 & 2.455 & $2,3,4-5$ \\
\hline Important human dimen. & 0.647 & 7,241 & N.S. & & & & & & & & & \\
\hline Separation church/state & 2.304 & 7,241 & .027 & 2.625 & 2.495 & 2.415 & 2.000 & 1.875 & 2.100 & 2.885 & 2.727 & N.S. \\
\hline Evaluate/grade students & 1.060 & 7,242 & N.S. & & & & & & & & & \\
\hline Inadequate prof. train. & 3.172 & 7,240 & .003 & 2.250 & 2.208 & 2.062 & 2.385 & 1.500 & 2.100 & 2.731 & 2.091 & $3,5-7$ \\
\hline Respect indiv. beliefs & 1.705 & 7,242 & N.S. & & & & & & & & & \\
\hline More resource material & 0.790 & 7,240 & N.S. & & & & & & & & & \\
\hline Lack of support/peers & 1.535 & 7,232 & N.S. & & & & & & & & & \\
\hline Lack of supportadmin. & 1.724 & 7,232 & N.S. & & & & & & & & & \\
\hline Appropriate content & 0.469 & 7,232 & N.S. & & & & & & & & & \\
\hline Feel adequately train. & 1.790 & 7,238 & N.S. & & & & & & & & & \\
\hline
\end{tabular}

$\bullet \mathrm{e} \leq .05$ ( $4=$ strongly agree; $1=$ strongly disagree $)$ 
The demographic variable, "respondents' institution type," is not a strong variable for explaining differences in respondents' attitudes toward including spiritual health material. It provides an intriguing, possible connection between the attitudes on spiritual health's vague definition and the self-perceived adequacy of professional training in spiritual health.

\section{Religious Affiliations}

The independent variable, "personal religious preference," provides variance in four statements on including spiritual health attitude. These are: (a) concern for separation of church and state, (b) lack of support from teaching peers, (c) lack of support from administration, and (d) feel adequately trained to teach spiritual health.

Respondents with a personal religious preference were more concerned about issues regarding the separation of church and state than respondents with no stated personal religious preference when addressing the inclusion of spiritual health. Also, respondents with a personal religious preference reported greater lack of support from teaching peers and administration for including spiritual health. Finally, respondents with a religious preference felt that they were less adequately trained to teach spiritual health (see Table 33 ). 
Table 33

Respondents Having a Personal Religious preference and Attitudes Toward Including Spiritual Health in college General Health courses

\begin{tabular}{|c|c|c|c|c|c|}
\hline \multirow[t]{2}{*}{ Attitudes } & \multirow[t]{2}{*}{ F-Value } & \multirow[t]{2}{*}{ DF } & \multirow[t]{2}{*}{ Prob.* } & \multicolumn{2}{|c|}{$\begin{array}{c}\text { Personal Religious } \\
\text { Aff. }\end{array}$} \\
\hline & & & & Yes & $\frac{\text { No }}{X}$ \\
\hline Vague definition & 1.569 & 1,247 & N.S. & & \\
\hline Important human dimension & 0.975 & 1,246 & N.S. & & \\
\hline Separation church/state & 8.478 & 1,246 & 0.004 & 2.562 & 2.128 \\
\hline Evaluate and grade students & 0.202 & 1,247 & N.S. & & \\
\hline Inadequate professional training & 1.704 & 1,245 & N.S. & & \\
\hline Respect individual belief system & 1.001 & 1,247 & N.S. & & \\
\hline More resource material & 0.051 & 1,245 & N.S. & & \\
\hline Lack of support/peers & 4.198 & 1,237 & 0.042 & 2.352 & 2.098 \\
\hline Lack of support/admin. & 9.058 & 1,237 & 0.003 & 2.389 & 1.989 \\
\hline Appropriate content area & 0.017 & 1,245 & N.S. & & \\
\hline Feel adequately trained & 4.172 & 1,243 & 0.042 & 2.584 & 2.833 \\
\hline
\end{tabular}

$\star^{2} \leq .05$ ( $4=$ strongly agree; $1=$ strongly disagree $)$ 
These findings, when coupled with the spiritual health attitude data, present an intriguing portrait. Respondents with personal religious preference appear certain of spiritual health's importance to themselves and to the total well-being of an individual, yet they are significantly more uncomfortable with spiritual health and are uncertain that a clear conceptual difference exists between spiritual health and religion (see Table 12 ).

The data on this research question suggest some potential reasons for this discomfort. If a clear conceptual difference between spiritual health and religion does not exist, than the confusion that this creates may account for a greater concern about church and state issues when one includes spiritual health. The confusion may have also influenced the respondents' attitudes regarding support from teaching peers and administration when including spiritual health.

\section{Institutional Religious}

Affiliation

The demographic variable, "institutional religious affiliation" provides significant results in one statement on including spiritual health attitude: concern for separation of church and state. No significant findings were reported in the other 10 attitudes toward statements of including spiritual health. 
Respondents who taught at an institution with a religious affiliation reported significantly less concern about the separation of church and state than those who taught at institutions without a religious affiliation when including spiritual health materials (see Table 34 ).

This finding appears to indicate that teaching in an environment that supports religious affiliation diminishes concern for separation of church and state. Institutional religious affiliation is not a strong variable in explaining differences among the respondents' attitudes toward including spiritual health in college general health courses.

\section{Signed a Faith statement}

signing a faith statement was a significant demographic variable in 4 of the 11 statements on attitudes about including spiritual health (see Table 35). Those members who signed a faith statement were less concerned about spiritual health's vague definition. They did not need more spiritual health resource material and felt very adequately trained to teach spiritual health. 
Table 34

Respondents from an Institution with a Religious Affiliation and Attitudes Toward Including Spiritual Health

in college General Health courses

\begin{tabular}{|l|l|l|l|l|l|}
\hline \multicolumn{1}{|c|}{ Attitudes } & F-Value & \multicolumn{1}{|c|}{ DF } & Prob.* & Yes & $\frac{\text { No }}{X}$ \\
\hline Vague definition & 0.196 & 1,243 & N.S. & & \\
\hline Important human dimension & 2.273 & 1,242 & N.S. & & \\
\hline Separation church/state & 5.046 & 1,242 & 0.026 & 2.080 & 2.516 \\
\hline Evaluate and grade students & 0.022 & 1,243 & N.S. & & \\
\hline Inadeguate professional training & 0.048 & 1,241 & N.S. & & \\
\hline Respect individual belief system & 1.460 & 1,243 & N.S. & & \\
\hline More resource material & 0.296 & 1,241 & N.S. & & \\
\hline Lack of support/peers & 2.744 & 1,233 & N.S. & & \\
\hline Lack of support/admin. & 3.552 & 1,233 & N.S. & & \\
\hline Appropriate content area & 1.077 & 1,241 & N.S. & & \\
\hline Feel adeguately trained & 1.129 & 1,239 & N.S. & & \\
\hline
\end{tabular}

${ }^{*} \mathrm{p} \leq .05(4=$ strongly agree; 1 = strongly disagree $)$ 
Table 35

Respondents Who Sign an Institutional Faith Statement and Attitudes Toward Including Spiritual Health

in College General Health Courses

\begin{tabular}{|c|c|c|c|c|c|}
\hline \multirow[t]{2}{*}{ Attitudes } & \multirow[t]{2}{*}{ F-Value } & \multirow[t]{2}{*}{$\mathrm{DF}$} & \multirow[t]{2}{*}{ Prob.* } & \multicolumn{2}{|c|}{$\begin{array}{c}\text { Sign of Faith } \\
\text { Statement }\end{array}$} \\
\hline & & & & $\frac{\text { Yes }}{x}$ & $\frac{\text { No }}{X}$ \\
\hline Vague definition & 5.507 & 1,244 & 0.020 & 1.667 & 2.479 \\
\hline Important human dimension & 0.969 & 1,243 & N.S. & & \\
\hline Separation church/state & 1.532 & 1,243 & N.S. & & \\
\hline Evaluate and grade students & 0.540 & 1,244 & N.S. & & \\
\hline Inadequate professional training & 4.782 & 1,242 & 0.030 & 1.500 & 2.223 \\
\hline Respect individual belief system & 1.980 & 1,244 & N.S. & & \\
\hline More resource material & 7.640 & 1,242 & 0.006 & 2.000 & 2.794 \\
\hline Lack of support/peers & 2.118 & 1,236 & N.S. & & \\
\hline Lack of support/admin. & 3.578 & 1,236 & N.S. & & \\
\hline Appropriate content area & 1.002 & 1,242 & N.S. & & \\
\hline Feel adeguately trained & 5.416 & 1,240 & 0.021 & 3.333 & 2.606 \\
\hline
\end{tabular}

${ }^{*} \mathrm{p} \leq .05$ ( 4 = strongly agree; 1 = strongly disagree) 
Due to the small number of responses in this demographic variable $(\underline{n}=6)$, the statistical significance is weakened. However, it is interesting to ponder the data's potential meaning. It may be possible that, in an organization where a signed faith statement is required, spiritual health is defined and taught within the specific tenets of the signed faith statement, thereby minimizing confusion over spiritual health.

\section{Geographic Region}

The demographic variable, "geographic region," provides two significant findings in respondents' attitudes toward including spiritual health in the classroom. These are spiritual health's vague definition and a concern for respecting individual beliefs. No significant differences were reported in nine of the attitudes toward statements of including spiritual health (see Table 36 ).

Bonferroni post-hoc findings show that respondents from the Northwest region were more concerned than were those from other geographic regions about the vague definition of spiritual health and with respecting the rights of individual belief systems. The data collected is inadequate to explain why the Northwest region reported significant differences in these two attitudes. A possible explanation may be that the Northwest has a rich history of rugged individualism that could be an influential factor in these attitudes. 
Table 36

Respondents' Geographical Region and Attitudes Toward Including Spiritual Health in College General Health Course

\begin{tabular}{|c|c|c|c|c|c|c|c|c|c|c|}
\hline Attitudes & F-Value & DF & Prob.* & $\frac{\mathrm{NW}}{\bar{X}}$ & $\frac{\text { MWest }}{X}$ & $\frac{\text { Swest }}{\bar{X}}$ & $\frac{\text { Cent }}{\bar{X}}$ & $\frac{\text { East }}{X}$ & $\frac{\text { South }}{\bar{X}}$ & $\begin{array}{l}\text { Post Hoc } \\
\text { BonFerroni }\end{array}$ \\
\hline Vague definition & 2.633 & 5,245 & .024 & 2.815 & 2.500 & 2.300 & 2.000 & 2.448 & 2.542 & $1-4$ \\
\hline Imporant human dimen. & 2.732 & 5.244 & .020 & 2.926 & 3.339 & 3.450 & 3.333 & 3.224 & 3.026 & N.S. \\
\hline Separation church/state & 1.088 & 5,244 & N.S. & & & & & & & \\
\hline Evaluate/grade students & 1.596 & 5,245 & N.S. & & & & & & & \\
\hline Inadequate prof. train. & 1.163 & 5,243 & N.S. & & & & & & & \\
\hline Respect indiv. beliefs & 2.605 & 5,245 & .026 & 2.556 & 1.982 & 1.967 & 1.952 & 2.121 & 2.102 & $1-2$ \\
\hline More resource material & 1.322 & 5,243 & N.S. & & & & & & & \\
\hline Lack of suppor/peers & 0.774 & 5,236 & N.S. & & & & & & & \\
\hline Lack of support/admin. & 1.075 & 5,236 & N.S. & & & & & & & \\
\hline Appropriate content & 1.369 & 5,243 & N.S. & & & & & & & \\
\hline Feel adequately train. & 1.409 & 5,242 & N.S. & & & & & & & \\
\hline
\end{tabular}

${ }^{*} \mathrm{~L} \leq .05$ ( 4 = strongly agree; 1 = strongly disagree) 
The connection between a concern over spiritual health's vague definition and the respecting of a student's individual belief systems is an interesting one for speculation. Perhaps Northwest AAHE members were concerned that, without a clear spiritual health definition, they may have indirectly offended a student's belief system. This speculation has support from other results that appear to demonstrate a clear connection between spiritual health's vague definition and concerns about including spiritual health material.

\section{Research Question Summary}

In summary, the research data demonstrates support for including spiritual health in college general health courses. The demographic variables of: (a) personal religious affiliation, (b) teach a general health course, (c) highest academic degree, (d) primary teaching responsibility, and (e) spiritual health training experiences most often provide the differences in respondents' attitudes toward including spiritual health in college general health courses.

The data repeatedly identify spiritual health's vague definition, concern for separation of church and state, and adequate spiritual health training as the respondents' main concerns about including spiritual health material. 


\section{Spiritual Health Training}

Research question seven asks: "Do AAHE college health educators perceive themselves to be adequately trained to teach spiritual health?"

Descriptive statistics found that the majority of the sample population, 56\% $(\underline{N}=142)$, thought they were adequately trained to teach spiritual health, with a reported mean score of 2.618. Previous demographic analysis, in research question five, revealed that respondents with a doctorate, who taught a general health course, signed a faith statement, and had spiritual health training experiences felt the most adequately trained in spiritual health.

Frequency statistics were run on spiritual health training experiences in order to attain a richer understanding of respondents' spiritual health training experiences. These experiences were listed on the survey: (a) personal studies, (b) seminar/workshop, (c) college spiritual health course, and (d) college course work in spiritual health (see Table 37 ).

From the spiritual health training experiences listed on the survey, "personal studies" was the most common type of spiritual health training. All spiritual health training options listed were attended by less than $50 \%$ of the respondents. 
Table 37

Spiritual Health Training

\begin{tabular}{lrrrrr}
\hline & \multicolumn{2}{c}{ Percentage } & \multicolumn{2}{c}{ Number } \\
\cline { 2 - 5 } Training Experience & Yes & No & Yes & No \\
& & & & & \\
& & $36 \%$ & $64 \%$ & 92 & 163 \\
Seminars/Workshops & $48 \%$ & $52 \%$ & 123 & 132 \\
Personal Studies & $6 \%$ & $94 \%$ & 16 & 239 \\
Spiritual Health Course & $39 \%$ & $61 \%$ & 100 & 155 \\
Course w/Spiritual Health Content & & & & \\
\hline
\end{tabular}

Cross-tabulation studies were done to determine if a connection may exist between respondents' spiritual health training experiences and self-perceived adequacy to teach spiritual health. Cross-tabulation reveals that the majority of respondents who had spiritual health training experience perceived themselves to be adequately trained to teach spiritual health (see Table 38).

Table 38

A Comparison of the Respondents who Felt Adequately Trained and the Percentage who Attended Training Activities

Training Method

\begin{tabular}{lll}
\hline Seminars/workshops & $80 \%$ & $20 \%$ \\
Personal Studies & $71 \%$ & $27 \%$ \\
Spiritual Health Course & $81 \%$ & $19 \%$ \\
Course with Spiritual Health Content & $73 \%$ & $25 \%$ \\
\hline
\end{tabular}

Yes No

$81 \% \quad 19 \%$

Attended Training 
The second cross-tabulation study reveals that the majority of respondents who had not had spiritual health training experience perceived themselves to be inadequately trained to teach spiritual health (see Table 39).

Table 39

A Comparison of the Respondents who Felt Inadequately Trained and the Percentage who Attended Training Activities

Training Method

Seminars/workshops

Personal studies

Spiritual Health course

Course with Spiritual Health content

$\frac{\text { Attended Training }}{\text { Yes }}$

$42 \%$

$41 \%$

$55 \%$

$44 \%$
578

$59 \%$

$45 \%$

$56 \%$

The results indicate that a potential connection exists between spiritual health training and an individual's perception of his or her adequacy to teach spiritual health. The results also indicate other influential factors that may determine adequacy of training were not identified by this study. Results imply that personal perception on adequacy to teach spiritual health is a multi-faceted process, and that the spiritual health training experiences identified in this survey are only one aspect.

since "spiritual health training" was identified as a significant demographic variable in explaining several attitude variances in research questions five and six, a 
second-level analysis was done to determine if a connection existed between respondents' perception of adequate spiritual health training and their practices of including spiritual health in their general health courses.

A cross-tabulation between the independent variable, "respondents' perception of spiritual health training adequacy," and the dependent variable, "the practice of including spiritual health in general health courses," was done. The majority of those who included spiritual health, perceived themselves to be adequately trained to teach spiritual health (see Table 40). A minority (39\%), felt they were adequately trained to teach spiritual health, but they chose not to include spiritual health in their course. The results suggest that there may be other factors in conjunction with adequate spiritual health training that influenced the respondent's decision not to include spiritual health materials.

Table 40

A Comparison of Respondents Who Include Spiritual Health in a college Health course and Perceived Adequacy of Spiritual Health Teaching

Adequately Trained in Spiritual Health $\frac{\text { Include Spiritual Health in Course }}{\text { Yes }}$
Disagree

Agree
$20.7 \%$

$79.3 \%$
$61 \%$

$39 \%$ 


\section{Discriminate Factors}

Research question eight asks: "From the demographic data, spiritual health attitude data, including spiritual health attitude data, and spiritual health training data collected on the survey," are there a set of factors that can discriminate who would include and who would not include spiritual health in their general health course?

Two statistical steps were taken to answer this question. First, a factor analysis was done on the eight statements of spiritual health attitude and the 11 attitudes toward including spiritual health statements. Factor analysis was selected because it is a statistical technique that can identify relationships between many variables that may be overlooked in other statistics.

The factor analysis data identified two factors with an eigenvalue greater then one: (a) spiritual health importance factor, and (b) spiritual health social support factor (see Table 41). The other scaled variables, additional spiritual health attitude statements, and attitudes toward including spiritual health statements, were eliminated from the identified factors because they did not explain enough of the variance in people's attitudes to be included as a variable. 
Table 41

Factor Analysis Results from Spiritual Health Attitudes and Attitudes Toward Including Spiritual Health

\section{Factor}

Spiritual Health Importance Factor

(explained $22.5 \%$ of total variance)

Spiritual Health is important in a person's total wellbeing.

My personal spiritual health is important to me.

$\mathrm{SH}$ influences individual physical, emotional, mental wellbeing.

$\mathrm{SH}$ is important in a college general health course.

$\mathrm{SH}$ should not be excluded because of difficulty grading/evaluating.

I am comfortable including $\mathrm{SH}$, because I have adequate training.

Including SH would not cause me concern for individual belief system of the student.

Support for Spiritual Health Factor (explained $12.3 \%$ of total variance)

Lack of support from administration. Lack of support from teaching peers. Society's concern for separation of church and state.

In the second statistical step, a step-wise multiple regression was done. The independent variables were the two factors identified in the factor analysis and other nonscaled demographic variables that were significant in previous ANOVAs: (a) personal religious affiliation, (b) teach a general health course, (c) highest academic degree, and (d) spiritual health training. The dependent variable used was the attitude statement, "Spiritual health is an 
appropriate content area to include in a college general health course."

The multiple regression results conclude that respondents who scored high on the spiritual health importance factor and have taken a college course in spiritual health were the most likely to include spiritual health in a college general health course (see Table 42).

Table 42

Multiple Regression Analysis of Spiritual Health Factors and Appropriateness of Including Spiritual Health in a College General Health course

\begin{tabular}{|c|c|c|c|c|c|c|c|}
\hline step $_{\#}$ & $\begin{array}{l}\text { Indep. } \\
\text { Variable }\end{array}$ & $\mathbf{R}$ & $\mathrm{R}^{2}$ & $\begin{array}{c}\mathrm{R}^{2} \\
\text { Change }\end{array}$ & F & $\mathrm{DF}$ & $\mathrm{P}$ \\
\hline 1 & Factor one & .634 & .403 & - & 152.260 & 245 & 0.00 \\
\hline 2 & SHT 22 & .639 & .409 & .005 & 2.374 & 245 & 0.00 \\
\hline \multicolumn{8}{|c|}{$\begin{array}{l}\text { Subset Model: } \\
\text { Factor one--Spiritual Health Importance Factor } \\
\text { SHT 22--Attended a college course in spiritual health }\end{array}$} \\
\hline $\begin{array}{l}\text { Not } \\
\text { chan } \\
\text { Sp } \\
\text { Pe } \\
\text { Te } \\
\text { Hid } \\
\text { Pe } \\
\text { At } \\
\text { At }\end{array}$ & $\begin{array}{l}\text { ncluded in } \\
\text { e): } \\
\text { ritual Heal } \\
\text { sonal Relig } \\
\text { ch General } \\
\text { hest Academ } \\
\text { sonal studi } \\
\text { end spiritu } \\
\text { end college }\end{array}$ & $\begin{array}{l}\text { mod } \\
\text { Soci } \\
\text { is Af } \\
\text { lth } \\
\text { Degr } \\
\text { in } 5 \\
\text { heal } \\
\text { burse }\end{array}$ & $\begin{array}{l}\text { (did } \\
\text { Supp } \\
\text { liati } \\
\text { drse } \\
\text { fitua }\end{array}$ & $\begin{array}{l}\text { not prov } \\
\text { ct Facto }\end{array}$ & ide sign & icant & \\
\hline
\end{tabular}

These results suggest that the more important the respondent viewed spiritual health, the more likely it was 
that the respondent would include spiritual health in a college general health course.

In conclusion, Chapter IV presents the statistical results of this study. Discussion of the main themes suggested by the study's findings is treated in Chapter V. 
CHAPTER V

\title{
DISCUSSION AND RECOMMENDATION \\ FOR PRACTICE
}

\section{Introduction}

\begin{abstract}
This dissertation utilized data collected from a descriptive study of university and college members of the Association for the Advancement of Health Education (AAHE) . It provides some insights into AAHE university/college health educators' spiritual health attitudes, attitudes toward including spiritual health in college general health courses, current practices of including spiritual health in a college general health course and spiritual health training. A discussion of the main themes found in the study results is presented in the first section. The second section discusses the implications of these results for the health education profession. The final section presents suggestions for future research.
\end{abstract}

\section{Main Themes}

The descriptive study provides a broad overview of attitudes of the respondents regarding spiritual health. Because of the volume of statistical data, discussion on the specific findings from each research question was presented 
in Chapter IV. In this section, discussion covers the main themes that emerged from the findings and discussions of the eight research questions.

\section{Spiritual Health's}

Importance

Spiritual health is viewed as important by the respondents constitutes the first theme. Respondents expressed attitudes that indicated spiritual health is an important dimension for total health and well-being, that it influences health and well-being and that it is personally important to them. These attitudes support the literature that endorses the spiritual dimension of human beings (Fahlberg \& Fahlberg, 1991; Grof \& Grof, 1989; Jung, 1958; Maslow, 1971).

The importance of spiritual health is reflected in the respondents' decision to include spiritual health in a college general health course. The factor analysis and multiple regression statistics indicate that attitudes about spiritual health's importance and influence on health and well-being provide a significant explanation for who is most likely to include spiritual health material in health education.

\section{Appropriate to Include}

Spiritual Health

Respondents expressed attitudes that supported the importance and appropriateness of including spiritual health 
in college general health courses. This finding has potential importance. While the self-selection bias of the respondents tempers the results, it remains that a national study with a significant number of respondents reports findings that support the literature's contention that spiritual health is important and should be included in health education (Banks, 1980; Chapman, 1986; Diaz, 1993; Goodloe \& Arreola, 1992). This study appears to be the first to provide such evidence.

The survey results give support to spiritual health advocates who, through the years, have recommended that spiritual health be included in health education (Banks et al., 1984; Chandler et al., 1990; Chapman, 1986; Collins et al., 1986; Diaz, 1993; Goodloe \& Arreola, 1992; Hoyman, 1966; Jose \& Taylor, 1986; Osman \& Russell, 1979). Spiritual health may have more support in the health education profession than is reflected in the literature.

Decision to Include Spiritual Health

A third theme that emerged was that the decision to include spiritual health is a multi-faceted one. Respondents support including spiritual health in college general health courses. However, the data collected and analyzed show that the decision to include spiritual health is a complex and multi-dimensional one, whose intricacies go beyond the scope of this research. As mentioned earlier in 
this chapter, findings indicate that the respondents' attitudes about the importance of spiritual health determine their likelihood of including spiritual health in a college general health course. In addition, the data gathered for this research project indicate that some other issues may provide insights into the respondents' decision making process about including spiritual health material. These other issues suggest further research. Discussion of each of these issues follows.

Separation of church and state. One issue raised when including spiritual health in college general health courses is society's concern for separation of church and state. Society's concern for separation of church and state is frequently cited in the literature as a potential barrier to including spiritual health in health education materials (Chandler, Holden, \& Kolander, 1992; Goodloe \& Arreola, 1992). This study provided empirical support for this barrier. Consistently respondents expressed concern about this issue. Even those respondents who currently include spiritual health materials in their college general health course confirmed that society's concern for separation of church and state was an issue.

Interestingly, analysis of highest academic degree and personal religious affiliation yielded some information that provides further insight into this issue. Respondents with doctoral degrees reported strikingly less concern about 
separation of church and state than did respondents with bachelor's and master's degrees. In addition, doctoral respondents reported attitudes that saw a clear conceptual difference between spiritual health and religion. Respondents who expressed a personal religious affiliation reported higher concern for separation of church and state and less certainty about spiritual health and religion being conceptually distinct. A relationship may exist between these two attitudes, wherein viewing spiritual health as distinct from religion eases the concern about separation of church and state. This possible relationship has been articulated in the literature (Banks, Poehler, \& Russell, 1984) as a means for removing barriers for including spiritual health in health education.

Why do doctoral respondents conceptually differentiate between spiritual health and religion? The data analysis suggests that the content focus of a doctoral degree is not a factor. A possible explanation is that doctoral respondents may be more complex, cognitive conceptually. Reasons for this may be a self selection by ability to enter doctoral programs or the development of abstract thought during a doctoral program. Adult development theorists have noted that with increased cognitive development an individual becomes more abstract and conceptually complex in his or her thinking (Perry, as cited in Chickering, 1981). 
A connection may exist between conceptual complexity and the ability to differentiate between spirituality and religion.

Another possible interpretation of the findings is that doctoral respondents are more likely to work in institutions that encourage and support theoretical and conceptual thinking, thereby influencing their conceptual views on spiritual health and religion. However, the data analysis on institutional type would not support this interpretation. The institutional type demographic data analysis was not a decisive variable in explaining attitude differences.

An additional explanation may be found in exposure to academic training. Doctoral respondents may have had more opportunities to participate in or be exposed to health education training that built personal confidence. It may be that with increased confidence problematical areas are of less concern.

The data collected are not adequate to support a specific interpretation. Further research is needed to test these possible interpretations.

Spiritual health's vague definition. A second issue that emerged when analyzing data on including spiritual health materials was concern for spiritual health's vague definition, which was viewed as a barrier to including spiritual health in college health courses. This empirical finding supports discussions held in the literature regarding spiritual health's vague definition being a 
barrier to including the subject in health education materials (Bensley, 1991a; Chandler, Holden, Kolander, 1992; Jose \& Taylor, 1986; Ellison, 1982; Edwards, 1980).

Data results revealed that spiritual health's vague definition is not as high a concern for doctoral respondents as for those respondents with bachelor's and master's degrees. While the empirical evidence collected for this study does not offer an explanation for this result, a possible explanation may be that doctoral respondents have increased tolerance for ambiguity because of their academic training and cognitive development level. support for this interpretation is found with Loevinger's work on ego development in adult development. Loevinger (1976) theorized in her work on ego development that as the human ego developed it became more tolerant of ambiguity:

Increased ability to tolerate paradox and contradiction leads to greater conceptual complexity, shown by awareness of the discrepancies between inner reality and outward appearances, between psychological and physiological responses, between process and outcome. (pp. 22-23)

Therefore, a relationship may exist between tolerance for spiritual health's vague definition and cognitive development that may be facilitated by the doctoral process.

\section{Personal health teaching experience. A third issue} that emerged is a possible relationship between the respondents' professional experiences and their attitudes 
toward inciuding spiritual health in college general health courses. The respondents who had recent, direct experience in teaching a college personal health course revealed stronger attitudes about spiritual health's importance and appropriateness in a college general health course than did respondents who did not have this recent teaching experience. It may be possible that the actual experience of teaching a college general health course facilitated interactive experiences with the students and the health materials that provided experiential knowledge from which the instructor's attitudes on spiritual health were derived. spiritual health support. The data suggest that the amount of support for spiritual health is considered by the respondents when deciding to include spiritual health. This issue presents itself in two forms: (a) perceived support from one's immediate peers and administration; and (b) perceived support from social norms. While the data remain unclear and mixed about the influence of perceived support on decisions to include spiritual health in the college general health course, they suggest that colleague support is part of the multi-faceted influence to including spiritual health that needs further exploration. The literature addresses respondents' concerns about separation of church and state when they are contemplating whether to include spiritual health material (Bensley, 1991a; Chapman, 1986; Collins, 1987), but it does not address the 
possibility that colleague support, or a lack there of, is influential in the decision.

These issues highlight some of the complex, interrelated dimensions involved when respondents decide to include or exclude spiritual health material in the college general health course. The discussion now turns to the fourth main theme.

\section{Spiritual Health Training} Experience

The fourth theme from the data is that spiritual health training experience was the only demographic variable that consistently had a statistically significant relationship with spiritual health attitudes and attitudes toward including spiritual health in the college general health course. An apparent relationship exists between spiritual health training, spiritual health attitudes, and attitudes toward including spiritual health materials. Those respondents with spiritual health training experience reported more positive spiritual health attitudes, were more positive toward including spiritual health in college general health courses, and were less concerned about potential barriers to including spiritual health.

It cannot be discerned from the empirical data collected in this study whether people who are more positive toward spiritual health and including it in college general health courses take opportunities for spiritual health 
training opportunities, nor do we know if spiritual health training experiences influenced their spiritual health attitudes and attitudes toward including spiritual health. However, it is clear that a significant relationship existed between spiritual health training experiences and spiritual health attitudes and attitudes toward including spiritual health in health educational materials.

\section{Including spiritual Health} Practices

Another theme emerged with regard to the respondents' practices of including spiritual health in their college general health courses. The respondent's current spiritual health practices in including spiritual health appear in conflict with their stated spiritual health attitudes. Respondents, overwhelmingly, voiced support for the importance of and inclusion of spiritual health in college general health courses. Yet, when current practices of including spiritual health were reported, the including of spiritual health material was kept to a minimum.

The nature of the study makes it difficult to interpret this discrepancy. However, possible explanations include the following: (a) spiritual health is perceived as important, but not as important as other health subject areas within a finite class time; (b) the data suggest the uneasiness that exists around including spiritual health; and, (c) the discrepancy is an example of cognitive 
dissonance, wherein respondents' values and behaviors are out of alignment.

An additional explanation is the possibility that including spiritual health in the college general health course by respondents is a recent phenomenon. The data collected may represent the beginning of a trend to include spiritual health materials. Respondents may be experimenting with a limited coverage of spiritual health, and, in essence, "testing the waters." This possibility finds support with seaward (1994):

Unthinkable a decade ago, today it is not uncommon to see universities and corporate health-promotion programs including courses on spiritual wellbeing as well as more traditional programs on physical wellbeing. (p. 111)

Since no previous empirical data existed about respondents' practices in including spiritual health, it is difficult to determine if the data collected regarding current spiritual health practices of including the material in college general health courses are a constant, increasing, or decreasing phenomenon.

Perceived Adequacy of Spiritual Health Training

The findings present a sixth theme. Spiritual health is being taught by health educators who do not perceive themselves adequately trained to teach spiritual health. The data suggest that a large portion of respondents who 
include spiritual health in their college general health courses do not feel adequately trained in spiritual health.

If this is the case, professional concerns may exist regarding quality control. Health educators are teaching subject matter in which they are not trained. Unlike other areas in health education (Girvan et al., 1993), no professional knowledge standards are established. This is a precarious situation for several reasons. It places individual health educators in isolation teaching a potentially controversial subject. Potential for misinformation and abuse is higher than usual. This situation belittles spiritual health as a legitimate health education subject area and suggests that spiritual health is a passing trend, not a permanent human dimension that warrants being addressed along with the other human dimensions.

In conclusion, the descriptive survey was an initial study to gather empirical evidence on the spiritual health attitudes, attitudes toward including spiritual health in health education materials, and current practices of including spiritual health in college general health courses by AAHE university and college health educators. The six emergent themes presented by the empirical data generate implications for AAHE members and, possibly, health educators outside the AAHE organization. 


\section{Implications}

The implications are clear. Spiritual health is considered important and influential in promoting the health and well-being of humans. Spiritual health is viewed as an appropriate subject to include in college general health courses. Further research and discussion is needed on spiritual health and its being included in health education material.

As a professional organization with stated goals to support members' professional needs, including updating members, AAHE needs to take an active role in promoting further research and dialogue on spiritual health and its being included in health education materials. With a response rate of $54 \%$, a substantial number of AAHE members have said that spiritual health warrants further attention.

\section{Recommendations}

From the analysis of the descriptive study, three recommendations for the profession have emerged.

Recommendation one: Further spiritual health dialogue needs to be sanctioned and encouraged by professional organizations. Spiritual health is an important topic for further pursuit. The results of the study overwhelmingly show interest in and support for including spiritual health in health education materials. The empirical data collected strongly indicate areas of concern about including spiritual 
health in college general health courses. spiritual health discussions and further research need to be brought to the forefront, where debate and dialogue can bring greater understanding and clarification of spiritual health to health educators.

Evidence collected indicates a strong concern for external support and approval when one includes spiritual health material. Discussions on spiritual health that are supported and approved by professional organizations could increase the status of the discussion and provide the external support and approval needed for meaningful exchange to occur.

Recommendation two: Spiritual health resources from other professions need to be gathered and modified to include in health education curricula and materials. While respondents did not express strong attitudes that more spiritual health materials are needed, responses to concerns about including spiritual health--separation of church and state, vague definition--may be reduced with inclusion of resources (Bragdon, 1990; Edwards, 1980; Jung, 1958; Maslow, 1976; Seaward, 1994) that exist in other professions. Recommendation three: Training in spiritual health needs to occur. The survey results clearly demonstrate that a relationship exists between training in spiritual health and clarity of attitudes regarding spiritual health. The 
data and literature offer clues into which subject areas need to be included in spiritual health training:

1. Cognitive information clarifying the difference between spiritual health and religion (Banks et al., 1984).

2. Open discussion on the perceived barriers to including spiritual health (Goodloe \& Arreola, 1992).

3. Methodologies for teaching spiritual health (reflective practice, being one example) (Jose \& Taylor, 1986).

4. Dialogue on methods for evaluating spiritual health in the classroom situation (Diaz, 1993).

5. A spiritual health material resource list.

\section{Future Research}

From the data collected and analyzed, several future research areas are indicated:

1. Expand the research population base beyond AAHE members who work predominately in colleges and universities to obtain greater insight into spiritual health attitudes of health educators working in other arenas.

2. Expand research to include qualitative research methods to gain additional understanding and meaning of health educators' attitudes of spiritual health and attitudes toward including spiritual health in health education. 
3. Explore the potential relationships identified in the demographic analysis. Examples of such research include: (a) degree of academic training and individual's conceptual development, (b) conceptual distinction between spiritual health and religion, (c) personal health teaching experience and spiritual health attitudes, and (d) perceived colleague support and its influence on including spiritual health in health education.

4. Support research that seeks to define spiritual health.

5. Explore the types, resources, and levels of spiritual health training in which health educators participate.

6. Use qualitative and quantitative research methods to gain a richer and fuller understanding of the multifaceted decision-making process respondents use to decide whether or not to include spiritual health.

7. Research the spiritual health attitudes and attitudes about including spiritual health in health education materials of college level students.

8. Compare spiritual health attitudes among AAHE university and college members and college level students.

\section{Conclusion}

Spiritual health is advocated in the literature of health education (Bensley, 1991a; Chandler \& Kolander, 1990; 
Jose \& Taylor, 1986) and other professions (Boutell \& Bozett, 1990; Kelly, 1992). Assertions are made about why more spiritual health is not included in health education (Bensley, 1991b; Diza, 1993; Goodloe \& Arreola, 1992; Jose \& Taylor, 1986). However, little research has been done to support or refute these assertions.

A descriptive study was done on university and college health educators who were members of AAHE. The study's intent was to gain greater understanding of health educators' spiritual health attitudes, current status of spiritual health in their college general health courses, and spiritual health training experiences.

Findings indicate that spiritual health is viewed as important and influential in the health and well-being of individuals. Also, spiritual health is considered an appropriate subject to include in college general health courses. The decision to include spiritual health appears to be a complex one with many influencing variables. Spiritual health is currently included on a limited basis in a large number of college general health courses. Finally, the findings indicate a connection exists between attitudes concerning spiritual health and including it in college general health courses and spiritual health training experiences.

These findings provide data that give insights into spiritual health in the health education profession. This 
descriptive study is designed to provide broad overviews. Further research is needed to gain a deeper understanding of spiritual health's status in health education. 


\section{REFERENCES}

Banks, R. L. (1980). Health and the spiritual dimension: Relationships and implications for professional preparation programs. The Journal of School Health, 50(4), 195-202.

Banks R. L., Poehler, D. L., \& Russell, R. D. (1984). spirit and human-spiritual interaction as a factor in health and in health education. Health Education, 15, 16-19.

Bensley, R. J. (1991a). Defining spiritual health: A review of the literature. Journal of Health Education, $\underline{22}(5), 287-290$.

Bensley, R. J. (1991b). Spiritual health as a component of worksite health promotion/wellness programming: A review of the literature. Journal of Health Education, $\underline{22}(6), 352-353$.

Bergin, A. E. (1980). Religious and humanistic values: A reply to Ellis and Walls. Journal of Consulting and Clinical Psychology, 48, 642-645.

Bergin, A., \& Jensen, J. (1990). Religiosity of psychotherapists: A national survey. Psychotherapy, 27, 3-7.

Blimling, G. S. (1990). Developing character in college students. NASPA Journal, 27(4), 266-273.

Boutell, K. A., \& Bozett, F. (1990). Nurses' assessment of patients' spirituality: Continuing education implications. The Journal of Continuing Education in Nursing, 21 (4), 172-176.

Bragdon, E. (1990). The call of spiritual emergency. New York: Harper Row.

Chandler, C. K., Holden, J. M. \& \& Kolander, C. A. (1992). Counseling for spiritual wellness: Theory and practice. Journal of Counseling and Development, 71, 168-175. 
Chandler, C. K., \& Kolander, C. A. (1990, April 1). Spiritual health: A balance of all dimensions. Paper presented at the national AAPHERD National Convention, New Orleans, LA.

Chapman, L. (1986). Spiritual health: A missing component from health promotion. American Journal of Health Promotion, 1(1), 38-41.

Chapman, L. (1987). Developing a useful perspective on spiritual health: Love, joy, peace, and fulfillment. American Journal of Health Promotion, 1(4), 12-17.

Chickering, A. W. (1981). The modern American college. San Francisco: Jossey-Bass.

Collins, J. R., Hurst, J. C., \& Jacobson, J. K. (1987) . The blind spot extended: Spirituality. Journal of College Student Personnel, 28(3), 274-276.

Coughlin, E. K. (1992, April 1). Social scientists again turn attention to religion's place in the world. Chronicle of Higher Education, 38(30), A6-A8.

DeArmond, M. M. (1990). Designing the future of college health. NASPA Journal, 27(4), 275-280.

Diaz, D. P. (1993). Foundations for spirituality: Establishing the viability of spirituality within the health disciplines. Journal of Health Education, $\underline{24}(6), 324-326$.

Donatelle, R. \& Hales, D. (1991). Access to health. Englewood Cliffs, NJ: Prentice Hall.

Donatelle, R. J., Schima, M., Champeaus, D., \& MalkinWasheim, D. (1993). Professional credentialing: At what cost? Journal of Health Education, 24 (5), 288291 .

Edwards, T. H. (1980). Spiritual formation in theological schools: Ferment and challenge. Theological Education, 4, 7-51.

Ellison, C. W. (1982, January). Spiritual well-being: Conceptualization and measurement. Paper presented at the Duke University Medical Center conference on Spiritual Disease, Durham, NC. 
Fahlberg, L. L., \& Fahlberg, L. A. (1991). Exploring spirituality and consciousness with an expanded science: Beyond the ego with empiricism, phenomenology, and contemplation. American Journal of Health promotion, $\underline{5}(4), 273-281$.

Friend, G. (1991). Formal moral education and individual moral development. Gainesville: University of Florida, Institute of Higher Education. (ERIC Document Reproduction Service No. ED 344541 )

Girvan, J. T., Hamburg, M. V., \& Miner, K. R. (1993) . Credentialing the health education profession. Journal of Health Education, 24 (5), 260.

Goodloe, N. R., \& Arreola, P. M. (1992). Spiritual health: Out of the closet. Journal of Health Education, 23(4), 221-226.

Grof, S., \& Grof, C. (Eds). (1989). Spiritual emergency: When personal transformation becomes a crisis. Los Angeles: Jeremy P. Tarcher.

Hales, D. (1994). An invitation to health (6th ed.). Redwood City, CA: Benjamin/Cummings Publisher.

Hoyman, H. S. (1966). The spiritual dimension of a man's health in today's world. The Journal of School Health, $\underline{45}(9)$, 509-518.

Ignelzi, M. G. (1990). Ethical education in a college environment: The just community approach. NASPA Journal, 27(3), 192-198.

Jose, N. L., \& Taylor, E. L. (1986, Fall/winter). Spiritual health: A look at barriers to its inclusion in the health education curriculum. The Eta Sigma Gamman, pp. 16-18.

Jung, c. G. (1958). The undiscovered self. New York: Mentor Books.

Kelly, E. W. (1992). Religious and spiritual issues in university-based counselor education programs: A national survey of current status and practice. Final report of a research project. Washington, DC: George Washington University. (ERIC Document Reproduction Service No. ED 350496$)$

Lannert, J. L. (1991). Resistance and countertransference issues with spiritual and religious clients. Journal of Humanistic Psychology, 31(4), 68-76. 
Lather, P. (1986). Research as praxis. Harvard Educational Review, $\underline{56}(3), 257-277$.

Loevinger, J., \& Blasi, A. (1976). Ego development: Conception and theories. San Francisco: Jossey-Bass.

Lukoff, D., Turner, R., \& Lu, F. G. (1993). Transpersonal psychology research review: Psychospiritual dimensions of healing. The Journal of Transpersonal Psychology, $\underline{25}(1), 11-28$.

Maslow, A. H. (1970). Motivation and personality. New York: Harper and Row.

Maslow, A. (1971). Farther reaches of human nature. New York: Viking.

Maslow, A. H. (1976). The farther reaches of human nature. New York: Penguin Books.

Mentkowski, M. (1988). Educating for moral development: Lessons learned from experience. Counseling and Values, $\underline{32}(3), 193-200$.

Moberg, D. O. (1971). Background and issues, spiritual wellbeing: White house conference on aging. Washington: Government Printing office.

Nichols, D. R., \& Gobble, D. C. (1991). World views, systems theory, and health promotion. American Journal of Health promotion, $6(1), 30-34$.

Nolte, A. E., \& Hamburg, M. V. (1993). Development of national certification for health education specialists. Journal of Health Education, 24(5), 261262 .

Oberteuffer, D., \& Beyrer M. K. (1966). School health education. New York: Harper and Row.

Oregon House Bill 3565, 66th Oregon Legislative Assembly-1991 Regular Session (1991).

Osman, J., \& Russell, R. (1979). The spiritual aspects of health. Journal of School Health, $49,359$.

Sappington, D. , \& Wilson, F. R. (1990). Toward an assessment of spiritual maturity: A critique of measurement tools. Christian Education Journal, 12(3), 46-68. 
Seaward, B. L. (1991). Spiritual wellbeing: A health education model. Journal of Health Education, 22(3), 166-169.

Seaward, B. L. (1994). Managing stress. Boston: Jones and Bartlett Publishers.

Sechrist, w. C. (1979). Total wellness and holistic health, a bandwagon we cannot afford to jump onto. Health Education, 10(5), 27.

Shafranske, E. P., \& Gorsuch, R. L. (1984). Factors associated with the perception of spirituality in psychotherapy. Journal of Transpersonal Psychology, $16(2), 231-41$.

Shafranske, E. P., \& Maloney, H. N. (1990). Clinical psychologists' religious and spiritual orientations and their practice of psychotherapy. Psychotherapy, 27, $72-78$.

Sprinthall, N. A., \& McVay, J. G. (1987). Value development during the college years: A cause for concern and an opportunity for growth. Counseling and values, $31(2), 126-137$.

Staff. (1994a, September/October). AAHPERD goals. AAHPERD Update, p. 3

Staff. (1994b, November/December). Report to the AAHPERD board of governors. HE-xtra, $19(5)$, pp. 1,6 .

Stoll, R. (1979). Guidelines for spiritual assessment. American Journal of Nursing, $9,1575-1577$.

U.S. Department of Health and Human Services, Public Health Service. (1990). Healthy people 2000: National health promotion and disease prevention objectives. Washington, DC: Superintendent of Documents, Government Printing office.

Wilkinson, L. (1990). SYSTAT: The system for statistics [Computer program]. Evanstone, IL: SYSTAT, Inc.

Witmer, J. M., \& Sweeney, T. J. (1992). A holistic model for wellness and prevention over the life span. Journal of Counseling and Development, 71, 140-148. 
APPENDIX A

SPIRITUAL HEALTH SURVEY 


\section{SPIRITUAL HEALTH SURVEY}

For the purpose of this study, Spiritual Health means seeking a purpose and neaning in life, a sense of personal fulfillment, values, morals and ethics, and/or a relationship with a higher being or greater force than oneself.

\section{SPIRITUAL HEALTH ATTITUDES}

For each of the following items please circle the number that reflects your attitude towards opiritual health.

$\mathrm{SA}=$ otrongly agree, $\mathrm{A}=$ agree, $\mathrm{DA}=$ disagree, $\mathrm{SDA}=$ strongly disagree

1. Spiritual health is an important dimension in a person's total well-being.

2. My peroonal spiritual health is important to me.

3. I am satisfied with my opiritual health.

4. I find spiritual health to be an uncomfortable subject.

5. Spiritual health influences an individual's physical, mental, social, and emotional well-being.

j. Spiritual health can inciude diverse cultural and religious traditions.

7. Spiritual health is a private, personal journey.

8. I think there is a clear conceptual difference between spiritual health and religion.

$\begin{array}{llll}\text { SA } & \text { A } & \text { DA } & \text { SDA } \\ 4 & 3 & 2 & 1 \\ 4 & 3 & 2 & 1 \\ 4 & 3 & 2 & 1 \\ 4 & 3 & 2 & 1 \\ 4 & 3 & 2 & 1 \\ 4 & 3 & 2 & 1 \\ 4 & 3 & 2 & 1 \\ 4 & 3 & 2 & 1\end{array}$

II. ATTITUDES ABOUT INCLUDING SPIRITUAL HEAITH

For each of the following items please circle the number that reflects your attitude towards including spiritual health in a collegiate general health course (examples of such a course would be personal health, health and fitness, or wellness).

$\mathrm{SA}=$ strongly agree, $\mathrm{A}=$ agree, $\mathrm{DA}=$ disagree, $\mathrm{SDA}=$ strongly disagree

9. Spiritual health's vacue definition makes it a hard concept to include in a general health course.

10. Spiritual health is an important human dimension to present in a collegiate general health course.

11. Society's concern for separation of church and state makes teaching spiritual health difficult in a general health course.

$\begin{array}{cccc}\text { SA } & \text { A } & \text { DA } & \text { SDA } \\ 4 & 3 & 2 & 1 \\ 4 & 3 & 2 & 1 \\ 4 & 3 & 2 & 1\end{array}$


12. Because a student's spiritual health is hard co evaluate and grade, it is best not to include spiritual health in a general health course.

13. I am/would be uncomfortable including spiritual health materials in a general health course because I have inadequate professional training in the subject area.

14. Including spiritual health in a general health course, would cause me concern about respecting the student's individual belief systems.

15. More spiritual health would be included in general health courses if more resource materials were available.

16. I perceive a lack of support from my teaching peers to include more spiritual health in a general health course.

17. I perceive a lack of support from my administrators to include more spiritual health in a general health course.

18. Spiritual health is an appropriate content area to include in a college general health course.

19. I feel adequately trained to teach spiritual health.

$\begin{array}{cccc}\text { SA } & \text { A } & \text { DA } & \text { SDA } \\ 4 & 3 & 2 & 1 \\ 4 & 3 & 2 & 1 \\ 4 & 3 & 2 & 1 \\ 4 & 3 & 2 & 1 \\ 4 & 3 & 2 & 1 \\ 4 & 3 & 2 & 1 \\ 4 & 3 & 2 & 1 \\ 4 & 3 & 2 & 1\end{array}$

\section{SPIRITUAL HEALTH TRAINING}

20. I have attended workshops or seminars on spiritual health.

21. I have done personal studies in apiritual health.

yes no

22. In my degree program, I took a specific course on spiritual health.

23. In my degree program, I took courbes that included spiritual health content.

yes yes

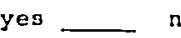
no

\section{DEMOGRAPHICS}

Please answer the following questions about your university or college:

24. What is the primary classification of your univeraity/college? (Please check one)

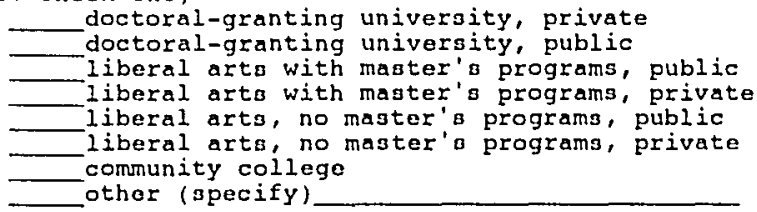

25. Does your University/college have a religious affiliation? no If yes, what is the affiliation? yes no 
Please answer the following questions about yourself:

female

27. What is your regional AAHPERD asgociation? northwegt southwest central eastern. south

28. Do you have to sign a faith statement before you teach at your institution?

29. Do you have a personal religious affiliation? If yes, what is the affiliation? yes no

30. What is your highest academic degree? bachelors masters yes no

31. What is the main focus of your highest academic degree? health education $\begin{aligned} & \text { pubile health } \\ & \text { physical education }-\end{aligned}$ other (specify)

32. Indicate current primary teaching responsibility: (check only one)

health methods

first aid

firness

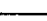

environmental health

health program planning other (specify)

Eexuality general health nutrition disease prevention health program evaluation

mental health wellness community health

33. Please indicate the areas you have taught in (check all that apply)

health methods ___ sexualtiy

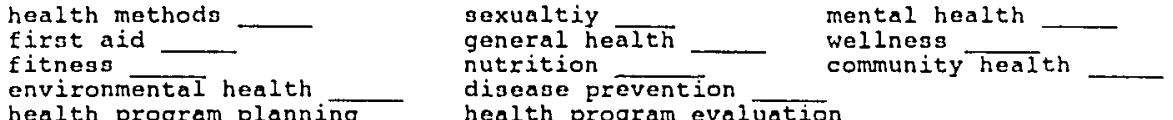

environmental health health program planning _ health program evaluation

other (apecify)

34. Your age group:

35. Your ethnic group:

less than 25 years

$26-35$ years

$36-45$ years

$46-55$ years

55 years

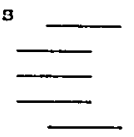

White

Spanish surname African American Asian Pacific

Native American

other

\section{SPIRITUAL HEALTH INCLUSION TN CURRENT CURRICULA}

36. Did you teach a college level general health course (examples of such a course would be personal health, health and fitness,or wellness) during the $1992-94$ academic years?

(if your response is no, please skip to section VI).

yes no

37. If your answer to question $\# 36$ is yes, pick one course to answer this section. If you teach more than one, pick the course most representative of your teaching load. Course title:

38. How many credita is this couroe? quarter___semester

39. Is this course requirod for graduation at your institution?

yes no 
40. What is the average student enrollment (all sections) in this course during an academic year?

less than 200 $200-400$ $400-600$ $600-800$ $800-1,000$ over 1,000

41. How many sections of the course do you teach during an average academic year?
$1-3$
$4-6$
$7-9$
$10-12$ more than 12

42. How many years have you taught this courge?

$$
0-5 \text { years_ 6-10 years___ } 11-15 \text { years }
$$

16-20 years $21+$ years

43. Is spiritual health covered in this course? (If you answered no, skip to section VI). 
APPENDIX B

CHARTS 
Chart 1

Respondents' Institution Type and Spiritual Health Attitudes

\begin{tabular}{|c|c|c|c|c|c|c|c|c|c|c|c|}
\hline Attitude & F-Value & $\mathrm{DF}$ & Prob.* & $\begin{array}{l}\text { Type1 } \\
\text { Priv } \\
\bar{X} \\
\end{array}$ & $\begin{array}{l}\text { Type1 } \\
\text { Publ } \\
\bar{x} \\
\end{array}$ & $\begin{array}{l}\text { Type2 } \\
\text { Priv } \\
\bar{x} \\
\end{array}$ & $\begin{array}{l}\text { Type2 } \\
\text { Publ } \\
\bar{X}\end{array}$ & $\begin{array}{l}\text { Type3 } \\
\text { Priv } \\
\bar{X} \\
\end{array}$ & $\begin{array}{c}\text { Type3 } \\
\bar{x} \\
\end{array}$ & $\begin{array}{r}\mathrm{CC} \\
\bar{x} \\
\end{array}$ & $\begin{array}{l}\text { Post Hoc } \\
\text { BonFerroni }\end{array}$ \\
\hline Important to total well-being & 1.248 & 7,243 & N.S. & $\mathrm{x}$ & $\mathrm{x}$ & $\mathrm{x}$ & $\mathrm{x}$ & $\mathrm{x}$ & $\mathrm{X}$ & $\mathrm{x}$ & \\
\hline Personally important to me & 1.244 & 7,243 & N.S. & $\mathrm{x}$ & $\mathrm{x}$ & $\mathrm{x}$ & $\mathrm{x}$ & $\mathrm{x}$ & $\mathrm{x}$ & $\mathrm{x}$ & \\
\hline Satisfied w/personal SH & 2.099 & 7,243 & .04 & 2.875 & 3.093 & 3.231 & 3.385 & 3.625 & 3.400 & 3.185 & N.S. \\
\hline Uncomforable subject & 1.639 & 7,243 & N.S. & $\mathrm{x}$ & $\mathrm{x}$ & $\mathrm{x}$ & $\mathrm{x}$ & $x$ & $\mathrm{x}$ & $\mathrm{x}$ & \\
\hline SH influences well-being & 1.620 & 7,242 & N.S. & $\mathrm{x}$ & $\mathrm{x}$ & $\mathrm{x}$ & $\mathrm{x}$ & $\mathrm{x}$ & $\mathrm{x}$ & $\mathrm{x}$ & \\
\hline $\begin{array}{l}\text { Diverse culture/religious } \\
\text { traditions }\end{array}$ & 2.098 & 7,242 & .04 & 3.250 & 3.680 & 3.538 & 3.667 & 3.750 & 3.300 & 3.444 & N.S. \\
\hline Private, personal journey & 1.927 & 7,243 & N.S. & $\mathrm{x}$ & $\mathrm{x}$ & $\mathrm{x}$ & $\mathrm{x}$ & $\mathrm{x}$ & $\mathrm{x}$ & $x$ & \\
\hline $\begin{array}{l}\text { Concept diff. betw. SH \& } \\
\text { religion }\end{array}$ & 1.125 & 7,242 & N.S. & $\mathrm{X}$ & $x$ & $x$ & $x$ & $x$ & $x$ & $x$ & \\
\hline
\end{tabular}

$* \mathrm{e} \leq .05$ (4= strongly agrec: $l=$ strongly disagree) 
Chart 2

Respondents' Gender and Spiritual Health Attitudes

\begin{tabular}{|l|l|l|l|}
\hline \multicolumn{1}{|c|}{ Attitudes } & F-Value & DF & Prob.* \\
\hline Important to total well-being & 0.643 & 1,254 & N.S. \\
\hline Personally important to me & 0.417 & 1,254 & N.S. \\
\hline Satisfied w/personal SH & 0.434 & 1,254 & N.S. \\
\hline Uncomfortable subject & 0.618 & 1,254 & N.S. \\
\hline SH influences well-being & 0.044 & 1,253 & N.S. \\
\hline Diverse culture/religion traditions & 3.164 & 1,253 & N.S. \\
\hline Private, personal journey & 0.541 & 1,254 & N.S. \\
\hline Concept diff. betw. SH \& religion & 0.008 & 1,253 & N.S. \\
\hline
\end{tabular}

${ }^{*} \mathrm{p} \leq .05$ ( $4=$ strongly agree: $1=$ strongly disagree)

\section{Chart 3}

\section{Respondents' Ethnicity and Spiritual Health Attitudes}

\begin{tabular}{|l|l|l|l|}
\hline \multicolumn{1}{|c|}{ Attitudes } & F-Value & DF & Prob.* \\
\hline Important to total well-being & 0.156 & 3,208 & N.S. \\
\hline Personally important to me & 0.166 & 3,208 & N.S. \\
\hline Satisfied w/personal SH & 1.132 & 3,208 & N.S. \\
\hline Uncomfortable subject & 0.757 & 3,208 & N.S. \\
\hline SH influences well-being & 0.873 & 3,207 & N.S. \\
\hline Diverse culture/religion traditions & 0.289 & 3,207 & N.S. \\
\hline Private, personal journey & 1.265 & 3,208 & N.S. \\
\hline Concept diff. betw. SH \& religion & 0.191 & 3.207 & N.S. \\
\hline
\end{tabular}

${ }^{*} \mathrm{~g} \leq .05$ (4= strongly agree: $1=$ strongly disagree) 
Chart 4

Respondents' Geographical Region and Spiritual Health Attitudes

\begin{tabular}{|l|l|l|l|}
\hline \multicolumn{1}{|c|}{ Attitudes } & F-Value & \multicolumn{1}{c|}{ DF } & Prob.* \\
\hline Important to total well-being & 1.904 & 5,246 & N.S. \\
\hline Personally important to me & 1.626 & 5,246 & N.S. \\
\hline Satisfied w/personal SH & 0.131 & 5,246 & N.S. \\
\hline Uncomfortable subject & 1.944 & 5,246 & N.S. \\
\hline SH influences well-being & 1.767 & 5,245 & N.S. \\
\hline Diverse culture/religion traditions & 1.388 & 5,245 & N.S. \\
\hline Private, personal journey & 0.313 & 5,246 & N.S. \\
\hline Concept diff. betw. SH \& religion & 2.011 & 5,245 & N.S. \\
\hline
\end{tabular}

${ }^{\star} \mathrm{P} \leq .05$ ( $4=$ strongly agree: $1=$ strongly disagree)

\section{Chart 5}

\section{Respondents' Highest Academic Degree Focus and Spiritual Health Attitudes}

\begin{tabular}{|l|l|l|l|}
\hline \multicolumn{1}{|c|}{ Attitudes } & F-Value & DF & Prob.* \\
\hline Important to total well-being & 0.414 & 5,249 & N.S. \\
\hline Personally important to me & 0.422 & 5,249 & N.S. \\
\hline Satisfied w/personal SH & 0.950 & 5,249 & N.S. \\
\hline Uncomfortable subject & 0.823 & 5,249 & N.S. \\
\hline SH influences well-being & 0.540 & 5,248 & N.S. \\
\hline Diverse culture/religion traditions & 0.809 & 5,248 & N.S. \\
\hline Private, personal journey & 1.348 & 5,249 & N.S. \\
\hline Concept diff. betw. SH \& religion & 1.441 & 5,248 & N.S. \\
\hline
\end{tabular}

${ }^{\star} \mathrm{p} \leq .05$ ( $4=$ strongly agree: $1=$ strongly disagree) 


\section{Chart 6}

Respondents' Ethnicity and Attitudes Toward Including Spiritual Health in College General Health Course

\begin{tabular}{|l|c|c|c|}
\hline \multicolumn{1}{|c|}{ Altitudes } & F-Value & DF & Prob. \\
\hline Vague definition & 0.235 & 3,207 & N.S. \\
\hline Important human dimen. & 1.176 & 3,206 & N.S. \\
\hline Separation church/state & 0.811 & 3,206 & N.S. \\
\hline Evaluate/grade students & 0.268 & 3,207 & N.S. \\
\hline Inadequate prof. train. & 0.488 & 3,205 & N.S. \\
\hline Respect indiv. beliefs & 1.259 & 3.207 & N.S. \\
\hline More resource material & 0.173 & 3.250 & N.S. \\
\hline Lack of suppor/peers & 1.045 & 3.200 & N.S. \\
\hline Lack of support/admin. & 0.949 & 3.199 & N.S. \\
\hline Appropriate content & 0.712 & 3.205 & N.S. \\
\hline Fecl adequately train. & 2.183 & 3.203 & N.S. \\
\hline
\end{tabular}

${ }^{*} \mathrm{p} \leq .05$ ( $4=$ strongly agree: $1=$ strongly disagree)

\section{Chart 7}

Respondents' Gender and Attitudes Toward Including Spiritual Health in College General Health Course

\begin{tabular}{|l|c|c|c|}
\hline \multicolumn{1}{|c|}{ Altitudes } & F-Value & DF & Prob.* \\
\hline Vague definition & 0.021 & 1,253 & N.S. \\
\hline Important human dimen. & 0.010 & 1,252 & N.S. \\
\hline Scparation church/state & 0.456 & 1,252 & N.S. \\
\hline Evaluate/grade students & 0.911 & 1,253 & N.S. \\
\hline Inadequate prof. Irain. & 1.739 & 1,251 & N.S. \\
\hline Resnect indiv. beliefs & 0.137 & 1,253 & N.S. \\
\hline More resource material & 0.175 & 1,251 & N.S. \\
\hline Lack of support/reurs & 0.086 & 1,243 & N.S. \\
\hline Lack of support/admin. & 0.008 & 1,243 & N.S. \\
\hline Appropriate content & 0.025 & 1,251 & N.S. \\
\hline Feel adequately train. & 1.349 & 1,249 & N.S. \\
\hline
\end{tabular}

o 5.05 ( 4 = strongly agree: $1=$ strongly disagree) 


\section{Chart 8}

Respondents' Age and Attitudes Toward Including Spiritual Health in College General Health Course

\begin{tabular}{|c|c|c|c|c|c|c|c|c|c|}
\hline Attitudes & F-Value & DF & Prob.* & $\begin{array}{c}\text { Age }<25 \\
\pm\end{array}$ & $\begin{array}{l}\text { Mean } \\
\text { Age 26-35 } \\
\pm\end{array}$ & $\begin{array}{l}\text { Mean } \\
\text { Age 36-35 } \\
\pm\end{array}$ & $\begin{array}{l}\text { Mean } \\
\text { Age 46-55 } \\
\pm\end{array}$ & $\begin{array}{c}\text { Mean } \\
\text { Age } 55+ \\
\pm\end{array}$ & $\begin{array}{l}\text { Post Hoc } \\
\text { BonFerroni }\end{array}$ \\
\hline Vague definition & 0.849 & 4,248 & N.S. & & & & & & \\
\hline Important human dimen. & 0.385 & 4,247 & N.S. & & & & & & \\
\hline Separation church/state & 3.112 & 4,247 & 0.016 & 2.500 & 2.279 & 2.323 & 2.704 & 2,757 & N.S. \\
\hline Evaluste/grade students & 2.066 & 4,248 & N.S. & & & & & & \\
\hline Inadequate prof. train. & 1.590 & 4,246 & N.S. & & & & & & \\
\hline Respect indiv, beliefs & 2.392 & 4,248 & N.S. & & & & & & \\
\hline More resource material & 0.397 & 4,246 & N.S. & & & & & & \\
\hline Lack of support/peers & 1.855 & 4,238 & N.S. & & & & & & \\
\hline Lack of suppor/admin. & 0.766 & 4,328 & N.S. & & & & & & \\
\hline Appropriate content & 0.643 & 4,246 & N.S. & & & & & & \\
\hline Feel adequately train. & 1.728 & 4,244 & N.S. & & & & & & \\
\hline
\end{tabular}

* $\mathrm{S} \leq .05$ (4 = strongly agree; 1 = strongly disagree $)$ 